\title{
WestVirginiaUniversity
}

THE RESEARCH REPOSITORY @ WVU

Graduate Theses, Dissertations, and Problem Reports

2007

\section{Power market analysis tool for congestion management}

Silpa Parnandi

West Virginia University

Follow this and additional works at: https://researchrepository.wvu.edu/etd

\section{Recommended Citation}

Parnandi, Silpa, "Power market analysis tool for congestion management" (2007). Graduate Theses, Dissertations, and Problem Reports. 1807.

https://researchrepository.wvu.edu/etd/1807

This Thesis is protected by copyright and/or related rights. It has been brought to you by the The Research Repository @ WVU with permission from the rights-holder(s). You are free to use this Thesis in any way that is permitted by the copyright and related rights legislation that applies to your use. For other uses you must obtain permission from the rights-holder(s) directly, unless additional rights are indicated by a Creative Commons license in the record and/ or on the work itself. This Thesis has been accepted for inclusion in WVU Graduate Theses, Dissertations, and Problem Reports collection by an authorized administrator of The Research Repository @ WVU. For more information, please contact researchrepository@mail.wvu.edu. 


\title{
Power Market Analysis Tool for Congestion Management
}

\author{
by \\ Silpa Parnandi \\ Thesis submitted to the \\ College of Engineering and Mineral Resources \\ at West Virginia University \\ in partial fulfillment of the requirements \\ for the degree of \\ Master of Science \\ in \\ Electrical Engineering \\ Professor Muhammad Choudhry, Ph.D. \\ Research Assistant Professor Karl Schoder, Ph.D. \\ Professor Ali Feliachi, Ph.D., Chair \\ Lane Department of Computer Science and Electrical Engineering \\ Morgantown, West Virginia \\ 2007
}

Keywords: Electricity markets, Load curtailment, Congestion management, N-1 contingency analysis, PowerWorld, Security constrained OPF, LMP 


\author{
Abstract \\ Power Market Analysis Tool for Congestion Management \\ by \\ Silpa Parnandi \\ Master of Science in Electrical Engineering \\ West Virginia University \\ Professor Ali Feliachi, Ph.D., Chair
}

The privatization and deregulation of electricity markets has increased competition and electricity may be produced and consumed in amounts that would cause the transmission system to operate beyond transfer limits - the system is congested. Hence, congestion management is a fundamental transmission management problem. In this thesis, a power market analysis tool is designed for congestion management. The tool creates an interface between PowerWorld ${ }^{\complement}$, a professional software tool to compute power flows, and MATLAB ${ }^{\circledR}$. The tool helps in analyzing power flow results, batch-processing of large case studies, and providing the user with options to manage congestions. A graphical user interface has been designed to help the user learn and interact with the tool.

Based on the generator and load bid data, the tool performs (N-1) security analysis. In case of congestion, the user can choose one of three congestion relief methods. Transmission Line Relief Sensitivity (sensitivities of line flows to load curtailment), Economic Load Management (a product of three indices that measure (i) the sensitivity of the line flow to load curtailment, (ii) the level of customer incentive to cut down consumption, and (iii) the customer's acceptable range of curtailment), and VAR Support (installment of additional VAR devices). The congestion alleviation methods are explained and tested on a six bus test system and the IEEE 24 bus Reliability Test System. 


\section{Acknowledgements}

I would like to express my sincere gratitude, and thanks to my advisor Dr. Ali Feliachi for his guidance and constant support throughout my Masters program. Also, I am grateful for the support and valuable suggestions of Dr. Karl Schoder at every step of this work. I am thankful to my committee member Dr. Muhammad Choudhry for his advice throughout my graduate education.

A special thank you to all my APERC lab colleagues Ramesh Khajjayam, Talpasai Lakkaraju, Ram Praveen Saladi, Pradeep Pant, Ali Karimi, Anisha Fernandes, Koushaly Naresh Kumar, Rabie Belkacemi, and Sarah Eftekharnejad for their encouragement and help. Many thanks to all my morgantown friends for the wonderful time.

Last but never the least, I would like to thank my husband for his love and support throughout this work. My family, presently in India have always been my source for inspiration. I can never thank enough my father, mother and little brother for their love and faith in me. 


\section{Contents}

Abstract $\quad$ ii

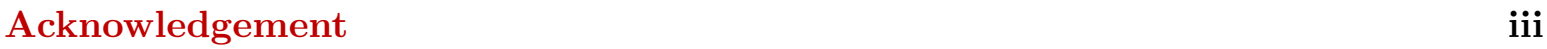

List of Figures $\quad$ vi

List of Tables $\quad$ viii

$\begin{array}{ll}\text { Acronyms } & \text { ix }\end{array}$

1 Introduction $\quad 1$

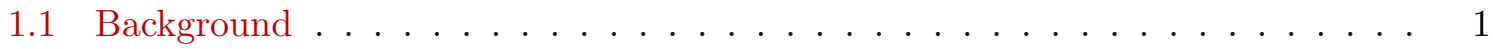

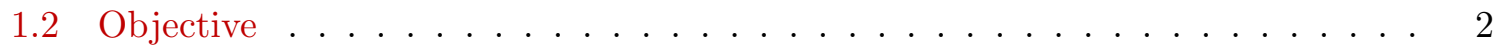

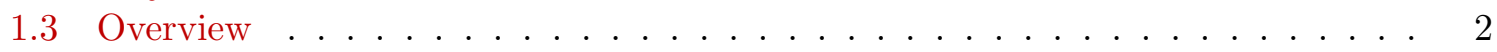

2 Literature Review $\quad 4$

2.1 Electricity Market . . . . . . . . . . . . . . . . . 4

2.1.1 Entities in a Deregulated Electricity Market . . . . . . . . . . . . 5

2.1.2 Market Clearing Mechanism . . . . . . . . . . . . . . 6

2.2 Spot Pricing . . . . . . . . . . . . . . . . . . . . 6

$2.3 \mathrm{~N}-1$ Contingency Criterion . . . . . . . . . . . . . . . . 7

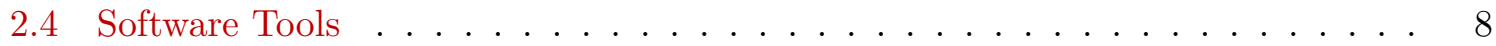

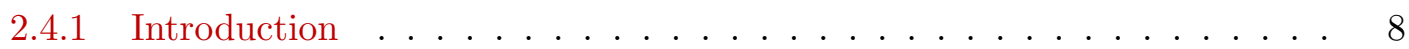

2.4 PowerWorld . . . . . . . . . . . . . . . . . . . . 8

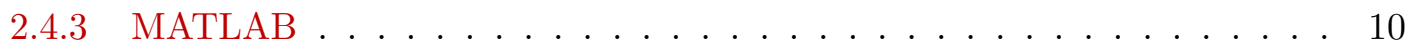

3 Congestion Management $\quad 12$

3.1 Introduction . . . . . . . . . . . . . . . . . . . . 12

3.2 Related Work . . . . . . . . . . . . . . . . . . . . . . . . . . . . . . . . . . . . .

3.3 Congestion Management in U.S Electricity Markets . . . . . . . . . . . . . 15

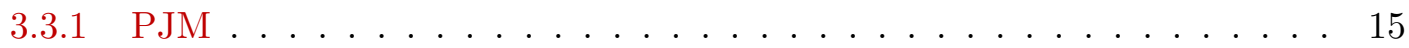

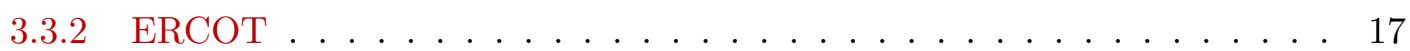

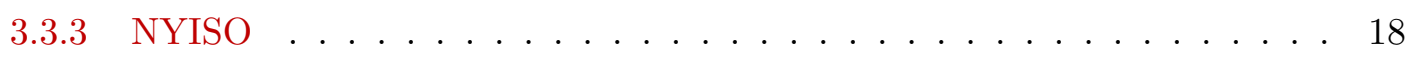

3.4 Methods of Congestion Management . . . . . . . . . . . . . . 20

3.4.1 TLR Sensitivities Based Load Curtailment . . . . . . . . . . . . 21

3.4.2 Economic Load Management for Congestion Relief . . . . . . . . . . . . 22 
3.4.3 VAR Support for Congestion Relief . . . . . . . . . . . . . . . . . 24

4 Power Market Analysis Tool (PMAT) 25

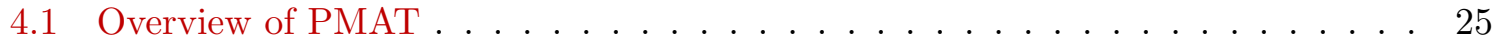

4.1 .1 Class Diagram of PMAT . . . . . . . . . . . . . . . 26

4.1 .2 Starting/Setup PMAT . . . . . . . . . . . . . . . . . . . . . . . . . . . . . 26

4.1 .3 Opening a Case File . . . . . . . . . . . . . . . . . . . 27

4.1 .4 Output Data . . . . . . . . . . . . . . . . 30

4.1 .5 Congestion Relief . . . . . . . . . . . . . . . . . 31

4.2 Example . . . . . . . . . . . . . . . . . . . . . 33

5 Case Studies and Discussion $\quad 39$

5.1 Test Systems Description _. . . . . . . . . . . . . . . . . 39

5.1 .1 Six Bus Test System . . . . . . . . . . . . . . . . . . 39

5.1 .2 IEEE 24 Bus Test System . . . . . . . . . . . . . . . . . . . 40

5.2 Results and Discussion . . . . . . . . . . . . . . . . . . . . . . . . . . . . . .

5.2 .1 Results for Six Bus Test System . . . . . . . . . . . . . . 42

5.2 .2 Results for IEEE 24 Bus RTS . . . . . . . . . . . . . . . . 48

6 Conclusions and Future Work $\quad 55$

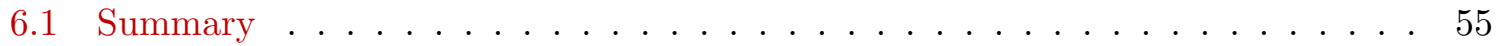

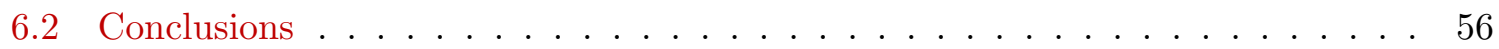

6.3 Future Work . . . . . . . . . . . . . . . . . . . 56

$\begin{array}{ll}\text { APPENDIX } & 57\end{array}$

$\begin{array}{ll}\text { A Six-Bus System } & \mathbf{5 7}\end{array}$

A.1 Network Data . . . . . . . . . . . . . . . . . . . 57

A.2 Market Data . . . . . . . . . . . . . . . . . 57

B IEEE 24 Bus Reliability Test System $\quad 59$

B.1 Network Data . . . . . . . . . . . . . . . . . . . 59

B.2 Market Data . . . . . . . . . . . . . . . . . 62

$\begin{array}{ll}\text { C Data Formats } & 64\end{array}$

$\begin{array}{ll}\text { D API Documentation } & 66\end{array}$

$\begin{array}{ll}\text { References } & 68\end{array}$

$\begin{array}{ll}\text { Approval Page } & 72\end{array}$ 


\section{List of Figures}

3.1 Power System Two Bus Example . . . . . . . . . . . . . . . . . . . . . . . 12

(a) Two-Bus Example with Congestion . . . . . . . . . . . . . . . . 12

(b) Two-Bus Example with Congestion Alleviated . . . . . . . . . . . . . . 12

3.2 Power System 4 Bus Example . . . . . . . . . . . . . . . . . . . . . . 14

(a) Before constraint is active . . . . . . . . . . . . . . . 14

(b) Active constraint - negative LMPs . . . . . . . . . . . . . . . 14

(c) Increasing load at bus 2 removes constraint . . . . . . . . . . . . . . 14

(d) Increasing load at bus 3 removes constraint . . . . . . . . . . . . . . 14

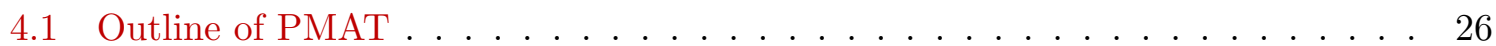

4.2 Class Diagram of PMAT . . . . . . . . . . . . . . . . 27

4.3 Main GUI of PMAT . . . . . . . . . . . . . . . . . 28

4.4 Flow Chart of PMAT . . . . . . . . . . . . . . . . . . 29

4.5 Options dialog of PMAT . . . . . . . . . . . . . . . . . . . . 32

4.6 Six Bus Test System - PowerWorld One line Diagram . . . . . . . . . . . . . 33

4.7 Comparison of LMPs with Line 2-4 Outage and without Contingency . . . . . 34

4.8 Bus Voltage Magnitudes for OPF w/o contingencies of Six Bus Test System . . 35

4.9 Line MVA Flows for Gen 2 Outage for Six Bus Test System . . . . . . . . . . . 36

4.10 Cost Function of Generator 1 for Six Bus Test System . . . . . . . . . . . . 37

4.11 LMPs for the outage of lines 1-4 and 2-3 for Six Bus Test System . . . . . . . 38

5.1 Single line diagram of Six Bus Test System [57] . . . . . . . . . . . . . . 40

5.2 Single line diagram of IEEE 24 Bus Single Area Reliability Test System [47] . . 41

5.3 LMP Statistics of Six Bus Test System for 14 (N-1) contingency without Congestion Relief . . . . . . . . . . . . . . . . . . . 43

5.4 LMP Statistics of Six Bus Test System for 14 (N-1) contingency with TLR Sensitivity Method . . . . . . . . . . . . . . . . 44

5.5 LMP Statistics of Six Bus Test System for 14 (N-1) contingency with Economic Load Management Method . . . . . . . . . . . . . . . . . 46

5.6 LMP Statistics of Six Bus Test System for 14 (N-1) contingency with VAR Support . . . . . . . . . . . . . . . . . 47

5.7 Max Loads Served at each bus for 14 (N-1) contingencies - Six Bus Test System 49

5.8 LMP Statistics of IEEE RTS for 70 (N-1) contingencies without Congestion Relief 50

5.9 LMP Statistics of IEEE RTS for 70 (N-1) contingencies with TLR Sensitivity

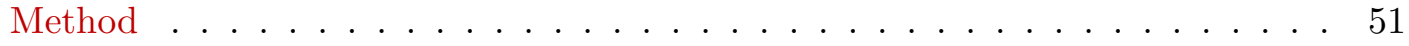


5.10 LMP Statistics of IEEE RTS for 70 (N-1) contingencies with Economic Load Management Method . . . . . . . . . . . . . . . . 52

5.11 LMP Statistics of IEEE RTS for 70 (N-1) contingencies with VAR Support . . 53

5.12 Max Loads Served at each bus for $70(\mathrm{~N}-1)$ contingencies - IEEE 24 Bus Test System . . . . . . . . . . . . . . . . . . 5 54

D.1 PMAT file system hierarchy . . . . . . . . . . . . . . . . 66 


\section{List of Tables}

3.1 PJM Thermal Operating Criteria - Actual Thermal Overloads . . . . . . . . . 16

3.2 PJM Thermal Operating Criteria - Contingency Thermal Overloads . . . . . . 16

5.1 LMP values for $(\mathrm{N}-1)$ contingencies - Six Bus Test System . . . . . . . . . . 42

5.2 LMP values for the (N-1) contingencies and TLR Sensitivity based relief method - Six Bus Test System . . . . . . . . . . . . . . . . . . . . . 43

5.3 LMP values for (N-1) contingencies and Economic Load Management - Six Bus Test System . . . . . . . . . . . . . . . . . . . . 45

5.4 LMP values for the (N-1) contingencies and VAR Support - Six Bus test System 46

5.5 Max load served for 14 (N-1) contingencies - Six Bus Test System . . . . . . . 47

5.6 Comparison of all Congestion Relief Methods - Six Bus Test System . . . . . . 48

5.7 Max load served for $70(N-1)$ contingencies - IEEE 24 Bus RTS . . . . . . . . 52

5.8 Comparison of all the Congestion Relief Methods - IEEE 24 RTS . . . . . . . . 53

A.1 Generator Data for Six Bus Test System . . . . . . . . . . . . . . 57

A.2 Load Data for Six Bus Test System . . . . . . . . . . . . . . . . 57

A.3 Line Data for Six Bus Test System . . . . . . . . . . . . . 58

A.4 Generator Cost Data for Six Bus Test System . . . . . . . . . . . . 58

A.5 Load Cost Data for Six Bus System . . . . . . . . . . . . . 58

B.1 Generator Data for IEEE 24 Bus RTS . . . . . . . . . . . . . . . . . 60

B.2 Load Data for IEEE 24 Bus RTS . . . . . . . . . . . . . . . . . . . 60

B.3 Line Data for IEEE 24 Bus RTS . . . . . . . . . . . . . . . . . . 61

B.4 Generator Cost Data for IEEE 24 Bus RTS . . . . . . . . . . . . . . . . . 62

B.5 Load Cost Data for IEEE 24 Bus RTS . . . . . . . . . . . . . . . . 63

C.1 Generator and Load Data Format . . . . . . . . . . . . . . . . . . . . 64

C.2 Generator Data format of Six Bus System . . . . . . . . . . . . . . . . 64

C.3 Load Data format of Six Bus System . . . . . . . . . . . . . . . . . . 65

C.4 Generator Data format of IEEE 24 Bus RTS . . . . . . . . . . . . . . . . . 65

C.5 Load Data format of IEEE 24 Bus RTS . . . . . . . . . . . . . . . . . 65

D.1 Description of functions in PMAT API . . . . . . . . . . 67 


\section{Acronyms}

Acronyms used in this thesis are listed below:

$\begin{aligned} \text { AGC } & \text { Area Generation Control } \\ \text { API } & \text { Application Programming Interface } \\ \text { DISCO } & \text { Distribution Company } \\ \text { ERCOT } & \text { Electric Reliability Council of Texas } \\ \text { ESCO } & \text { Energy Service Company } \\ \text { FACTS } & \text { Flexible AC Transmission Systems } \\ \text { GENCO } & \text { Generation Company } \\ \text { GUI } & \text { Graphical User Interface } \\ \text { IEEE } & \text { Institute of Electrical and Electronics Engineers } \\ \text { ISO } & \text { Independent System Operator } \\ \text { LMP } & \text { Locational Marginal Price } \\ \text { MCP } & \text { Market Clearing Price } \\ \text { NERC } & \text { North American Electric Reliability Council } \\ \text { NYISO } & \text { New York Independent System Operator } \\ \text { OOP } & \text { Object Oriented Programming } \\ \text { OPF } & \text { Optimal Power Flow } \\ \text { PJM } & \text { Pennsylvania-New Jersey-Maryland Interconnection } \\ \text { PMAT } & \text { Power Market Analysis Tool } \\ \text { PTDF } & \text { Power Transfer Distribution Factor } \\ \text { RTO } & \text { Regional Transmission Operator } \\ \text { RTS } & \text { Reliability Test System } \\ & \text { continued on next page } \\ & \end{aligned}$


continued from previous page

\begin{aligned} \hline SCOPF & Security Constrained Optimal Power Flow \\ SVC & Static Var Compensator \\ TCSC & Thyristor Controlled Series Capacitor \\ TRANSCO & Transmission Company \\ UPFC & Unified Power Flow Controller \end{aligned}




\section{Chapter}

1

\section{Introduction}

\section{$1.1 \quad$ Background}

The privatization and deregulation of electricity markets has a very large impact on almost all the power systems around the world. Competitive electricity markets are complex systems with many participants who buy and sell electricity. Much of the complexity arises from the limitations of the underlying transmission systems and the fact that supply and demand must be in balance at all times. The Independent System Operator (ISO) is a regulating entity independent from the electric companies and optimizes the overall system operation. Spot pricing theory is used for economic generation and load dispatch. Under the pool system, locational prices are calculated by the marginal cost of optimal power flow solutions.

In any competitive market, system security plays a vital role from the market/system operator's point of view. When the producers and consumers of electric energy desire to produce and consume in amounts that would cause the transmission system to operate at or beyond one or more transfer limits, the system is said to be congested. Congestion management is about controlling the transmission system so that transfer limits are observed and is perhaps the most fundamental transmission management problem. Congestion before deregulation was treated in terms of steady-state security and the basic objective was to control the generators' 
output so that system remained secure (no limits were violated) at the lowest cost as seen by the mutually agreeing vertically integrated utilities. But with deregulation, congestion has become a term in conjunction with power systems and competition. When there is a con-

gestion in a transmission system, locational prices can be significantly different from those of unconstrained optimal solutions. Hence, congestion alleviation is very important issue and is an active area of research [21], [26], [52], [53], [58], [60].

\section{$1.2 \quad$ Objective}

The power flow problem consists of a given transmission network where all lines are represented by a pi-equivalent circuit and transformers by an ideal voltage transformer in series with an impedance. Generators and loads represent the boundary conditions of the solution. System congestion occurs due to active limits on the transmission lines or voltage levels, representing thermal and stability limits. Sometimes disturbances lead to emergency conditions and, therefore, need to be anticipated for the secure operation of any power system. Power system security, which is a major engineering as well as economic issue, prompts to investigate various methods of congestion management in the electricity market framework. The objectives of this work are summarized as follows:

1. Design a power market analysis tool for congestion management (PMAT) in MATLAB.

2. Develop an Application Programming Interface (API) that interacts with PowerWorld for computing locational marginal prices (LMPs) and performs (N-1) security analysis.

3. Demonstrate various methods of congestion management such as Sensitivity based load curtailment, Economic load management, and VAR support.

4. Provide a graphic user interface (GUI) to showcase the capabilities of the API and interaction with the user for research and teaching purposes.

\subsection{Overview}

This section briefly gives an overview of the remaining chapters of this thesis:

- Chapter 2: Literature Review 
This chapter gives a brief overview of electricity markets. Section 2.1 gives an introduction to entities in the current electricity markets and market clearing mechanism. Section 2.2 explains the details of locational marginal pricing, Section 2.3 explains the $(\mathrm{N}-1)$ contingency criteria, and Section 2.4 discusses the software tools used in this thesis.

- Chapter 3: Congestion Management

This chapter explains details of congestion management techniques. Section 3.1 gives the definition of congestion with a two-bus system example, and explains congestion management in markets. Section 3.2 provides an overview of the related work in congestion management. Section 3.3 provides an overview of the transmission congestion management procedures in three ISOs: PJM, ERCOT, and NYISO. Section 3.4 discusses the background and working of the congestion management methods used in this thesis.

- Chapter 4: Power Market Analysis Tool (PMAT)

An overview, class diagram, flow chart, and features of PMAT are presented in this chapter. Section 4.1 explains the setup of the PMAT, opening a case file, the input and output data, and the congestion relief procedures. In Section 4.2 an example is given to demonstrate PMAT and its workflow.

- Chapter 5: Case Studies and Discussion

This chapter gives the description of the two test systems in Section 5.1, results and discussions for these case studies follow in Section 5.2.

- Chapter 6: Conclusions

This chapter presents the summary of the work in Section 6.1, Section 6.2 gives the conclusions of the work, and possible directions for future work are provided in Section 6.3 .

The Appendices A and B provide the network and market data of the six bus test system and the IEEE 24 bus Reliability Test System used in this work. The data format of the market bid data is shown in Appendix C, and Appendix D provides the API documentation. 


\section{Chapter}

2

\section{Literature Review}

This section provides a brief overview of electricity markets. Various market participating entities are explained. The pricing scheme and the process of operation are discussed. The $(\mathrm{N}-1)$ contingency criteria is discussed. A brief overview of the software tools used in this work is provided.

\subsection{Electricity Market}

A possible definition of an electricity market is as follows: "An electricity market is a system for effecting the purchase and sale of electricity using supply and demand bids to set the price [55]". Deregulation is the process by which governments remove restrictions on businesses and individuals in order to encourage the efficient operation of markets. In the past, the electric power industry has been vertically integrated, meaning that a central authority monitored and controlled all the activities in generation, transmission, and distribution. For the last decade or so, the electric power industry has been undergoing a process of restructuring, in particular the separation of transmission from generation activities.

Deregulation is intended to encourage competition among utilities and power marketers to reduce energy prices. There is therefore a physical requirement for a controlling agency, the 
power system operator, to coordinate the dispatch of generating units to meet the expected demand of the system across the transmission grid. This system operator must never be involved in the market competition, and is usually called the Independent System Operator (ISO).

\subsubsection{Entities in a Deregulated Electricity Market}

Many entities are present in today's deregulated electricity markets [49]. The basic division of the participants can be categorized according to generation, transmission, and distribution.

Generation Companies (GENCOS):

Operates and maintains existing generating plants. The Gencos interact with the market acting on behalf of the plant owners to bid into the power pool for economic dispatch.

Transmission Companies (TRANSCOS):

Constructs and maintains the network of transmission lines. The Transcos should ensure the availability of the transmission system to all the entities in the system.

Distribution Companies (DISCOS):

Owns and operates local distribution facilities. The Discos purchase electricity in the wholesale market and supply it to the final customers.

Energy Services Companies (ESCOS):

These may be large industrial customers, customer pools or private companies, and their main goal is to purchase power at the least cost for their customers from GENCOS. They participate in the market like DISCOS, except that they do not own or operate the local distribution systems.

\section{$\underline{\text { Customers }}$}

These are the consumers of electricity. They can choose to purchase electricity from the spotmarket by bidding for purchase or buying directly from a GENCO, a DISCO, or an ESCO.

$\underline{\text { Independent System Operator (ISO): }}$

An entity that will monitor the reliability of the power system and coordinate the supply of electricity. ISO is a non-profit corporation that uses governance models developed by the 
Federal Energy Regulatory Commission [20]. In the deregulated electricity market it also acts as a marketplace in wholesale power.

$\underline{\text { Regional Transmission Operator (RTO): }}$

Similar to an ISO is an Regional Transmission Operator, the primary difference is that RTO coordinates, controls and monitors the operation of the electric power transmission system over a wider area.

\subsubsection{Market Clearing Mechanism}

In most markets, both GENCOS and ESCOS bid into the market supervised by ISO. A market clearing price (MCP) is obtained by stacking the supply bids in order of increasing prices and the demand bids in order of decreasing prices. This market clearing process is referred to as double-sided auction [11].

However, the customers (load) in most markets do not actively bid, i.e., the load is inelastic. In this case, the system price is determined by matching the supply curve with a forecast of expected load. The lowest priced bid to intersect with the system demand forecast determines the MCP and such a market model is known as single or one-sided auction [11].

\subsection{Spot Pricing}

In the current deregulated environment in the United States, the most popular model for energy pricing is based on the concept of nodal (spot) pricing extending the MCP introduced above to the distinguished nodes (buses) of the power system. Pricing energy on the basis of the location of its withdrawal or injection in a network was proposed in [50]. The spot price is based on the principle that a unit of power has different prices at different points in the network. The main reason for this spatial discrimination in energy prices are transmission line losses and transmission congestion. These spatially differentiated spot prices are also called Locational Marginal Prices (LMP) [4]. LMP is the cost to serve the next MW of load at a specific location using the lowest production cost of all available generation, while observing all transmission limits [41].

The market uses LMPs that reflect the value of energy at specific locations and at the time it is delivered. If the lowest priced electricity can reach all locations, prices are the same across 
the entire grid. When there is transmission congestion, energy cannot freely flow to certain locations. In such cases, more expensive electricity is ordered to meet that demand. As a result, the locational marginal price is higher in those locations. LMP is based on:

- Actual flow of energy

- Actual system operating conditions

\section{LMP $=$ Generation Marginal Cost + Transmission Congestion Cost + Cost of Marginal Losses}

The energy market consists of day-ahead and real-time markets. The day-ahead market is a forward market in which hourly LMPs are calculated for the next operating day based on generation offers, demand bids, and scheduled bilateral transactions.

The real-time market is a spot market in which current LMPs are calculated at five-minute intervals based on actual grid operating conditions [40].

According to the regional transmission operator (RTO), Pennsylvania-New Jersey-Maryland Interconnection (PJM) [41], the following steps are part of LMP calculations:

1. Determine current system conditions

- Energy demand

- Generator MW values

- System topology

2. Process generator bids and dispatch rates to determine flexible generators

3. Collect current system constraint data

4. Execute locational price algorithm

\section{$2.3 \quad$ N-1 Contingency Criterion}

For years, power systems have been expected to remain operational following a single contingency, the widely known (N-1) criterion. A contingency, as defined by North American Electric Reliability Council (NERC) [32], is the unexpected failure or outage of a system component, such as a generator, transmission line, circuit breaker, or switch. Systems are designed 
to withstand one contingency, i.e., (N-1) criterion. Unfortunately, some events trigger others and cascading failures might occur. Therefore, not all contingencies are equal, and the number of components in a given system makes it prohibitive to evaluate all (single) contingencies. The system is considered (N-1) secure when a single (the next) contingency will not cause any system limits to be violated. Some power systems are designed to withstand specific (N-2) and (N-3) contingencies.

In general, while considering $(\mathrm{N}-1)$ criterion several approaches can be taken to identify a critical component that makes the system prone to collapse. For example, critical line can be identified through its loading and/or Available Transfer Capability (ATC). Typically, when the system is stable for critical line outages, it is said to be stable and secure for the outage of any line in the system.

In this work a contingency could be associated with the loss of either a transmission line or a generator. (N-1) criterion therefore refers to the outage of any line or any generator in the network and the congestion management process includes studies of sequential outages of these elements. To be N-1 secure means that a single contingency will not cause any limits to be violated.

\subsection{Software Tools}

\subsubsection{Introduction}

Using an Optimal Power Flow (OPF), a spot price market can be simulated with all engineering constraints enforced. In this way, the impact of transmission constraints on the spot prices in the market can be directly assessed. Using the OPF as a software engine to simulate a spot market has been an active area of research. PowerWorld [44] is one such tool that simulates electricity market behavior through AC or DC power flow computations and linear programming to minimize costs.

\subsubsection{PowerWorld}

PowerWorld simulator is an interactive power systems simulation package designed to simulate power systems operation on the transmission level with a time frame ranging from several minutes to several days. The software contains a power flow analysis package capable of 
efficiently solving systems. Some of the key features of the PowerWorld simulator are:

- Interactive, Animated Diagrams

- Modeling capabilities

- Contingency Analysis

- Area Generation Control (AGC)

- Script Actions

\section{Models and Routines in Power World}

Optimal Power Flow (OPF)

The OPF in PowerWorld simulator provides the ability to optimally dispatch the generation in an area or group of areas while enforcing the transmission line limits. The LMP values at all the buses in the power system are calculated while taking transmission congestion into consideration. The OPF algorithm in PowerWorld has the purpose of minimizing an objective function (total operation cost) or control actions by changing different system controls while meeting power balance constraints and enforcing base case operating limits.

Security Constrained Optimal Power Flow (SCOPF)

The SCOPF is for the economical operation of the system while considering not only normal operating limits, but also violations that would occur during contingencies. The SCOPF changes the system pre-contingency operating point so that the total operating cost is minimized and at the same time no power flow limit is violated for anticipated contingencies. The SCOPF has two objective functions in PowerWorld simulator. Minimum cost and minimum control change. Minimum cost minimizes the sum of the total generation costs. Minimum control change attempts to minimize the change in the generation. The result of the SCOPF will be different from the OPF solution because the SCOPF meets additional inequality constraints associated with the contingency violations.

$\underline{\text { Simulation Automation Server }}$

Simulation Automation Server (SimAuto) allows to extend the functionality of PowerWorld simulator to any external program. The SimAuto acts as a Component Object Model (COM) object, which can be accessed by various Windows-based programming languages that support 
the COM interface. The programming tools can be Microsoft Visual Basic, Visual $\mathrm{C}++$, MATLAB, etc. With SimAuto one can launch the PowerWorld simulator within another application to access the data, perform simulator functions, and retrieve results.

\subsubsection{MATLAB}

MATLAB [29] is a high-level language and interactive environment that enables to perform computationally intensive tasks faster than with traditional programming languages such as $\mathrm{C}, \mathrm{C}++$, and Fortran. MATLAB can be used in a wide range of applications including image processing, communications, control design, etc. Some of the primary features of MATLAB are:

- Development environment for managing code and data

- High-level language for technical computing

- Tools for building custom graphical user interfaces

- Add-on toolboxes for the extension of MATLAB environment

\section{Object-Oriented Programming Approach}

The MATLAB Object-Oriented Programming (OOP) feature is used for the development of the tool in this thesis. A brief overview of OOP is given in this section.

OOP is a programming paradigm that uses abstraction to create models based on the real world. It utilizes several techniques from previously established paradigms including modularity, polymorphism, and encapsulation [56].

Object: Objects are the basic run-time entities in an object-oriented system. A problem is analyzed in terms of objects and the communication among them. When a program is executed, objects interact with each other by sending messages. Different objects can interact with each other without knowing their implementation details [38].

Class: A class is a template for objects of the same type. Once a class is defined, any number of objects can be created from it [38]. 
When using well-designed classes, object-oriented programming can significantly increase code reuse and make programs easier to maintain and extend. OOP differs from ordinary structured programming in MATLAB in these important ways: [30]

- Function and operator overloading: Methods that override existing MATLAB functions can be created. When a function is called with a user-defined object as an argument, MATLAB first checks to see if there is a method defined for the object's class. If there is, MATLAB calls it rather than the normal MATLAB function.

- Encapsulation of data and methods: Object properties can be made visible and made accessible only with class methods. This protects the object properties from operations that are not intended for the object's class.

- Inheritance: Class hierarchies of parent and child classes in which the child class inherits data fields and methods from the parent can be created. A child class can inherit from one parent (single inheritance) or many parents (multiple inheritance). Inheritance can span one or more generations. Inheritance enables sharing common parent functions and enforcing common behavior among all child classes.

- Aggregation: Classes can be created using aggregation, in which an object contains other objects. This is appropriate when an object type is part of another object type. For example, a bus object, a generator object, and a line object can be a part of a power system network object. 


\section{CHAPter}

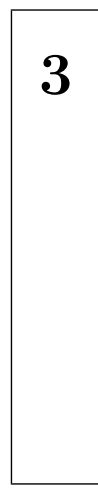

\section{Congestion Management}

\subsection{Introduction}

In deregulated power systems, congestion in the transmission system is a major problem and may lead to price spikes. Transmission congestion occurs when there is insufficient transmission capacity to meet the demands of all customers. In heavily congested conditions, transmission congestion can be relieved by curtailing a portion of non-firm transactions.

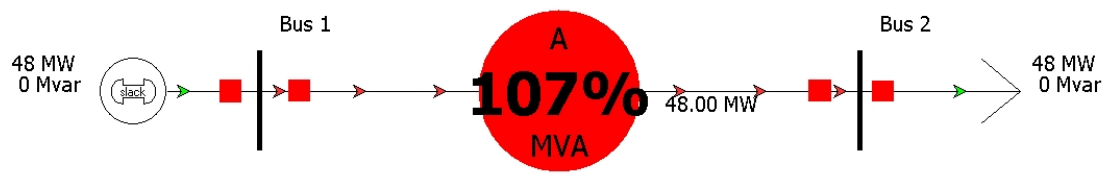

(a) Two-Bus Example with Congestion

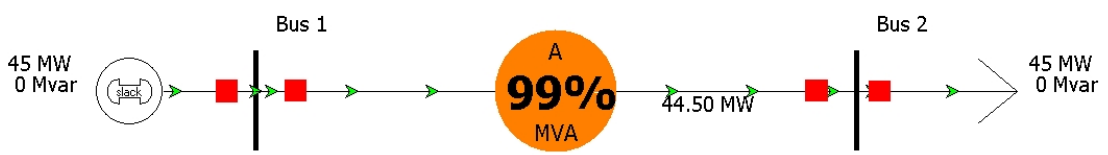

(b) Two-Bus Example with Congestion Alleviated

Figure 3.1: Power System Two Bus Example 
An example of a two-bus system shown in Figure 3.1 explains transmission congestion. In subfigure (a), the maximum real power output of the generator is $50 \mathrm{MW}$, the transmission line flow limit is $45 \mathrm{MVA}$ and the load is $48 \mathrm{MW}$. There is a transmission overload in the transmission line to serve the load. Congestion can be alleviated by curtailing some portion of the load. In subfigure (b), the load is curtailed from $48 \mathrm{MW}$ to $45 \mathrm{MW}$ and the congestion is alleviated.

Negative LMPs: Negative LMPs can occur in highly congested systems at one or more buses. This is usually always coupled with high LMPs at other buses. Serving an additional MW of load at the negative LMP bus will reduce the operating costs. More flow to the loads at these buses create counterflows that tends to mitigate congestion in an element. This allows for dispatch of cheaper generation, thereby decreasing the overall operating costs. The results are typically neglected and load needs to be reduced to alleviate the congestion in the system. Examples and explanation can be found at PowerWorld's [46] and New England ISO's web sites [34]. An example of a 4 bus power system shown in Figure 3.2 demonstrates negative LMPs. In subfigure (a), the load at bus 1 is $82 \mathrm{MW}$ and the transmission line from bus 2 to bus 1 is not constrained. The LMPs at all the buses are $10 \$ / M W h$. In subfigure (b), the load at bus 1 is increased to $83 \mathrm{MW}$ and the line 1-2 is congested and hence the LMP at bus 1 is very high and the LMPs at buses 2 and 3 are negative. From subfigures (c) and (d), the congestion in the line 1-2 can be removed either by increasing the load at bus 2 from $1 \mathrm{MW}$ to $2 \mathrm{MW}$ or by increasing the load at bus 3 by $1 \mathrm{MW}$ respectively. By increasing loads at these buses creates counterflows that avoid congestion costs and for dispatch of cheaper generation.

Congestion can be reduced by the following methods:

- Generation Redispatch

- Modification of generating schedules

- Load Redispatch

- Shedding - reduce specific loads

- Encouraging some specific load serving entities to consume more power

- Using VAR Support

- Expansion of Transmission Lines

This work focuses on load shedding and using VAR support for congestion management. 


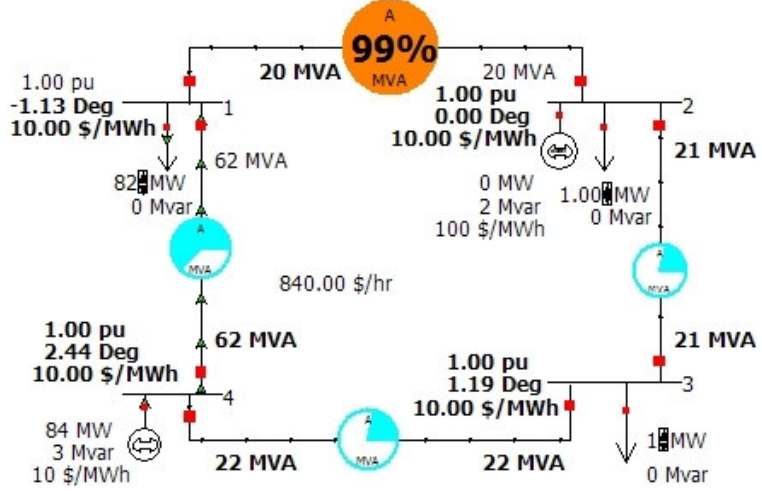

(a) Before constraint is active

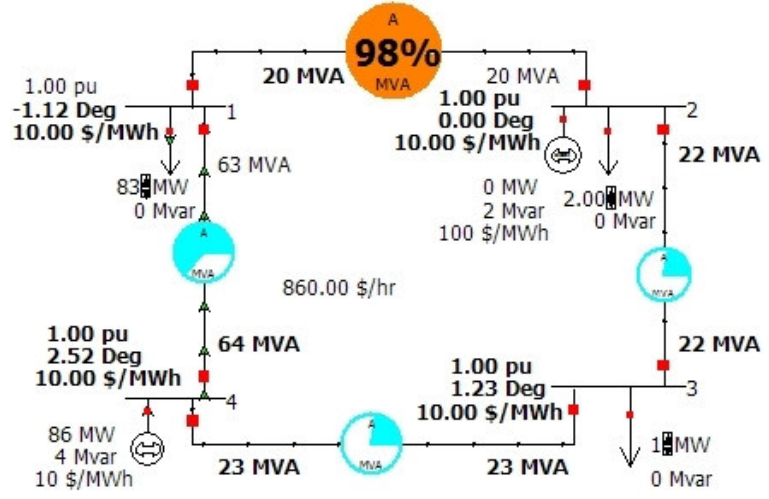

(c) Increasing load at bus 2 removes constraint

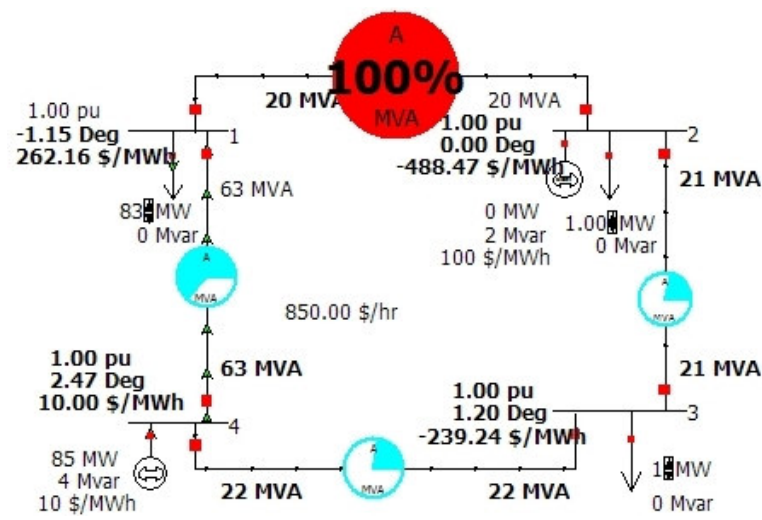

(b) Active constraint - negative LMPs

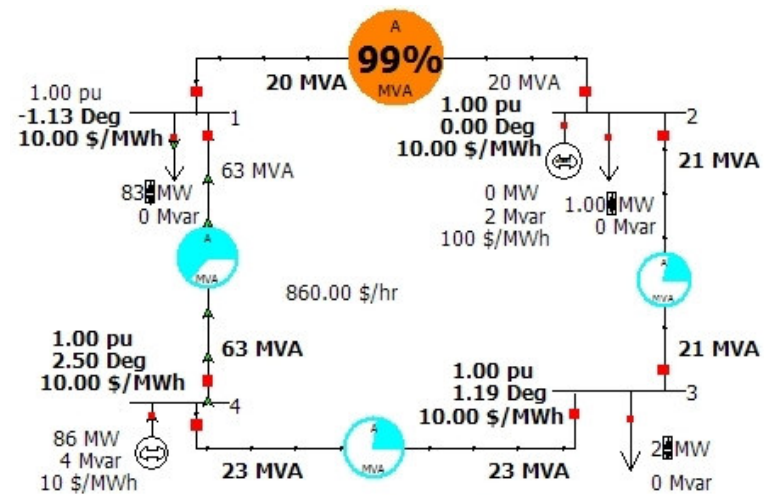

(d) Increasing load at bus 3 removes constraint

Figure 3.2: Power System 4 Bus Example

\subsection{Related Work}

This work will focus on means of load shedding. It is the main means to reduce transmission congestion. Dynamic stability emergencies are not considered in this thesis but may be included through flow limits below the thermal limits. Reactive power stability is not explicitly studied but indirectly included through voltage limits at buses. An evolution strategy to determine a secure state of the power system without congestion with redispatch is discussed in [12]. A hybrid model for congestion management analysis for both real and reactive power, which determines the optimal transaction and the corresponding load curtailment strategies based on classical gradient descent optimal power flow algorithm is proposed in [31]. By 
installation of VAR support using FACTS devices, congestion can be alleviated to a large extent [28], [51], [61]. Building new transmission lines or expanding the transmission network is usually a long-term proposition for congestion management [35], [42].

\subsection{Congestion Management in U.S Electricity Markets}

The congestion management procedures implemented in the various ISO's such as PennsylvaniaNew Jersey-Maryland Interconnection (PJM), Electric Reliability Council of Texas (ERCOT) and NewYork Independent System Operator (NYISO) are discussed in this section.

\subsubsection{PJM}

PJM Interconnection is a regional transmission organization that ensures the reliability of the electric power supply system in 13 states. PJM operates the wholesale electricity market and manages regional electric transmission planning to maintain the reliability of the power system.

In the PJM Transmission and Voltage Emergencies [42] manual, the types of transmission emergencies, criteria that constitute an emergency, and actions to alleviate transmission emergencies are summarized. The types of transmission emergencies can be classified as

- Thermal-transmission lines are loaded up to their thermal limits

- Reactive Stability-voltage drops

The different methods to mitigate transmission emergencies due to overloads and excess transfers in transmission lines are:

- Generator active power adjustment - raise/lower MW

- Phase angle regulator adjustment - increase/decrease phase angle

- Interchange schedule adjustment - import/export MW

- Transmission line switching - selected line switching

- Circuit breaker switching - change network topology 
- Customer load shedding - internal procedure and NERC transmission loading relief procedure

Load shedding is the last option when the congestion can not be alleviated through the remaining transmission emergency methods. Flow limits are further distinguished into normal limits, short term emergency (STE) limits, and load dump (115\% of STE). Violations may occur under actual (pre-contingency) or contingency (post-contingency) conditions. From the PJM manual [42], the PJM Thermal Operating Criteria for an actual and contingency thermal overload situations are shown in the Table 3.1 and Table 3.2.

Table 3.1: PJM Thermal Operating Criteria - Actual Thermal Overloads

\begin{tabular}{|c|c|c|}
\hline Rating Exceeded & Actuals & Time to Correct(mins) \\
\hline \hline Normal & Use all effective actions and emergency procedures except load dump & 15 \\
\hline STE & Use all the effective actions. Shed load if violation still exceeds STE after 15 mins & 15 \\
\hline Load Dump & Use all the effective actions. Shed load if violation still exceeds STE after 5 mins & 5 \\
\hline
\end{tabular}

Table 3.2: PJM Thermal Operating Criteria - Contingency Thermal Overloads

\begin{tabular}{|c|c|c|}
\hline Rating Exceeded & Contingencies & Time to Correct(mins) \\
\hline \hline Normal & Use all effective actions and emergency procedures except load dump & 15 \\
\hline STE & Use all effective actions and emergency procedures except load dump & 15 \\
\hline Load Dump & Use all the effective actions. Shed load if necessary to avoid post-contingency cascading & 5 \\
\hline
\end{tabular}

PJM curtails loads that contribute to the overload before re-dispatching the generators if the transmission customers have indicated that they are not willing to pay transmission congestion charges. If overload persists, even after re-dispatching the system, PJM will implement the NERC Transmission Loading Relief Procedure (TLR) [33]. Steps in the relief process are:

1. Notification of reliability coordinator

2. Hold interchange transactions

3. Reallocate firm transmission service

4. Reallocate non-firm transmission service

5. Curtail non-firm

6. Re-dispatch generation

7. Curtail firm 
8. Implement emergency procedures

PJM market offers wholesale electricity customers to hedge against the risk of congestion to protect them from the risk of high congestion costs. [43]. However, not all congestions can be hedged and this leads to unhedgeable congestion and PJM has an Economic Planning Process [39] that identifies this unhedgeable cost and determines the cost associated with it. This process evaluates whether the cost of upgrading the transmission system to relieve congestion is less than the cost of the congestion caused by the transmission limit.

\subsubsection{ERCOT}

ERCOT directs and ensures the reliable and cost-effective operation of its electric grid and enables fair and efficient market-driven solutions to meet customer's electric needs [15]. ERCOT 1) ensures the grid can accommodate the scheduled energy transfers, 2) ensures grid reliability, and 3) oversees retail transactions.

ERCOT uses two types of market re-dispatch procedures to alleviate transmission congestion [18]. To alleviate congestion between the market zones, ERCOT uses zonal operational constraints and for within a zone, ERCOT uses local operational constraints. Operations planning and System planning develop four types of action plans to respond to electric system constraints.

- Pre-contingency action plan-used ahead of the contingency because not feasible once the contingency occurs

- Remedial action plan-used after contingency occurs

- Mitigation plan-similar to remedial action plan but only used after all available generation re-dispatch is exhausted. After the pre-contingency and remedial action plans are executed and if still relief is needed, this method is appropriate

- Special protection plan-automatic actions using special protection systems

The Emergency Electric Curtailment Plan (EECP) [17] was developed to respond to short supply situations and restore Responsive Reserve to required levels. This procedure will direct the System Operator to declare an Emergency Notice for frequency restoration purposes. 
Emergency Electric Curtailment Plan (EECP) [16] At times it may be necessary to reduce ERCOT system demand because of a temporary decrease in available electricity supply. The objective of the EECP is to provide for maximum possible continuity of service while maintaining the integrity of the ERCOT Transmission Grid in order to reduce the chance of cascading outages predetermined procedures for curtailing demand during such emergencies, ERCOT initiates and coordinates the implementation of the EECP.

\subsubsection{NYISO}

The NYISO manages New York's electricity transmission grid, a network of high-voltage lines that carries electricity throughout the state, and oversees the wholesale electricity market. NYISO 1) maintains and enhances the regional reliability, 2) promotes and operates a fair and competitive electric wholesale market, 3) provides quality customer service, and 4) tries to achieve these objectives in a cost-effective manner.

In the NYISO Emergency Operations manual [35], the operating states and operating objectives during emergency conditions are explained. Severe system disturbances generally result in critically loaded transmission facilities, critical frequency deviations, high or low voltage conditions, or stability problems. The following operating states are defined for New York state:

1. Warning

2. Alert

3. Major Emergency

4. Restoration

The NYISO schedule coordinator, or the NYISO shift supervisor forecast the likelihood of the occurrence of states other than the Normal State in advance. If it is predicted that load relief either by voltage reduction or load shedding may be necessary during a future period, then the NYISO shift supervisor notifies all transmission owners and arranges corrective measures including:

- Curtailment of interruptible load 
- Manual voltage reduction

- Curtailment of non-essential market participant load

- Voluntary curtailment of large Load Serving Entities (LSE)

- Public appeals

NYISO reduces transmission flows that may cause thermal, voltage, and stability violations to properly allocate the reduction of transmission flows to relieve violations. When there are security violations that require reductions in transmission flow, NYISO takes action in the following sequence and to the extent possible, when system conditions and time permit:

1. Implement all routine actions using phase angle regulator tap positions, where possible.

2. Request all over-generation suppliers that are contributing to the problem to adjust their generation to match their schedules.

3. Request voluntary shifts on generation either below minimum dispatchable levels or above normal maximum levels to help relieve the violation.

4. Request reduction or cancellation of all transactions that contribute to the violation. Applicable transactions shall be curtailed in accordance with curtailment procedures described in the NYISO Transmission and Dispatching Operations Manual [36].

\section{$\underline{\text { Load Relief in NYISO }}$}

For all system conditions except system restoration, the transmission owners shed the load within the geographic area of their transmission district as requested by the NYISO shift supervisor in the following ratio:

$$
r_{L S}^{d}=\frac{P_{P L}^{d}}{\sum P_{P L}^{d}}
$$

where

$r_{L S}^{d}=$ Load shedding ratio

$P_{P L}^{d}=$ Estimated peak loading of transmission district for capability period

$\Sigma P_{P L}^{d}=$ Sum of transmission owners estimated peak loads for capability period 
$d=$ Transmission district

Load Shedding during System Restoration in NYISO

During system restoration, the NYISO determines the existing load in each transmission owner area. This load distribution should be used to determine the appropriate load shed allocation for each transmission owner based on their current load. The preferred method is to use the load-shed ratio is:

$$
r s_{L S}^{d}=\frac{P_{L}^{d}}{\sum P_{L}^{d}}
$$

where

$r s_{L S}^{d}=$ Load shedding ratio during system restoration

$P_{L}^{d}=$ Estimated load in the transmission district

$\Sigma P_{L}^{d}=$ Sum of transmission owners existing load

$d=$ Transmission district

\subsection{Methods of Congestion Management}

The power flow $P_{i j}$ through the transmission line $i-j$ is a function of the line reactance $X_{i j}$, the voltage magnitude $V_{i}, V_{j}$ and the phase angle between the sending and receiving end voltages $\delta_{i}-\delta_{j}$ as shown in equation 3.3.

$$
P_{i j}=\frac{V_{i} V_{j}}{X_{i j}} \sin \left(\delta_{i}-\delta_{j}\right)
$$

From the 3.3, one can see that the power flow can be affected by changing the voltage magnitudes, the reactance of the transmission lines or the power angle $\left(\delta_{i}-\delta_{j}\right)$. Voltage magnitudes can be controlled through VAR support. The reactance of the line can be reduced through series compensation and the power angle can be varied via power injection changes at either bus, e.g. generation or load changes.

In this thesis, voltage magnitudes and power angle are considered for congestion management. The three methods of congestion management provided in the tool are:

1. TLR Sensitivities Based Load Curtailment 
2. Economic Load Management for Congestion Relief

3. VAR Support

and these are discussed next.

\subsubsection{TLR Sensitivities Based Load Curtailment}

Transmission Line Relief (TLR) sensitivities can be considered as the inverse of the Power Transfer Distribution Factors (PTDFs)[59]. Both TLR sensitivities and PTDFs measure the sensitivity of the flow on a line to load curtailment. PTDFs determine the sensitivity of the flow on an element such as transmission line to a single power transfer. TLR Sensitivities determine the sensitivity of the flow on the single monitored element such as a transmission line to many different transactions in the system. In other words, TLR sensitivities gauge the sensitivity of a single monitored element to many different power transfers.

The TLR sensitivity values at all the load buses for the most overloaded line are considered and used for calculating the necessary load curtailment for the alleviation of the transmission congestion. The TLR sensitivity at a bus $k$ for a congested line $i-j$ is $S_{i j}^{k}$, and is calculated by

$$
S_{i j}^{k}=\frac{\overline{\Delta P_{i j}}}{\Delta P_{k}}
$$

The excess power flow on transmission line $i-j$ is given by:

$$
\overline{\Delta P_{i j}}=P_{i j}-\overline{P_{i j}}
$$

where

$P_{i j}=$ Actual power flow through transmission line $i-j$

$\overline{P_{i j}}=$ Flow limit of transmission line $i-j$

The new load $P_{k}^{\text {new }}$ at the bus $k$ can be calculated by

$$
\mathrm{P}_{\mathrm{k}}^{\text {new }}=P_{k}-\frac{S_{i j}^{k}}{\sum_{l=1}^{N} S_{i j}^{l}} \overline{\Delta P_{i j}}
$$


where

$P_{k}^{\text {new }}=$ Load after curtailment at bus $k$

$P_{k}=$ Load before curtailment at bus $k$

$S_{i j}^{l}=$ Sensitivity of power flow on line $i-j$ due to load change at bus $k$

$N=$ Total number of load buses

The higher the TLR sensitivity the more the effect of a single MW power transfer at any bus. So, based on the TLR sensitivity values the loads are curtailed in required amounts at the load buses in order to eliminate the transmission congestion on the congested line $i-j$. This method can be implemented for systems where load curtailment is a necessary option for obtaining (N-1) secure configurations.

\subsubsection{Economic Load Management for Congestion Relief}

Another possible solution for congestion management is to find customers who will volunteer to lower their consumption when transmission congestion occurs. By lowering the consumption, the congestion will "disappear" resulting in a significant reduction in bus marginal costs. A strategy to decide how much load should be curtailed for what customer is discussed here.

The anticipated effect of this congestion relief solution is to encourage consumers to be elastic against high prices of electricity. Hence, this congestion relief procedure could eventually protect all customers from high electricity prices in a deregulated environment. In [37], a set of indices are introduced to represent the level of effective and agreeable load curtailment in congested conditions. A short discussion on these indices is given below.

This method has three indices that are computed to calculate the overall index for the load management. The three factors considered for the index calculations are:

1. Power Flow Effect through Sensitivity Index,

2. Economic Factor for LMP Index, and

3. Load Reduction Preference for customer load curtailment index.

1. Sensitivity Index

The coefficient of the linear relationship between the amount of a transaction and the flow on 
a line is called the sensitivity [48].

Using the sensitivity factor $S_{i j}^{k}$, the expected change of power flow on the target branch $i-j$, due to a change in load power at bus $k$ is given by

$$
\Delta P_{i j}=S_{i j}^{k} \Delta P_{k}
$$

The sensitivity factors of different locations of the system are ranked by the following index:

$$
\mu_{S_{k}}=\frac{S_{i j}^{k}-S^{\min }}{S^{\max }-S^{\min }}
$$

The $S^{\max }$ is the maximum sensitivity and $S^{\min }$ the minimum. The index $\mu_{S k}$ is highest at 1 for the bus with highest sensitivity and 0 for the bus with the smallest sensitivity.

\section{LMP Index}

High electricity price is an incentive to reduce load. The following index measures the level of customer incentive to cut down on electricity consumption.

$$
\mu_{C k}=\frac{L M P_{k}-L M P^{\min }}{L M P^{\max }-L M P^{\min }}
$$

$L M P_{k}$ is the $L M P$ value at bus $k, L M P^{\max }$ and $L M P^{\min }$ are the highest and lowest locational prices, respectively. If $\mu_{C k}$ is 1 , the incentive is highest and if $\mu_{C k}$ is 0 , there is no such incentive.

\section{Customer load curtailment Index}

If the required reduction of the power flow on the congested branch is given by $\Delta P_{d}$, the required amount of adjustment $\Delta P^{k}$ at bus $k$ will be given by

$$
\Delta P^{k}=\frac{\Delta P_{d}}{S_{i j}^{k}}
$$

Generally, the higher the sensitivity, the smaller the amount of curtailment needed. The customer is supposed to express the acceptable range of curtailment by $P^{\max }$ and $P^{\min }$ at bus $k$, and the curtailment acceptance level is measured by

$$
\mu_{L k}=\frac{P^{\max }-\Delta P^{k}}{P^{\max }-P^{\min }}
$$

If the index $\mu_{L k}$ is 1 then the required amount of load reduction is in the acceptable range of the customer and if $\mu_{L k}$ is 0 then the required amount of load curtailment is more than the acceptable range. 
Overall, the index for a possible load management can then be given by

$$
\mu_{k}=\mu_{S k} \cdot \mu_{L k} \cdot \mu_{C k}
$$

A high $\mu_{k}$ represents a condition where the sensitivity is high, the amount of load curtailed is agreeable, and price incentive is attractive. The load curtailment should be as small as possible and the price after load curtailment should be reduced as much as possible. The load is curtailed at the bus with the highest $\mu_{k}$ value and the amount of load curtailment is $\Delta P^{k}$.

\subsubsection{VAR Support for Congestion Relief}

In the present day scenario, unplanned power transactions are rapidly increasing due to the competition among utilities to meet increasing demand and if transactions are not properly controlled, transmission lines are often operated and stressed to the limit. The increased use of existing transmission is made possible, in part, by reactive power compensation. The role of VAR support in the open power market is to help manage congestion.

Better utilization of the existing power system to increase power transfer capability by installing VAR support such as capacitor banks and FACTS (Flexible AC Transmission Systems) devices becomes imperative. Capacitors, Static VAR Compensator (SVC) [1], [8], [22], [26], Thyristor Controlled Series Capacitor (TCSC) [8], [19], [25] Unified Power Flow Controller (UPFC) [2], [3], [10], [22] are some of the examples of FACTS devices used for VAR support.

The main advantage of FACTS devices is the possibility of their installation for a short period compared to the planning and construction of new transmission lines [5]. FACTS not only improve the transmission capacity but also reduce the losses. However, FACTS devices are expensive. The investment cost of FACTS devices as described in [24] can be categorized as 1) device equipment cost, 2) necessary infrastructure cost, and 3) operation maintenance 


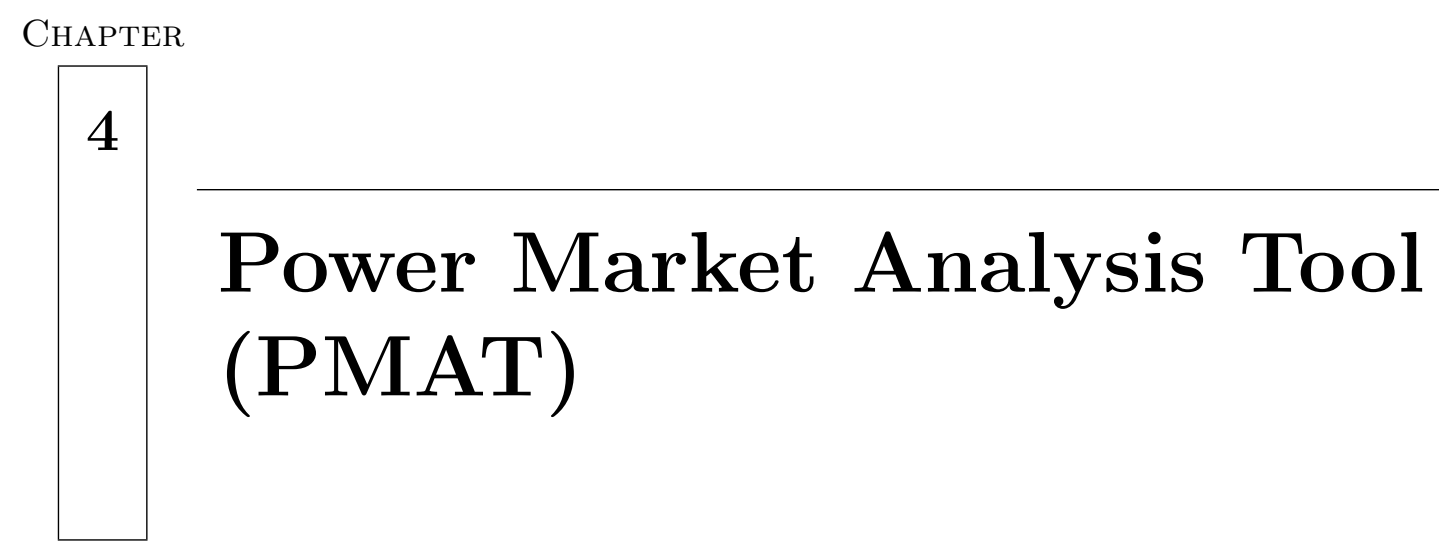

\subsection{Overview of PMAT}

PMAT is a MATLAB interface tool that provides access to the PowerWorld simulator functionality via SimAuto. MATLAB's object-oriented programming capabilities are used for implementing an API and a GUI. A one line diagram of the test system has to be designed in PowerWorld before PMAT can be used. The tool helps in adding, modifying, and retrieving data from the simulator at run time and to change settings and run case studies It allows batch processing of large case studies.

The outline of the Power Market Analysis Tool and its main features is shown in Figure 4.1. PMAT takes the bid curves and system conditions from the MATLAB user's application. PMAT is a MATLAB tool box with GUI and API features. It loads the PowerWorld binary (*.pwb) data file for solving the power flow computations using PowerWorld simulator. PMAT implements the congestion relief methods to obtain $(\mathrm{N}-1)$ secure configurations. The LMP report and the power flow data are the output for the user. 


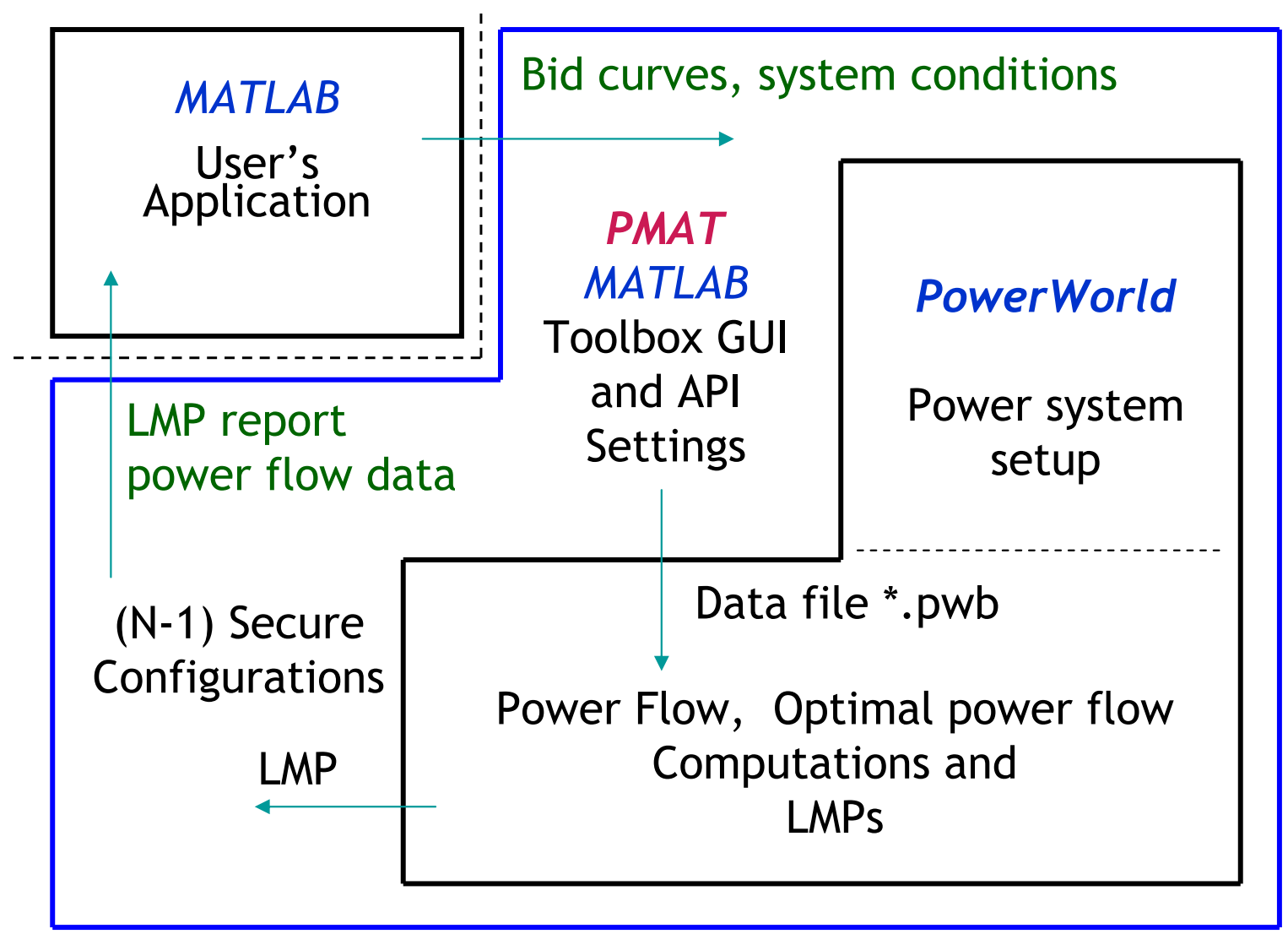

Figure 4.1: Outline of PMAT

\subsubsection{Class Diagram of PMAT}

The class diagram of PMAT is shown in the Figure 4.2. The class diagram shows the objects, their properties and the methods. The description of the methods is given in the Appendix D.1.

\subsubsection{Starting/Setup PMAT}

The PMAT main folder has to be added to MATLAB's path variable first. Afterward, PMAT can be launched by typing at the MATLAB prompt:

$>>$ pmat

During startup, all global objects and variables required by the tool, are created automatically 


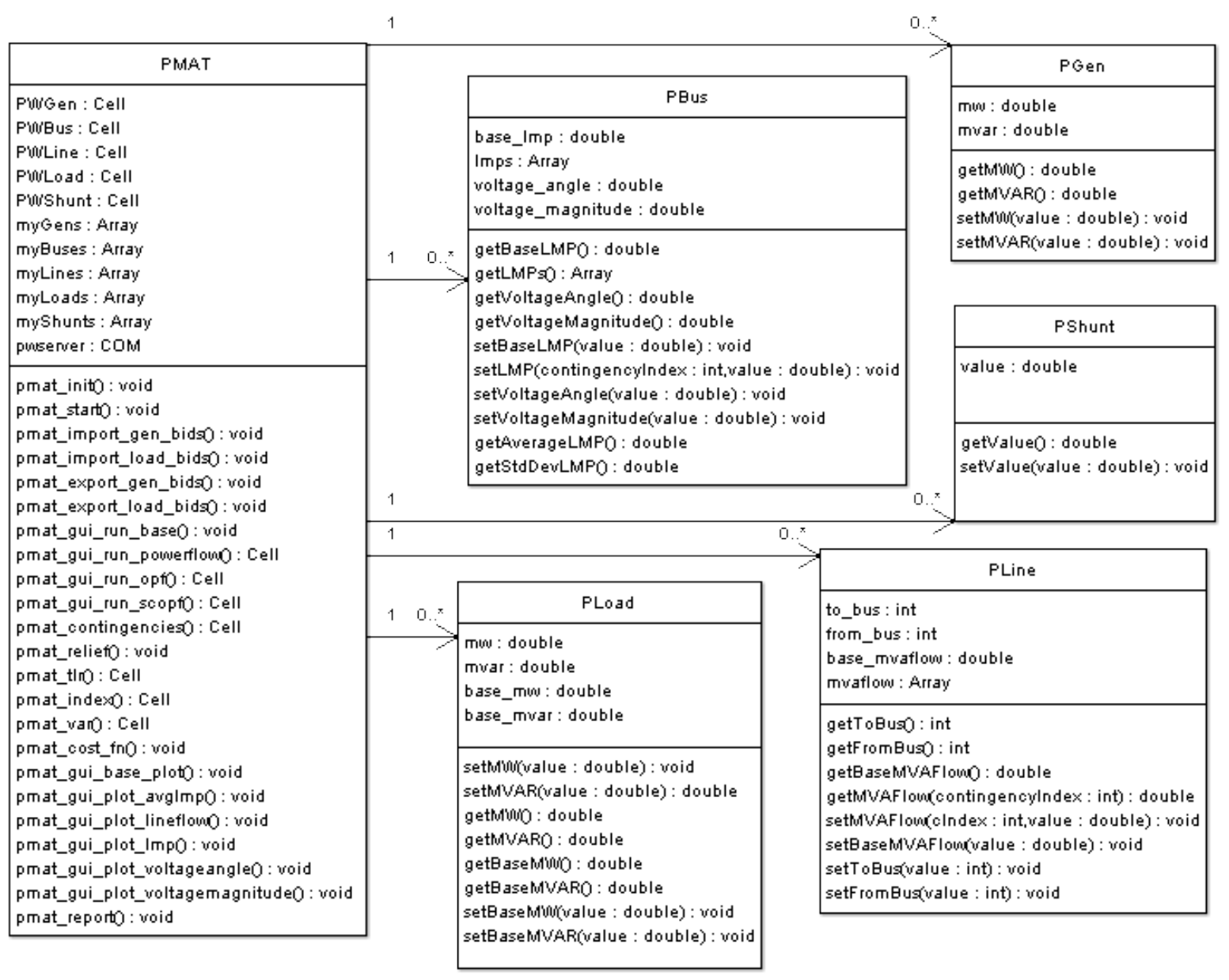

Figure 4.2: Class Diagram of PMAT

and the main graphical user interface window, depicted in Figure 4.3, is opened. All modules and procedures can be used by means of menus, option buttons, and push buttons.

The flow chart showing the steps and workflow of a case study using PMAT is given in Figure 4.4 .

\subsubsection{Opening a Case File}

A PowerWorld power system data file should be loaded for any operation. The name of the data file is displayed in the in the box titled "Choose a Data File" of the main window. The data file is a PowerWorld binary (*.pwb) file that has been designed in PowerWorld. Once a 


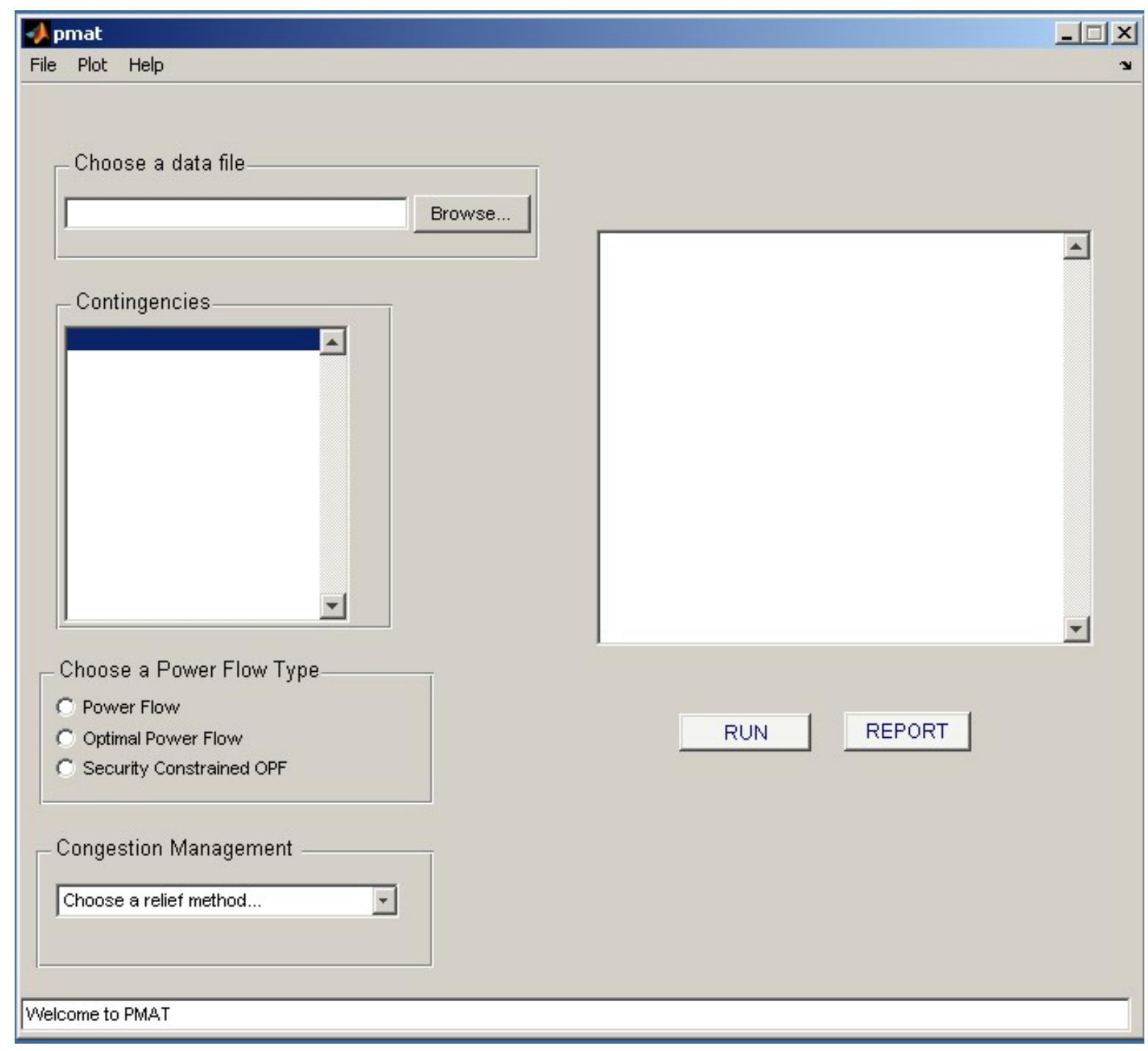

Figure 4.3: Main GUI of PMAT

data file is loaded and connection to the PowerWorld simulator is established, the total number of generators and transmission lines in the test case are populated in the Contingencies list box. PMAT provides an option of importing market data, the generator and load bids, through the File menu. The imported generator and load bids are loaded in the MATLAB workspace as *.mat files and are accessible to the user. The user can modify and save the bid data by exporting as *.mat file.

Once the data file is loaded, the power flow routine to set up the "base case" solution can 


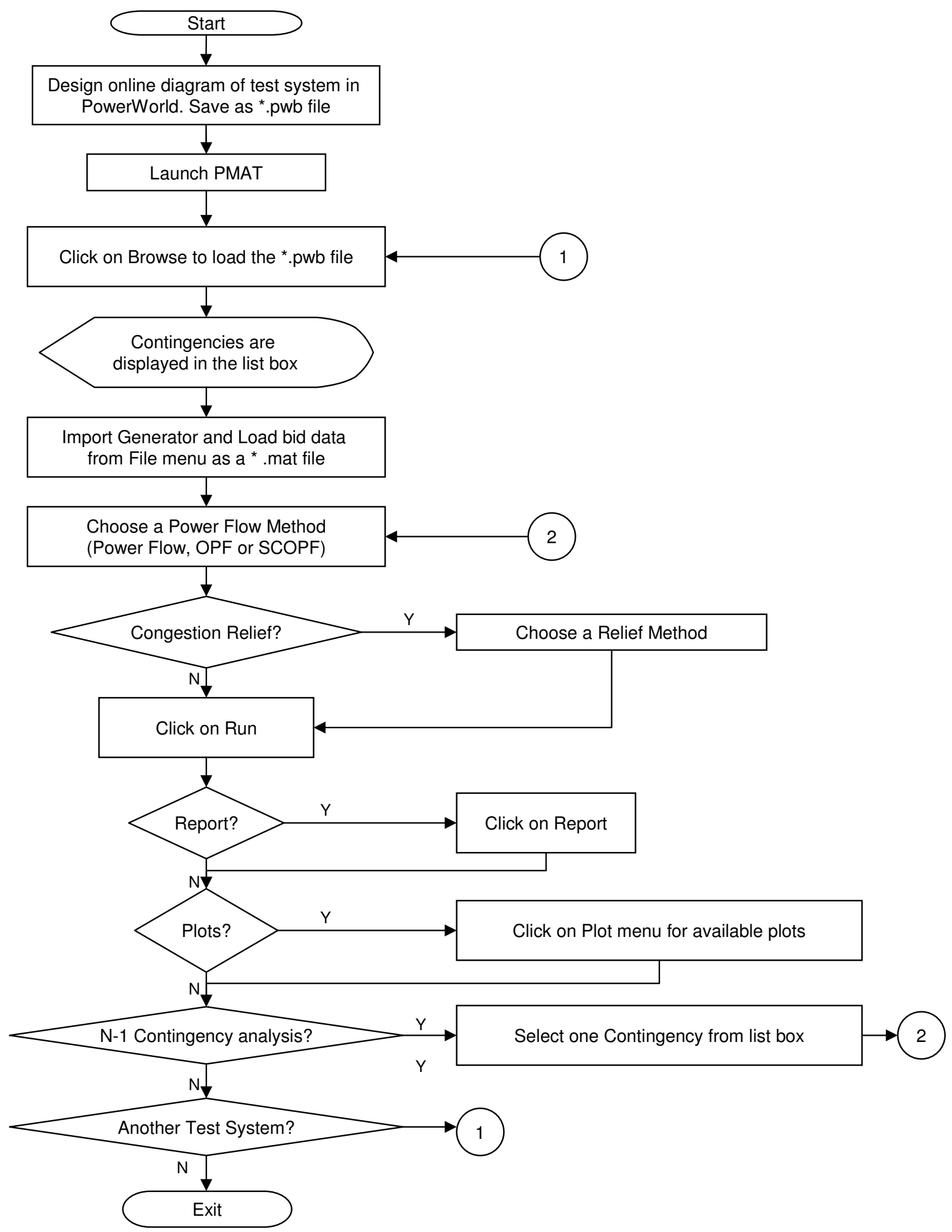

Figure 4.4: Flow Chart of PMAT 
be run. The power flow routine does not provide the option of solving the power flows for contingencies whereas the OPF and SCOPF routines allow (N-1) contingency analysis.

\subsubsection{Output Data}

The results of the power flows can be saved by clicking the option button REPORT after every power flow. The REPORT prompts the user to save the report as a *.txt file. The user has the option of overwriting the existing report or writing a new report. After saving the *.txt file, it automatically opens in the MATLAB editor. The results provided in the report for different power flows are:

- Power Flow: Provides the parameters for buses, transmission lines, generators, loads, and switched shunts.

- $O P F$ and SCOPF: Provides all the data of the power flow and also generator bids and limits, load bids and limits, LMPs at the buses, operating cost and losses in the system.

PMAT also provides a graphical view of the power flow results. The Plot menu helps the user to view the results of the power flows graphically. The following are various plots to choose from:

1. The LMPs at all the buses for the test system in case of OPF and SCOPF with and without contingencies

2. LMP statistics which include the Average, Maximum, Minimum, Average \pm Standard Deviation

3. Voltage magnitudes

4. Voltage phase angles

5. Transmission line flows and limits

6. Generator cost function

7. Load cost function 


\subsubsection{Congestion Relief}

When the contingencies are added while running the OPF and SCOPF, transmission congestion might occur at one or more transmission lines. Three congestion relieving methods as explained in Chapter 3 are available in PMAT. Users can choose the congestion relief method from the Congestion Management options provided in the main window of PMAT. The congestion relief methods try to alleviate the transmission congestion in all the congested lines. The results of the power flows after the congestion relief method can be viewed from the REPORT or from the Plot menu.

TLR Sensitivity Analysis

The TLR Sensitivity Analysis method for congestion relief implements the load curtailment technique based on the sensitivity values of the buses for the congested transmission lines and eliminates the congestion. The new load parameters can be viewed in the report along with other details. The new LMPs and the transmission line flows after the congestion relief can be viewed as graphical output through the Plot menu.

$\underline{\text { Economic Load Management }}$

The Economic Load Management method for congestion relief considers three factors for load management: TLR sensitivity values, LMPs, and the acceptable range of load curtailment. The acceptable range of load curtailment should be specified by the user for all the loads in the test system before running the relief scheme. The user can go to the Options in the File menu to enter the Min and Max \% of load curtailment. The Options dialog for six bus test system described in Section 5.1 is shown in Figure 4.5. Default values are provided by the program and the user can always change those values to study the effect of different values on the behavior of the system. The new results and the graphical plots can be viewed after the alleviation of congestion.

\section{VAR Support}

The VAR support devices that are available within the PowerWorld should be included while designing the one line diagram for the test system. The "Status" should be set to open, so that the devices are inactive when the base case power flows are solved without the VAR support. When there is transmission congestion, and if the user choses to relieve congestion through VAR support by selecting the VAR support scheme, the devices are connected to the 


\section{Options \\ Options}
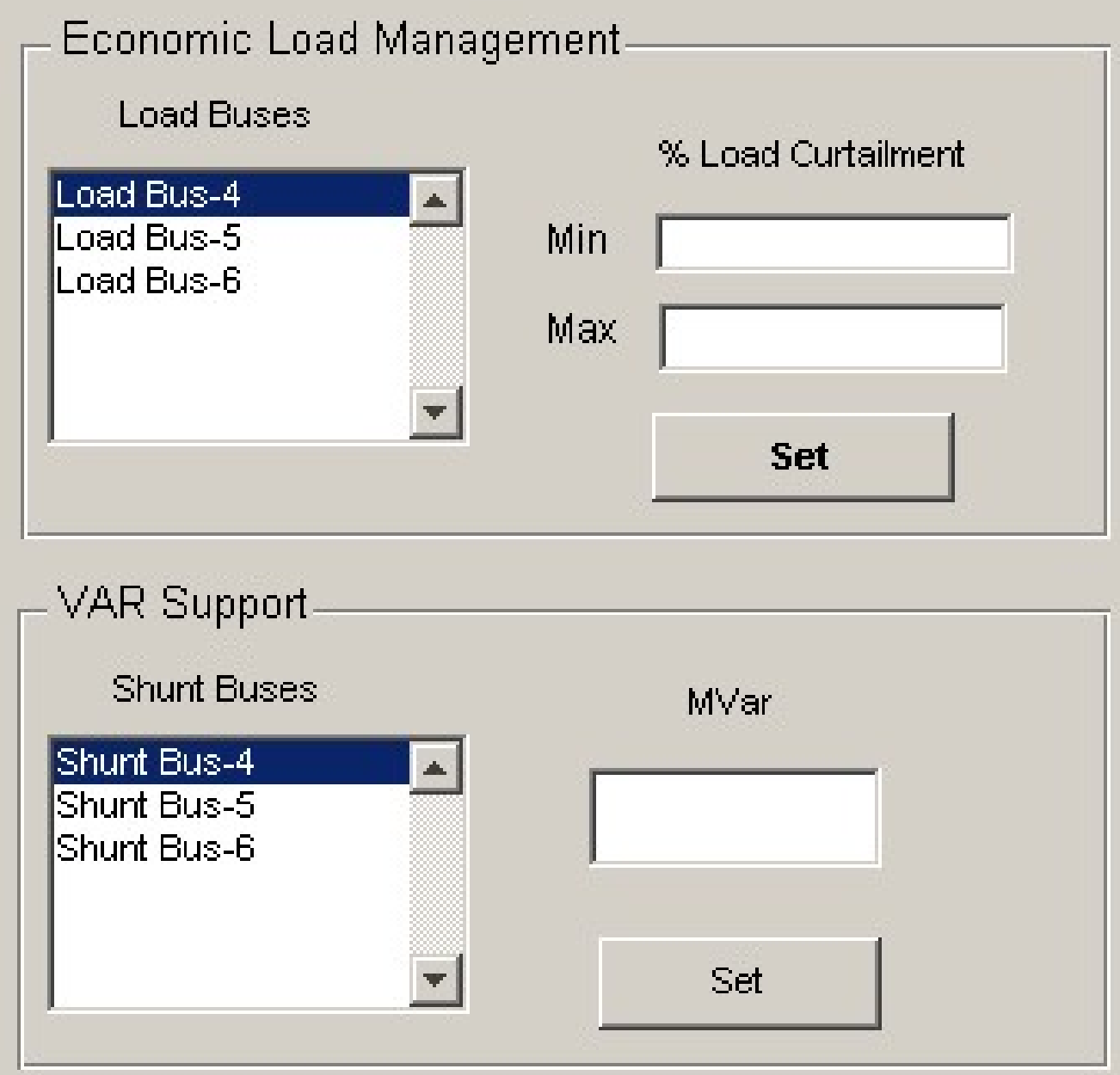

\section{CLOSE}

Figure 4.5: Options dialog of PMAT 
power system. Before implementing the scheme, the user should specify the MVAR value for the VAR support device at the available fields from the Options in the menu. Default MVAR values are provided by the program and the user can change the values using the GUI as shown in Figure 4.5.

\subsection{Example}

In this section one simple example will be used to illustrate how PMAT works. Let us consider the six bus test system. The one line diagram of the six bus system designed in the PowerWorld is as shown in Figure 4.6. The one line diagram should also contain the shunt devices at the desired buses but initially disconnected. The shunt devices are activated to implement the VAR support from within PMAT. The nominal MVAR of the shunt devices can be even set to zero.

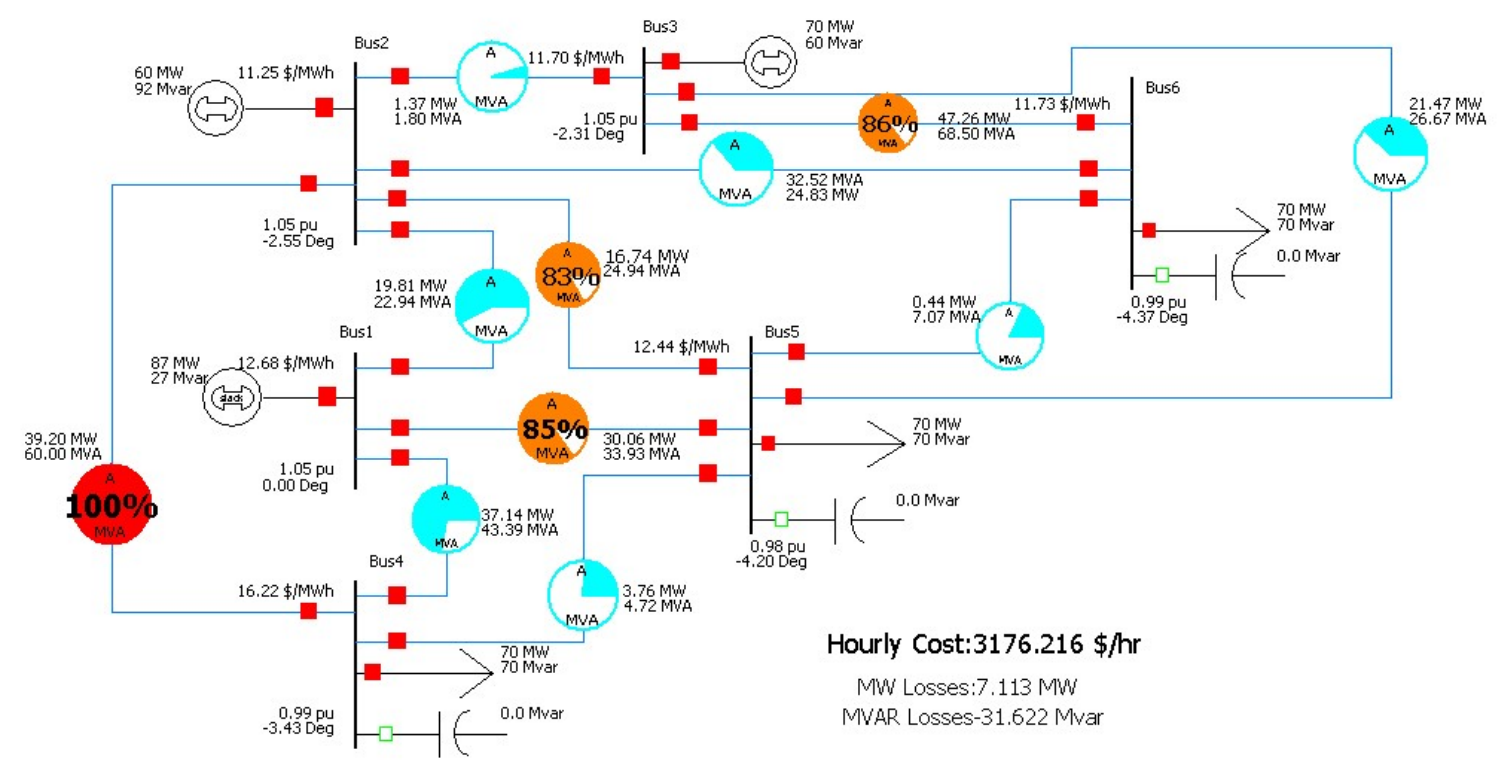

Figure 4.6: Six Bus Test System - PowerWorld One line Diagram

Once the one line diagram is ready for the test system, PowerWorld can be closed and PMAT can be launched as explained in the Subsection 4.1.2. The user can import the generator and supply bid data and solve the power flow/OPF/SCOPF with and without contingencies. For example, if the user wants to compare the LMPs for the outage of the line 2-4 with the base LMPs, the LMP plot can be obtained by clicking on the Bus LMP in the Plot menu. The 
plot obtained is shown in Figure 4.7. For more than one contingency the user can also plot the LMP statistics.

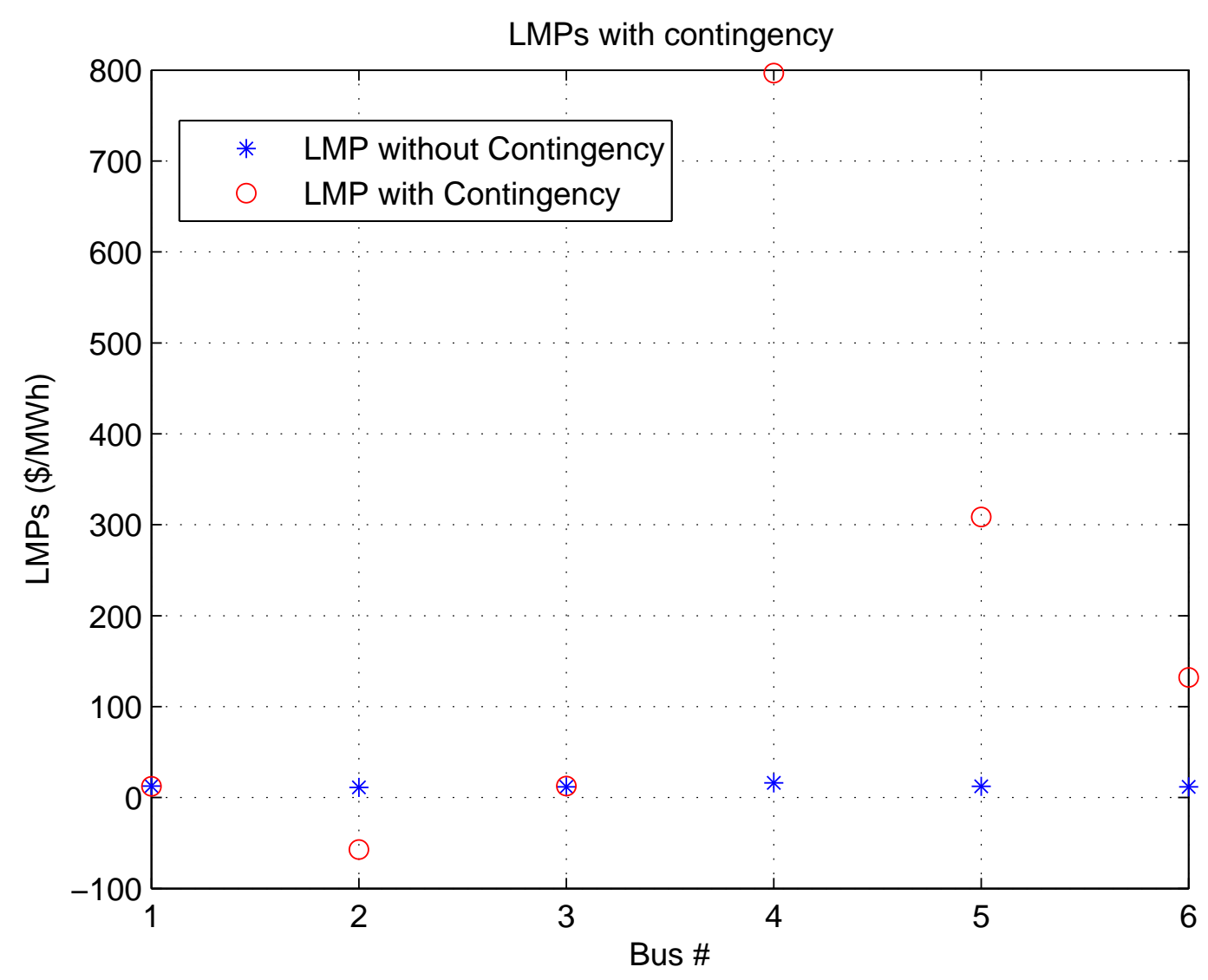

Figure 4.7: Comparison of LMPs with Line 2-4 Outage and without Contingency

From Figure 4.7, the LMPs at the buses for the contingency line 2-4, are as high as 800 $\$ / M W h$ and as low as $-60 \$ / M W h$ for the six bus test system because of high congestions. The user does not have to plot the LMPs individually but can observe the variation of LMPs with and without contingencies and also after implementing a congestion relief scheme with just a mouse click.

The bus voltage magnitudes and bus voltage angles can be plotted as bar graphs, both choices are available from the Plot menu. Figure 4.8 shows the bus voltage magnitude plots for the six bus test system. The bus voltage angles can be plotted similarly. 


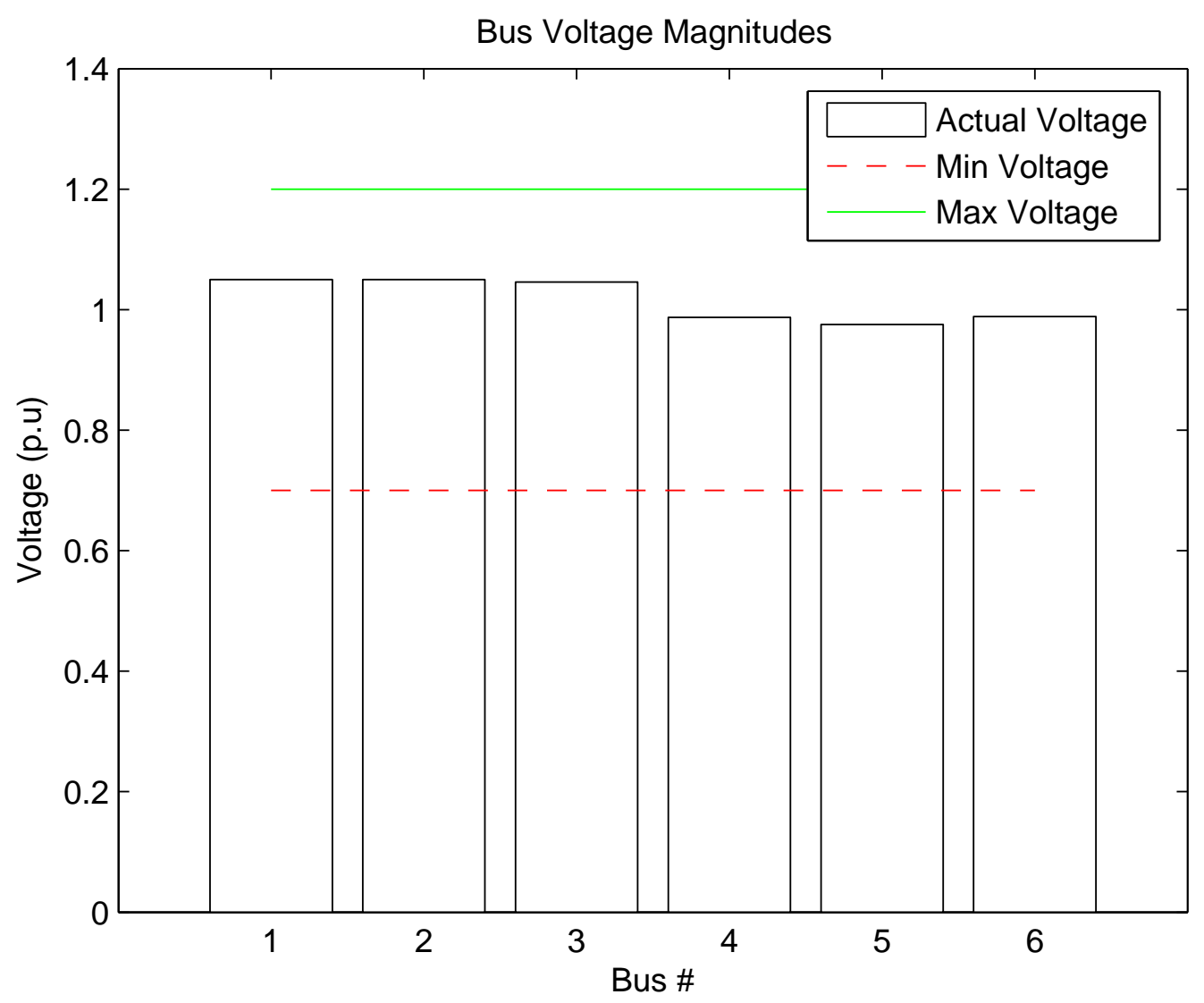

Figure 4.8: Bus Voltage Magnitudes for OPF w/o contingencies of Six Bus Test System

The line flows can also be plot from the Line Flow option from the Plot menu. The line flows in all the eleven transmission lines for generator 2 outage are shown in Figure 4.9.

From the Figure 4.9, the total power flow (MVA flow) in the transmission lines is compared to the MVA limit of the transmission line. When generator 2 fails, the MVA flow in the transmission lines 1-2 (line \#1), 1-4(line \#2), 1-5 (line \#3) and 3-6 (line \#9) exceeded their respective MVA flow limits.

The user can also plot the generator cost function, which gives the cost of the generator output and the load benefit function, which gives the price customers are willing to pay for the load consumption. The cost functions can be plotted for cubic cost model and piecewise linear model. In PowerWorld help file [45], the cubic cost model and piecewise cost model are 


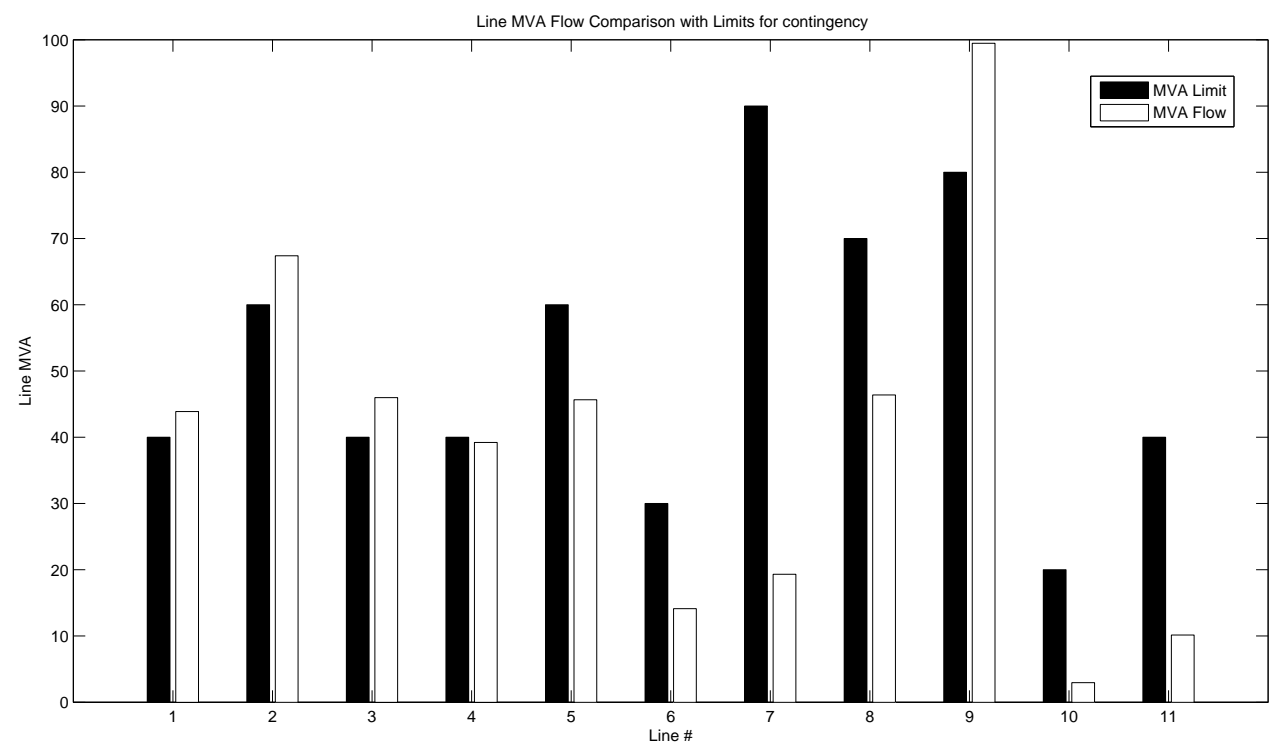

Figure 4.9: Line MVA Flows for Gen 2 Outage for Six Bus Test System

fc

explained. The cubic cost model is in the form:

$$
C\left(P_{g i}\right)=\left(a+b * P_{g i}+c * P_{g i}^{2}+d * P_{g i}^{3}\right)
$$

where

$P_{g i}=$ Output of the generator at bus $i$

$a=$ Fixed cost $(\$ / h)$

$b=$ Proportional cost $(\$ / M W h)$

$c=$ Quadratic cost $\left(\$ / M W^{2} h\right)$

$d=$ Cubic cost $\left(\$ / M W^{3} h\right)$

In piecewise linear cost model $M W$ output levels of generators and corresponding generating operating costs $\$ / M W h$ are specified for the generator in a tabular form. Similarly, the load benefit function can also be plotted in PMAT.

Figure 4.10 is the plot of the generator cost function for generator 1 (cubic cost function) for the six bus test system. The cost function for generator 1 is $213.1+11.67 x+0.0053 x^{2}$ ( $x$ is the active power output). The cubic coefficient $d$ is zero. The minimum and maximum limits 
of the generator active power output are $50 M W$ and $170 M W$ respectively.

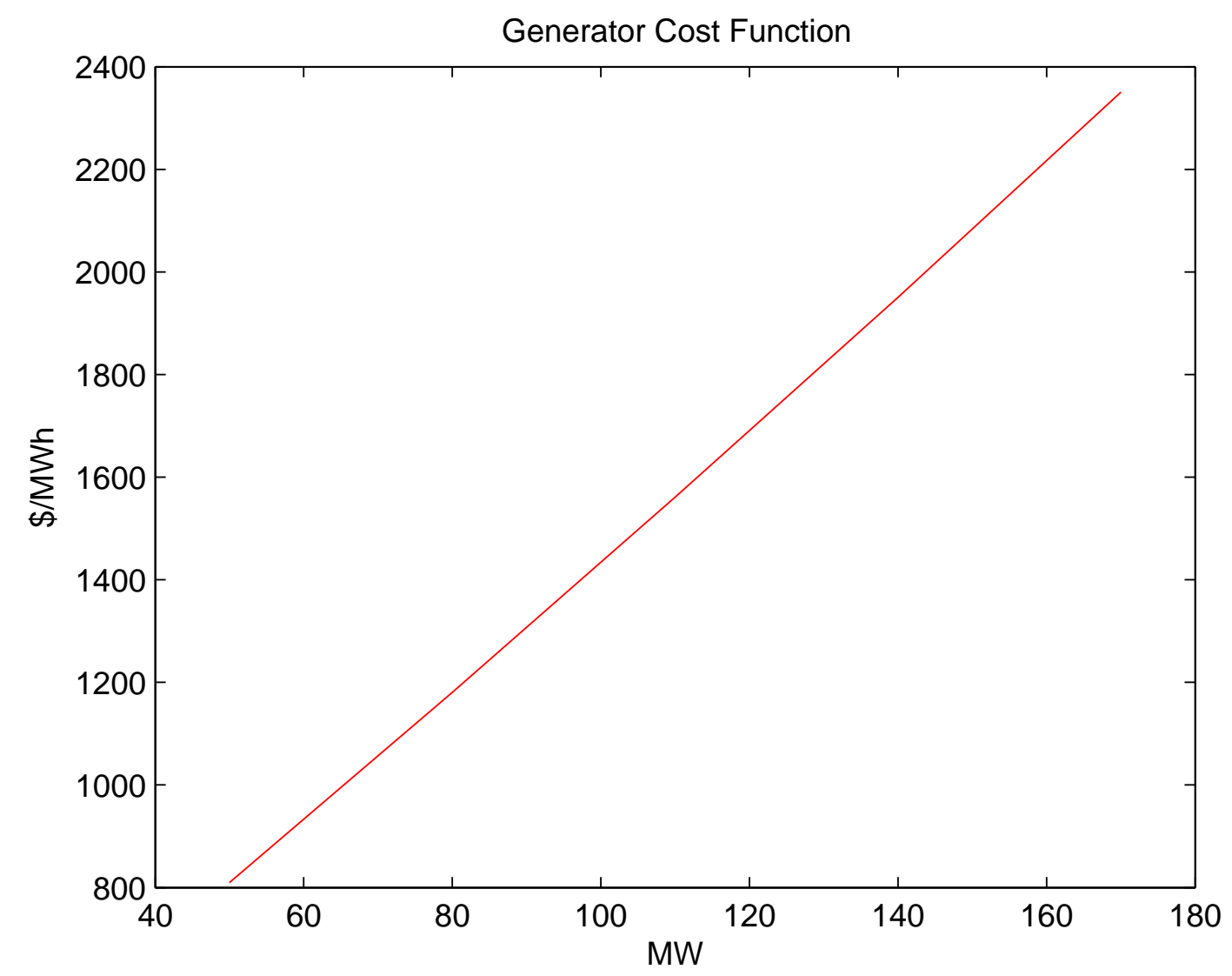

Figure 4.10: Cost Function of Generator 1 for Six Bus Test System

The LMP statistics are plotted for more than single contingencies. When the user wants to observe the behavior of any test system for the outage of more than a single component (generator or line) he/she can select an additional contingency by holding the ctrl key and selecting the contingencies. Figure 4.11 shows the LMPs for the outage of lines 1-4 and 2-3 for the six bus test system. From Figure 4.11, the maximum LMP at load buses 4, 5, and 6 when the line 1-4 is failed are around 750,150 , and $100 \$ / M W h$ respectively. But when the line 2-3 also failed, the LMPs are higher than for a single contingency and are approximately 900, 350, and 220 at the buses 4, 5, and 6 respectively. This example demonstrates that the more contingencies the more the congestions in any system and the LMPs are very high due to the $\$ 1000 / M W h$ line flow violation costs used in the cost optimization (linear programming). 
The Plot menu allows the user to save, print, and export graphs.

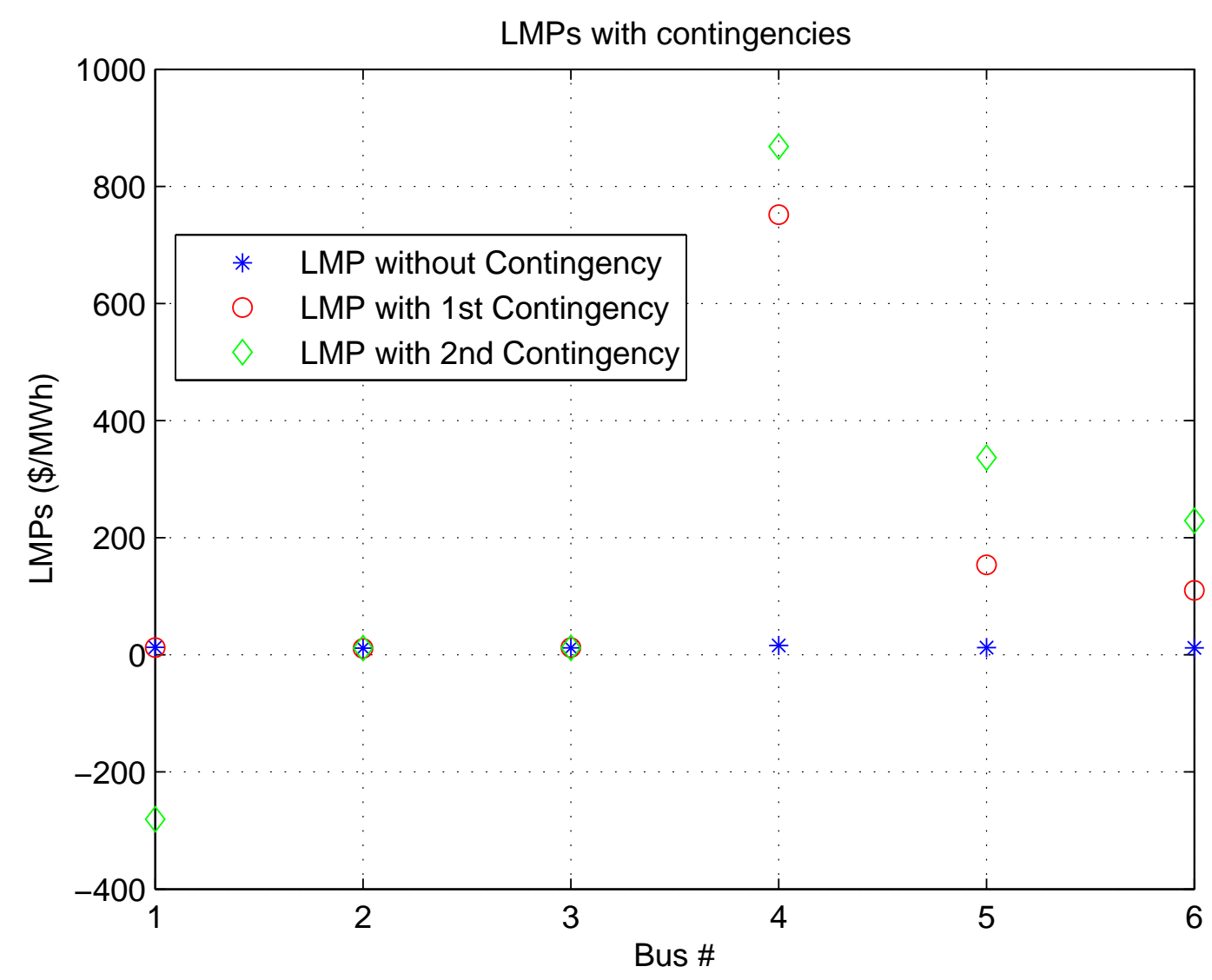

Figure 4.11: LMPs for the outage of lines 1-4 and 2-3 for Six Bus Test System

The Help menu in PMAT provides the information on how to use PMAT.

After the user completed a study in PMAT, the user can close the connection to the PowerWorld server from Exit in the File menu. 


\section{Chapter}

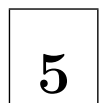

\section{Case Studies and Discussion}

The different congestion relief schemes described in Chapter 3 are applied to different electric systems through PMAT. This chapter gives the results and discusses the case studies in detail.

\subsection{Test Systems Description}

Two test systems have been tested and analyzed in this thesis to illustrate PMAT.

1. Six Bus Test System

2. IEEE 24 Bus Reliability Test System

\subsubsection{Six Bus Test System}

The six bus system data (generator, bus, and line data) are taken from [57]. The system represents 3 generation companies (GENCOS) that provide supply bids, 3 loads, and 11 transmission lines. The complete network data for this system is provided in Appendix A.1. The market data (generator and load cost curve data) is provided in Appendix A.2. The one line diagram is shown in Figure 5.1. 


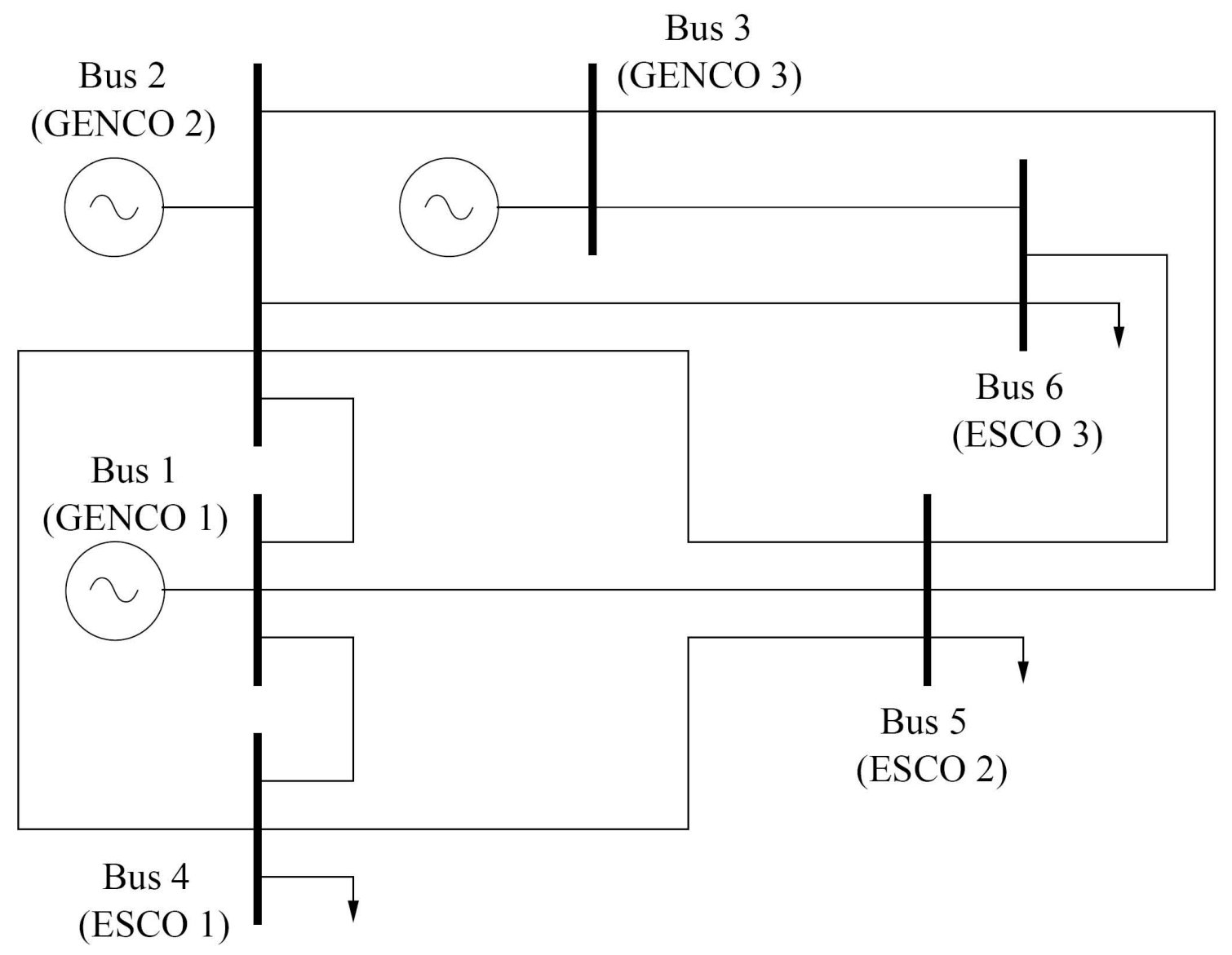

Figure 5.1: Single line diagram of Six Bus Test System [57]

\subsubsection{IEEE 24 Bus Test System}

The IEEE 24-bus Single Area Reliability Test System is a relatively large system with 24 buses including 33 generators, 17 loads, and 37 lines. Appendix B.1 provides more information on the IEEE 24 bus system data. Some of the transmission line MVA limits are modified in the test system in order to increase the transmission congestion in case of contingencies and demonstrate the effect of various congestion relief techniques provided in PMAT. The transmission line from bus 6 to bus 10 is out of service (disconnected) because of its high susceptance value when the power flow is run the line 6-10 is heavily congested. The one line diagram of IEEE 24-bus Single Area RTS is shown in Figure 5.2. 


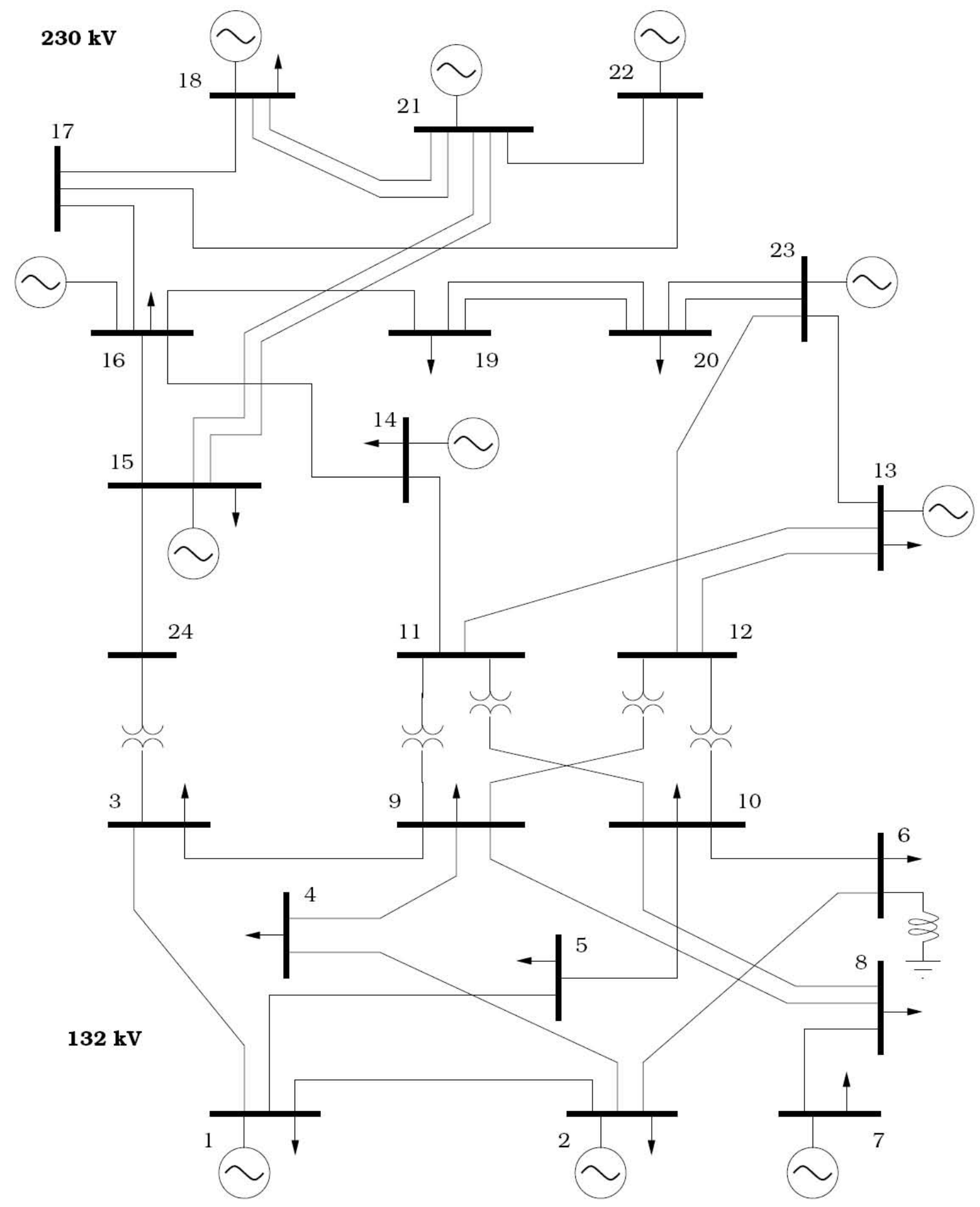

Figure 5.2: Single line diagram of IEEE 24 Bus Single Area Reliability Test System [47] 


\subsection{Results and Discussion}

\subsubsection{Results for Six Bus Test System}

The LMP statistics before and after congestion relief for the six bus test system are discussed in this section.

\section{LMP Values for (N-1) Contingencies}

There are 14 contingencies altogether (3 generators +11 transmission lines) for the six bus test system. From the cost curve data of the six bus test system A.4, the LMPs at all the buses are in the range of $11.00 \$ / M W h$ to $16.00 \$ / M W h$ without any contingencies. The LMPs at the buses are obtained for each contingency and given in Table 5.1.

Table 5.1: LMP values for (N-1) contingencies - Six Bus Test System

\begin{tabular}{|c|c|c|c|c|c|c|c|c|c|c|c|c|c|c|}
\hline \multirow{3}{*}{ Bus No: } & \multicolumn{14}{|c|}{ Contingencies } \\
\hline & \multicolumn{3}{|c|}{ Generators } & \multicolumn{11}{|c|}{ Lines } \\
\hline & 1 & 2 & 3 & $1-2$ & $1-4$ & $1-5$ & $2-3$ & $2-4$ & $2-5$ & $2-6$ & $3-5$ & $3-6$ & $4-5$ & $5-6$ \\
\hline Bus-1 & 394.93 & 12.36 & 12.36 & 12.36 & 12.36 & 12.36 & 12.68 & 12.36 & 12.68 & 12.68 & 12.99 & 12.36 & 12.68 & 12.68 \\
\hline Bus-2 & 12.80 & 409.09 & 12.80 & 11.60 & 11.20 & 5.30 & 11.20 & -57.07 & -85.11 & -81.50 & 11.20 & 11.92 & 11.55 & 11.37 \\
\hline Bus-3 & 12.10 & 13.29 & 260.88 & 11.78 & 12.49 & 12.49 & 12.00 & 12.49 & 12.10 & 12.10 & 11.70 & 12.10 & 11.70 & 11.70 \\
\hline Bus-4 & 686.09 & 573.27 & 266.57 & 13.17 & 751.50 & 44.52 & 16.42 & 796.78 & 376.57 & 398.18 & 294.03 & 12.90 & 16.10 & 16.22 \\
\hline Bus-5 & 445.63 & 583.14 & 576.06 & 12.05 & 153.66 & 295.32 & 12.58 & 308.48 & 199.38 & 462.02 & 626.28 & 12.18 & 11.86 & 12.68 \\
\hline Bus-6 & 379.64 & 889.61 & 285.49 & 11.77 & 109.99 & 196.44 & 11.94 & 132.01 & 26.74 & 781.76 & 252.38 & 11.95 & 11.66 & 11.61 \\
\hline
\end{tabular}

From data in Table 5.1, follows that negative LMPs at bus 2 for the outages of lines 2-4, 2-5, and 2-6, respectively occur. These negative LMPs denote that the system constraints cannot be obeyed by re-dispatching generation.

The LMP statistics for $14(\mathrm{~N}-1)$ contingencies are shown in Figure 5.3 and the LMPs are highly varying. The maximum LMP values vary in the range as high as $900 \$ / M W h$ and as low as $-100 \$ / M W h$. The average LMPs at all the buses are around $300 \$ / M W h$. It can be observed that each contingency has a different effect on the system, which in turn varies the LMPs over a wide range.

\section{Load Curtailment By TLR Sensitivity Relief Method}

The load curtailment by TLR Sensitivity Analysis method curtails the loads based on power flow sensitivity values to find a solution with no transmission congestion for the $14(\mathrm{~N}-1)$ 


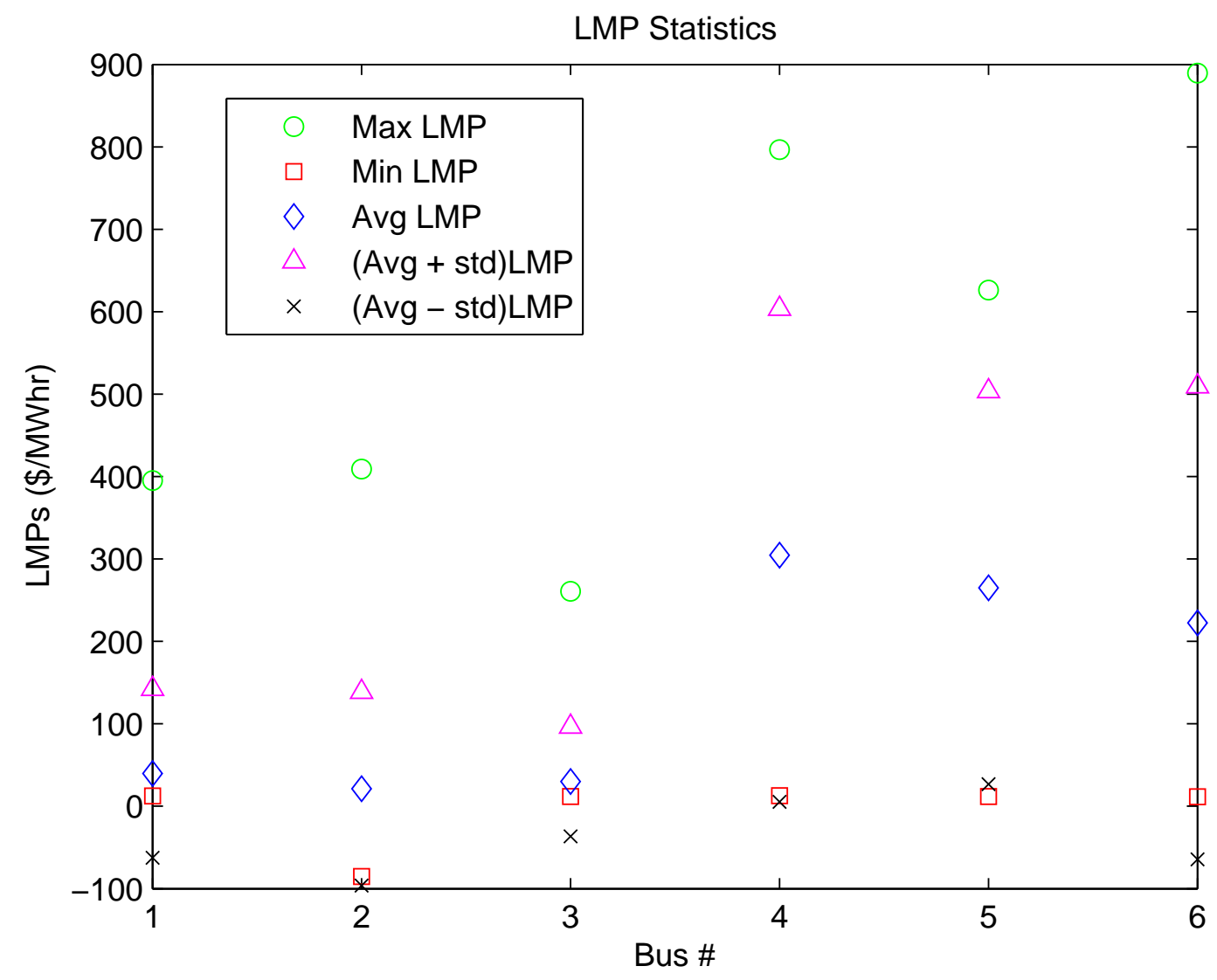

Figure 5.3: LMP Statistics of Six Bus Test System for 14 (N-1) contingency without Congestion Relief

contingencies for the six bus test system. The (N-1) secure LMPs for the six bus test system are given in Table 5.2 .

Table 5.2: LMP values for the (N-1) contingencies and TLR Sensitivity based relief method - Six Bus Test System

\begin{tabular}{|c|c|c|c|c|c|c|c|c|c|c|c|c|c|c|}
\hline \multirow{3}{*}{ Bus No: } & \multicolumn{14}{|c|}{ Contingencies } \\
\hline & \multicolumn{3}{|c|}{ Generators } & \multicolumn{11}{|c|}{ Lines } \\
\hline & 1 & 2 & 3 & $1-2$ & $1-4$ & $1-5$ & $2-3$ & $2-4$ & $2-5$ & $2-6$ & $3-5$ & $3-6$ & $4-5$ & $5-6$ \\
\hline Bus-1 & 12.00 & 12.49 & 12.36 & 11.60 & 11.60 & 11.61 & 11.60 & 11.60 & 11.60 & 11.60 & 11.60 & 11.60 & 11.60 & 11.60 \\
\hline Bus-2 & 12.00 & 12.49 & 12.36 & 11.60 & 11.60 & 11.60 & 11.60 & 11.60 & 11.60 & 11.60 & 11.60 & 11.60 & 11.60 & 11.60 \\
\hline Bus-3 & 12.00 & 12.49 & 12.36 & 11.60 & 11.60 & 11.70 & 11.60 & 11.60 & 11.60 & 11.60 & 11.60 & 11.60 & 11.60 & 11.60 \\
\hline Bus-4 & 12.00 & 12.49 & 12.36 & 11.60 & 11.60 & 11.64 & 11.60 & 11.60 & 11.60 & 11.60 & 11.60 & 11.60 & 11.60 & 11.60 \\
\hline Bus-5 & 12.00 & 12.49 & 13.36 & 11.60 & 11.60 & 12.86 & 11.60 & 11.60 & 11.60 & 11.60 & 11.60 & 11.60 & 11.60 & 11.60 \\
\hline Bus-6 & 12.00 & 12.49 & 12.36 & 11.60 & 11.60 & 11.71 & 11.60 & 11.60 & 11.60 & 11.60 & 11.60 & 11.60 & 11.60 & 11.60 \\
\hline
\end{tabular}

LMP Statistics for TLR Sensitivity Relief Method 
The LMP statistics after the TLR Sensitivity congestion relief method for 14 (N-1) contingencies are shown in Figure 5.4. It can be observed that the maximum LMPs have reduced from 900 to $12.5 \$ / M W h$ and the minimum LMPs are non-negative and are $11.6 \$ / M W h$. The average LMPs at the buses are about $11.76 \$ / M W h$ and the appropriate amount of load curtailment resulted in a secure system even under contingencies.

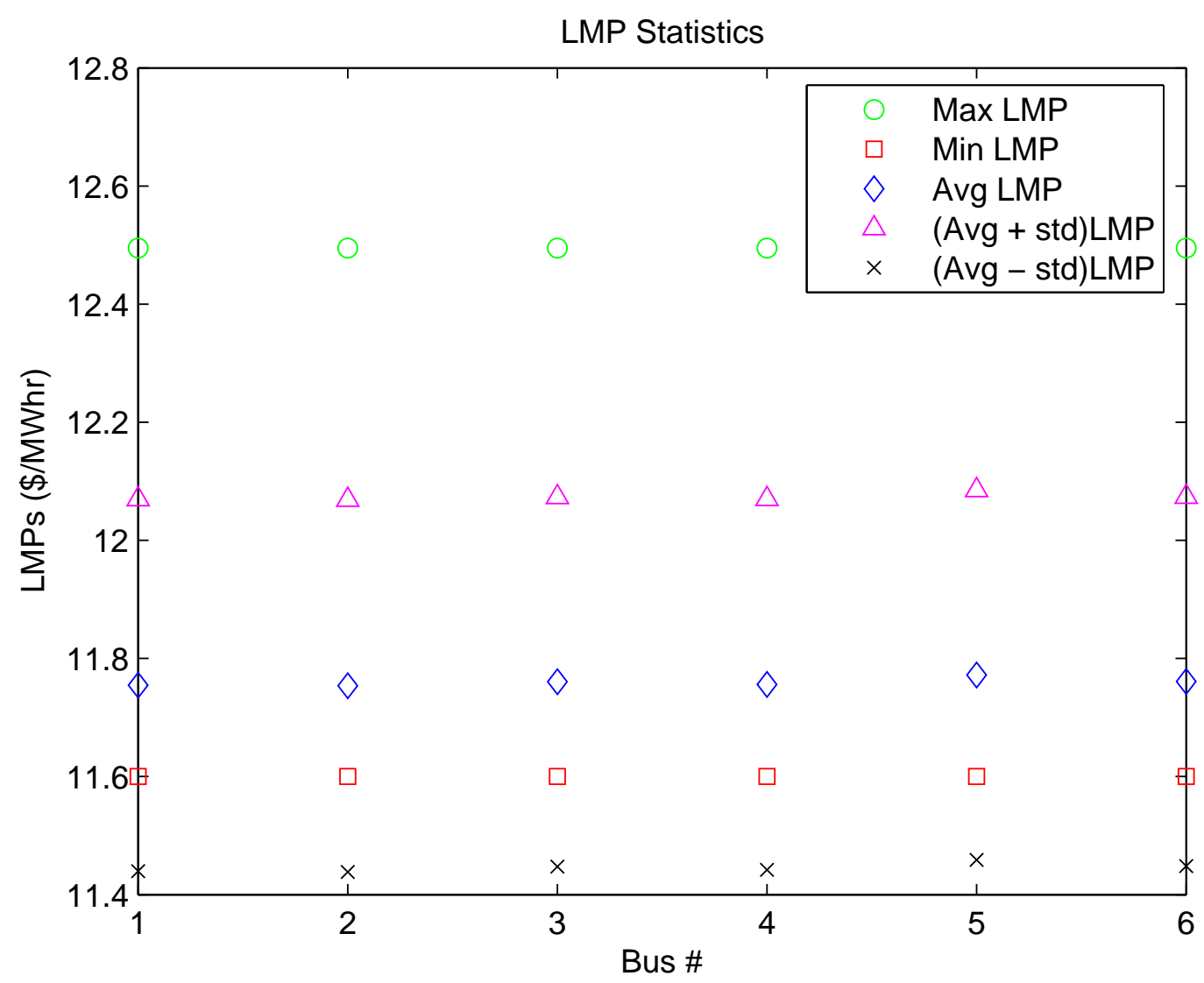

Figure 5.4: LMP Statistics of Six Bus Test System for 14 (N-1) contingency with TLR Sensitivity Method

\section{Economic Load Management}

The Economic Load Management method curtails the load based on the set of indices given in [37]. The TLR sensitivity Index, the LMP Index, and the Load Curtailment Index are used to adjust the loads until an (N-1) secure system is obtained. The maximum and minimum load 
curtailment parameters $P^{\max }$ and $P^{\min }$ are assumed to be $35 \%$ and $5 \%$ of the load at each load bus, respectively. The index for load reduction is the product of the three indices and the maximum value of the overall index is considered to curtail the load at the correspondig load bus. The (N-1) secure LMPs for the six bus test system are given in Table 5.3.

Table 5.3: LMP values for (N-1) contingencies and Economic Load Management - Six Bus Test System

\begin{tabular}{|c|c|c|c|c|c|c|c|c|c|c|c|c|c|c|}
\hline \multirow{3}{*}{ Bus No: } & \multicolumn{14}{|c|}{ Contingencies } \\
\hline & \multicolumn{3}{|c|}{ Generators } & \multicolumn{11}{|c|}{ Lines } \\
\hline & 1 & 2 & 3 & $1-2$ & $1-4$ & $1-5$ & $2-3$ & $2-4$ & $2-5$ & $2-6$ & $3-5$ & $3-6$ & $4-5$ & $5-6$ \\
\hline Bus-1 & 12.00 & 12.36 & 12.36 & 11.60 & 11.60 & 11.60 & 11.60 & 11.60 & 11.60 & 11.60 & 11.60 & 11.60 & 11.60 & 11.60 \\
\hline Bus-2 & 12.00 & 12.36 & 12.36 & 11.60 & 11.60 & 11.60 & 11.60 & 11.60 & 11.60 & 11.60 & 11.60 & 11.60 & 11.60 & 11.60 \\
\hline Bus-3 & 12.00 & 12.36 & 12.36 & 11.60 & 11.60 & 11.60 & 11.60 & 11.60 & 11.60 & 11.60 & 11.60 & 11.60 & 11.60 & 11.60 \\
\hline Bus-4 & 12.00 & 12.36 & 12.36 & 11.60 & 11.60 & 11.60 & 11.60 & 11.60 & 11.60 & 11.60 & 11.60 & 11.60 & 11.60 & 11.60 \\
\hline Bus-5 & 12.00 & 12.36 & 12.36 & 11.60 & 11.60 & 11.60 & 11.60 & 11.60 & 11.60 & 11.60 & 11.60 & 11.60 & 11.60 & 11.60 \\
\hline Bus-6 & 12.00 & 12.36 & 12.36 & 11.60 & 11.60 & 11.60 & 11.60 & 11.60 & 11.60 & 11.60 & 11.60 & 11.60 & 11.60 & 11.60 \\
\hline
\end{tabular}

LMP Statistics for Economic Load Management

The LMP statistics after the Economic Load Management congestion relief method for 14 (N1) contingencies are shown in Figure 5.5. It can be observed that the maximum LMPs have reduced from 900 to $12.35 \$ / M W h$ and the minimum LMPs are non-negative and about 11.6 $\$ / M W h$. The average LMPs are $11.74 \$ / M W h$. By comparing Figures 5.4 and 5.5, it can be observed that the LMP statistics for the TLR Sensitivity and Economic Load Management are almost the same.

\section{VAR Support}

Congestion management using VAR support is implemented in this method. It is assumed that VAR support devices (Switched Shunts) are installed at all the load buses but initially disconnected. By using the VAR support for alleviating congestion, the shunt devices are connected to the system and the amount of load curtailment decreases. The nominal MVAR value for the switched shunts at load buses 4, 5, and 6 chosen are 50 MVAR, 25 MVAR, and 25 MVAR respectively. The (N-1) secure LMPs for the six bus test system are given in Table 5.4. $\underline{\text { LMP Statistics for VAR Support }}$

The LMP statistics after installing VAR Support for $14(\mathrm{~N}-1)$ contingencies are shown in Figure 5.6. The maximum LMPs are in the range of 12.44 to $13.2 \$ / M W h$ and the minimum LMPs at all the buses are almost equal to $11.6 \$ / M W h$. It can be observed that the average 


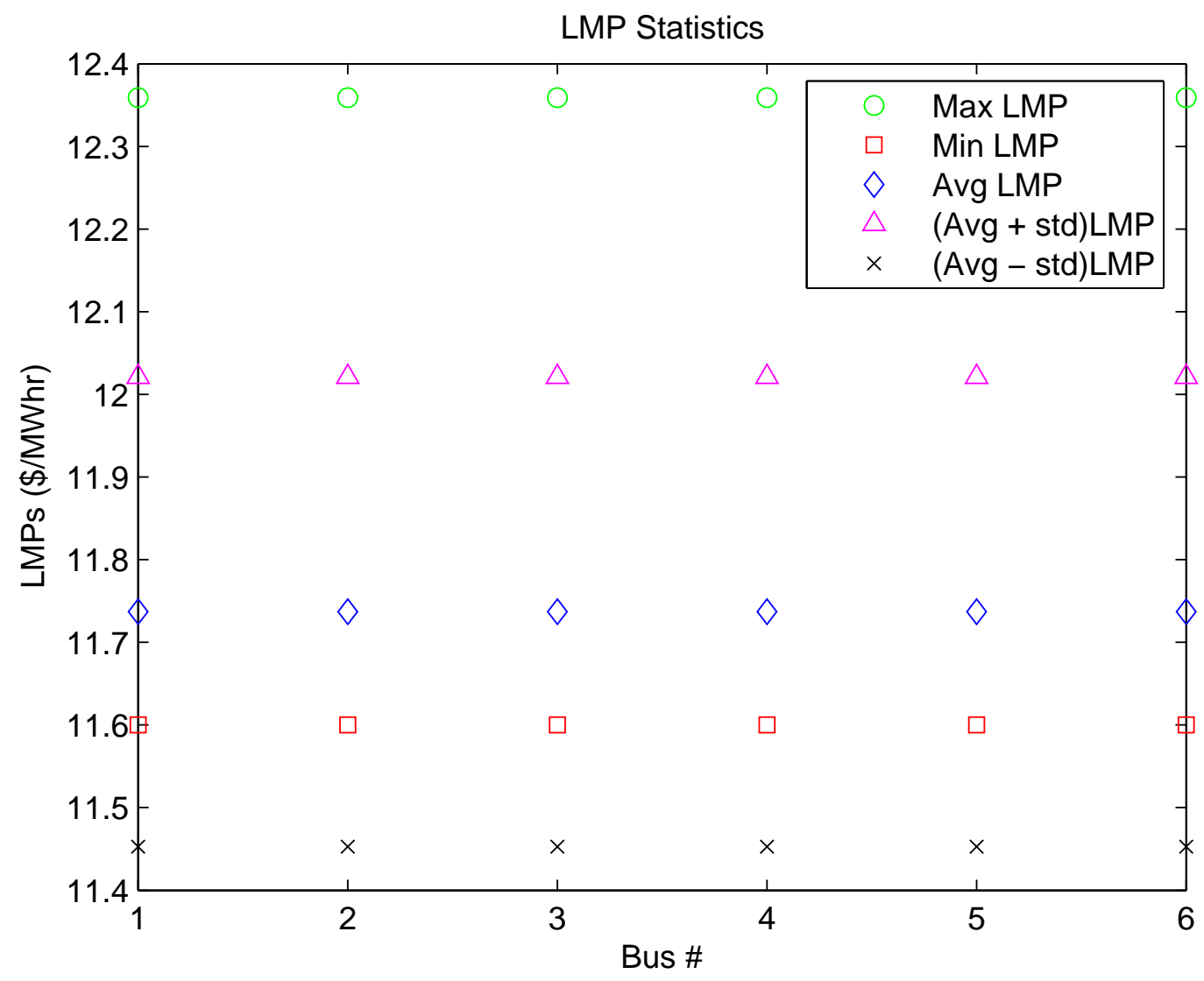

Figure 5.5: LMP Statistics of Six Bus Test System for 14 (N-1) contingency with Economic Load Management Method

Table 5.4: LMP values for the (N-1) contingencies and VAR Support - Six Bus test System

\begin{tabular}{|c|c|c|c|c|c|c|c|c|c|c|c|c|c|c|}
\hline \multirow{3}{*}{ Bus No: } & \multicolumn{14}{|c|}{ Contingencies } \\
\hline & \multicolumn{3}{|c|}{ Generators } & \multicolumn{11}{|c|}{ Lines } \\
\hline & 1 & 2 & 3 & $1-2$ & $1-4$ & $1-5$ & $2-3$ & $2-4$ & $2-5$ & $2-6$ & $3-5$ & $3-6$ & $4-5$ & $5-6$ \\
\hline Bus-1 & 12.00 & 12.68 & 12.68 & 11.70 & 11.70 & 11.70 & 11.70 & 11.70 & 11.70 & 11.70 & 11.70 & 11.70 & 11.70 & 11.70 \\
\hline Bus-2 & 12.00 & 12.68 & 12.68 & 11.70 & 11.70 & 11.70 & 11.70 & 11.70 & 11.70 & 11.70 & 11.70 & 11.70 & 11.70 & 11.70 \\
\hline Bus-3 & 12.00 & 12.68 & 12.68 & 11.70 & 11.70 & 11.70 & 11.70 & 11.70 & 11.70 & 11.70 & 11.70 & 11.70 & 11.70 & 11.70 \\
\hline Bus-4 & 12.00 & 12.68 & 12.68 & 11.70 & 11.70 & 11.70 & 11.70 & 11.70 & 11.70 & 11.70 & 11.70 & 11.70 & 11.70 & 11.70 \\
\hline Bus-5 & 12.00 & 12.68 & 12.68 & 11.70 & 11.70 & 11.70 & 11.70 & 11.70 & 11.70 & 11.70 & 11.70 & 11.70 & 11.70 & 11.70 \\
\hline Bus-6 & 12.00 & 12.68 & 12.68 & 11.70 & 11.70 & 11.70 & 11.70 & 11.70 & 11.70 & 11.70 & 11.70 & 11.70 & 11.70 & 11.70 \\
\hline
\end{tabular}

LMPs are $11.8 \$ / M W h$ and $(\mathrm{N}-1)$ secure LMPs can be obtained.

Comparison of load curtailment for different VAR support

The data given in Table 5.5 compares the maximum amount of load served through different MVAR capacities of VAR support to obtain (N-1) secure LMPs. Three switched shunts with 


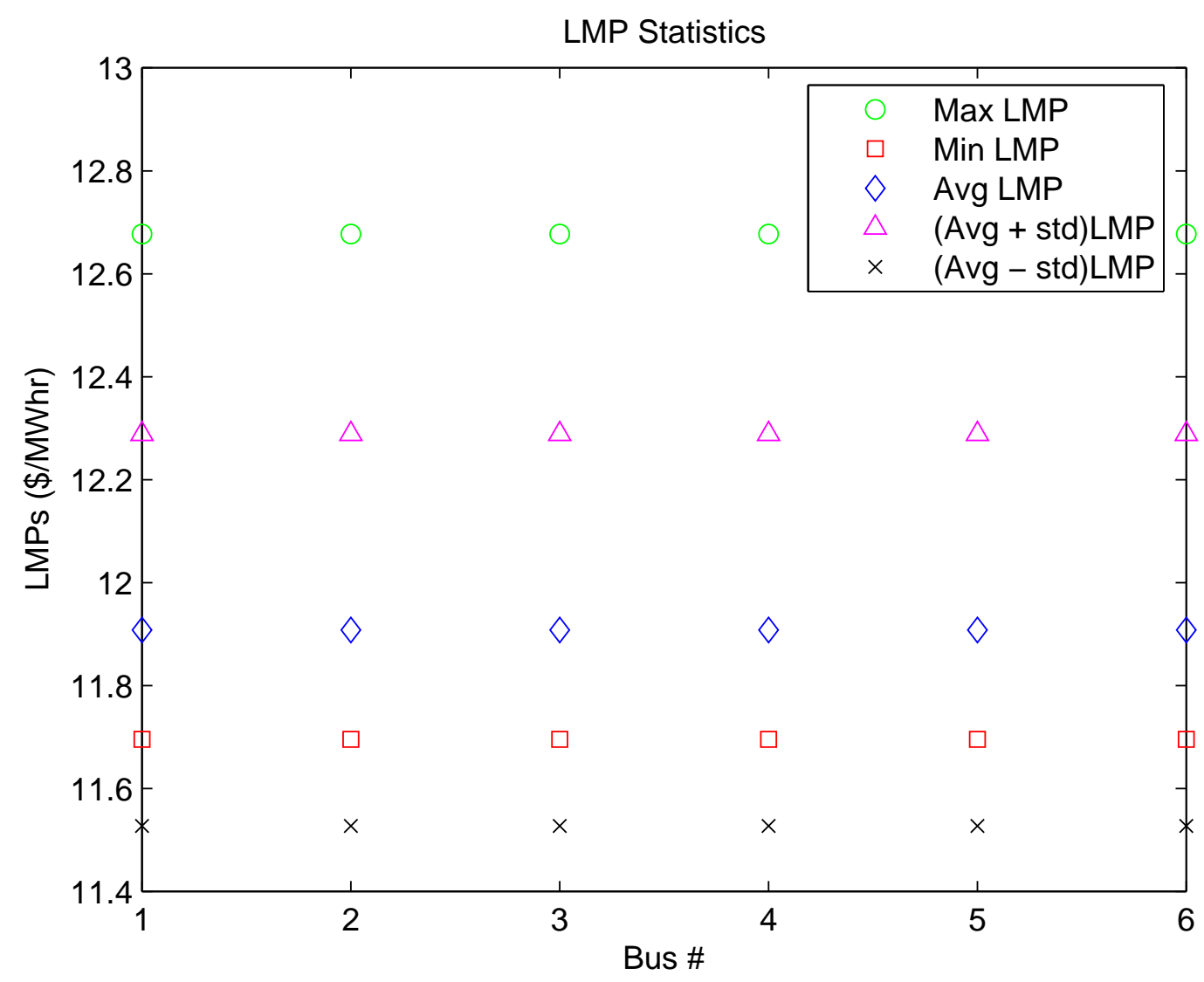

Figure 5.6: LMP Statistics of Six Bus Test System for 14 (N-1) contingency with VAR Support

maximum value of MVAR capacity 50, 25, and 25 are installed at buses 4, 5, and 6 respectively. The total MVAR capacity is considered for the comparison. Load curtailment is minimum for highest MVAR capacity.

Table 5.5: Max load served for $14(\mathrm{~N}-1)$ contingencies - Six Bus Test System

\begin{tabular}{|c|c|c|c|c|c|}
\hline \multicolumn{5}{|c|}{ MVAR } & \multicolumn{2}{c|}{ MW } \\
\hline Total MVAR Capacity & Bus 4 & Bus 5 & Bus 6 & Total Load (MW) & Curtailment (MW) \\
\hline \hline 100 & 50 & 25 & 25 & 191 & 19 \\
\hline 80 & 40 & 20 & 20 & 186.98 & 23.02 \\
\hline 60 & 30 & 15 & 15 & 184.25 & 25.75 \\
\hline 40 & 20 & 10 & 10 & 177.92 & 32.08 \\
\hline 20 & 10 & 5 & 5 & 171 & 39 \\
\hline 10 & 5 & 2.5 & 2.5 & 166 & 44 \\
\hline
\end{tabular}




\section{Comparison of all the three Congestion Relieving Methods}

From the results given in Tables 5.2, 5.3, and 5.4, it can be observed that the congestion relief methods the LMPs for $(\mathrm{N}-1)$ contingencies are equalized due to the congestion alleviation compared to the LMPs in Table 5.1. The transmission congestion obviously increases the LMPs in any power system leading to high prices and may make load curtailment a necessary measure to alleviate the situation.

The load curtailment requirements are different for all three congestion relieving methods to obtain (N-1) secure LMPs without any transmission congestions.

Table 5.6: Comparison of all Congestion Relief Methods - Six Bus Test System

\begin{tabular}{|c|c|c|c|c|c|c|}
\hline Congestion Relief Method & Total Load (MW) & Curtailment (MW) & Average LMP & Min LMP & Max LMP & STD \\
\hline None & 210 & 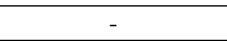 & 300 & -80 & $\overline{9900}$ & 300 \\
\hline TLR Sensitivity & 160 & 50 & 11.8 & 11.6 & 12.5 & 0.18 \\
\hline Economic Load Management & 152.21 & 57.79 & 11.72 & 11.6 & 12.36 & 0.32 \\
\hline VAR Support & 191 & 19 & 11.90 & 11.5 & 12.68 & 0.4 \\
\hline
\end{tabular}

From Table 5.6 we can observe that by installing VAR support at the load buses, the requirement for load curtailment is the least. The Economic Load Management curtails the most load to obtain (N-1) secure LMPs. Of course though the VAR support serves most load is the most expensive method of congestion relief methods presented as it requires additional components. Sensitivity Analysis method is the simple and fair method to alleviate transmission congestion for obtaining secure LMPs for the six bus test system.

It is a user's choice to make the decision about the congestion relief method. The effect of the relieving methods may vary from one power system to another power system. PMAT helps in analyzing the power system to choose the best method for congestion relief. Figure 5.7 shows the graphical view of the maximum loads served at each load bus while obtaining 14 (N-1) secure LMPs for all the three congestion relief methods.

\subsubsection{Results for IEEE 24 Bus RTS}

There are 70 contingencies altogether (33 generators +37 transmission lines) for the IEEE 24 bus RTS. The LMP statistics before and after congestion relief for the IEEE 24 bus RTS are discussed in this section. 


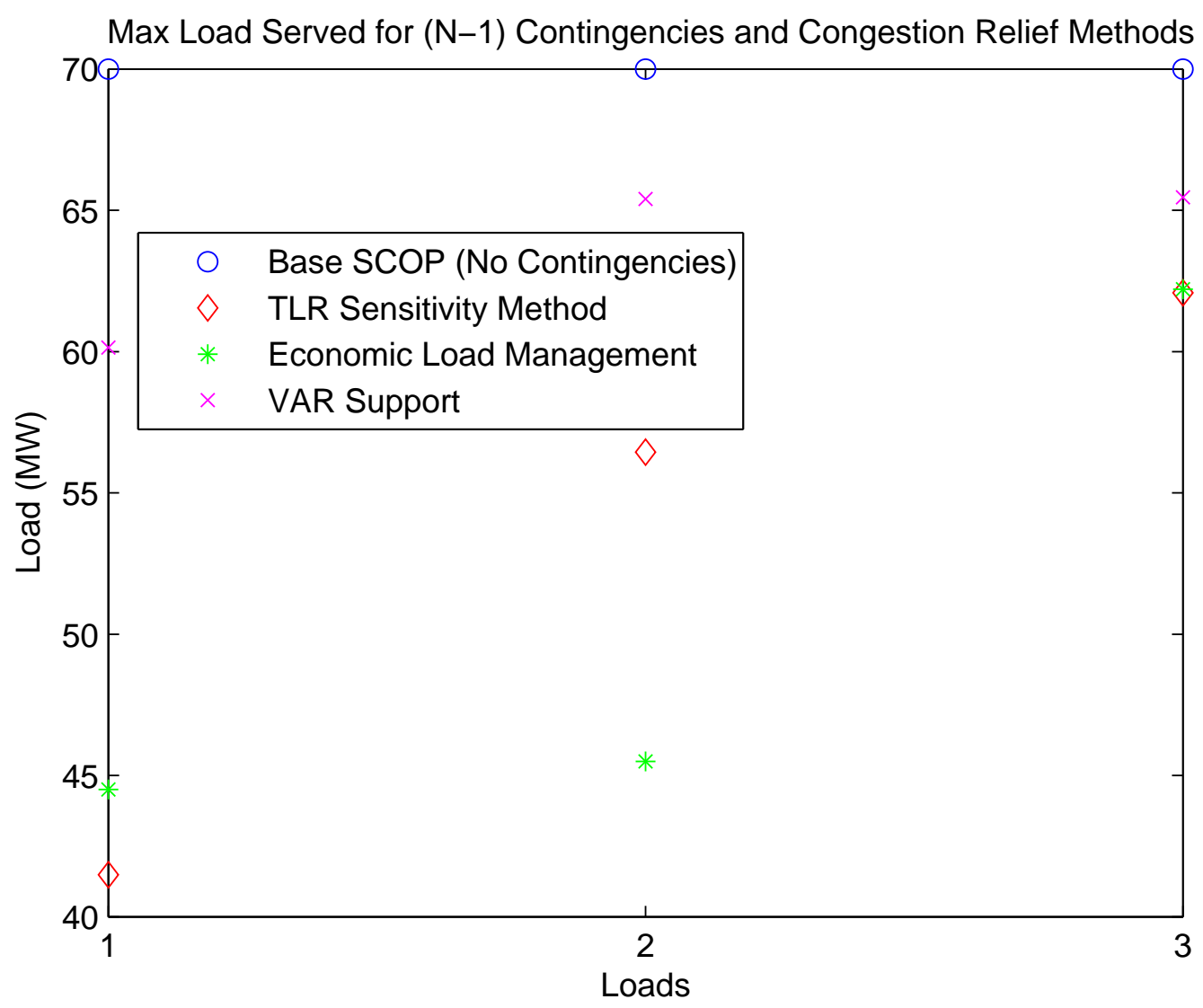

Figure 5.7: Max Loads Served at each bus for 14 (N-1) contingencies - Six Bus Test System

\section{Comparison of LMP Statistics with and without Congestion Relief Schemes}

From the cost curve data of the IEEE 24 Bus RTS B.2, the LMP at all buses is $29 \$ / M W h$ without any contingencies. The LMP statistics for 70 (N-1) contingencies are shown in Figure 5.8. The maximum LMP value is as high as $2200 \$ / M W h$. The average LMPs at almost all the buses are around $30 \$ / M W h$ but at bus 6 the average LMP is as high as $200 \$ / M W h$ as the transmission line from bus 2 to bus 6 is the most congested line for many contingencies.

\section{LMP Statistics for TLR Sensitivity Relief Method}

The LMP statistics after the TLR sensitivity congestion relief method for 70 (N-1) contingencies are shown in Figure 5.9. The average LMPs at almost all the buses are $29 \$ / M W h$ which explains that by appropriate amount of load curtailment, the LMPs are not very high even 


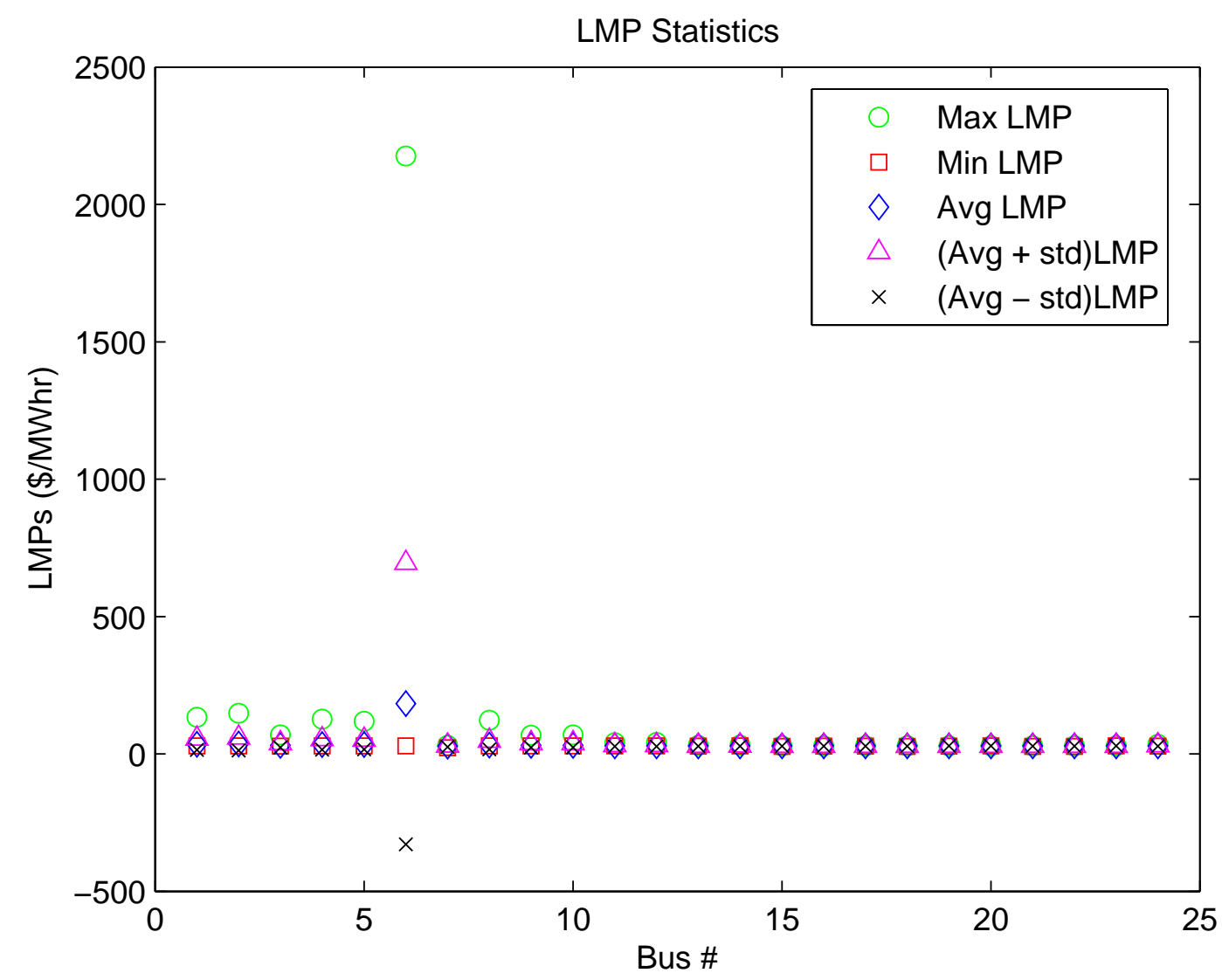

Figure 5.8: LMP Statistics of IEEE RTS for $70(N-1)$ contingencies without Congestion Relief

under contingencies.

LMP Statistics for Economic Load Management

The maximum and minimum load curtailment parameters $P^{\max }$ and $P^{\min }$ are assumed to be $35 \%$ and $5 \%$ of the load at each load bus, respectively. The index for load reduction is the product of the three indices and the maximum value of the overall index is considered to curtail the load at the correspondig load bus. The LMP Statistics after the Economic Load Management congestion relief method for $70(\mathrm{~N}-1)$ contingencies are shown in Figure 5.10. It can be observed that the maximum LMP at bus 6 has again reduced from 2200 to $29 \$ / M W h$.

\section{LMP Statistics for VAR Support}

It is assumed that VAR support (Switched Shunts) is installed at the buses initially but is 


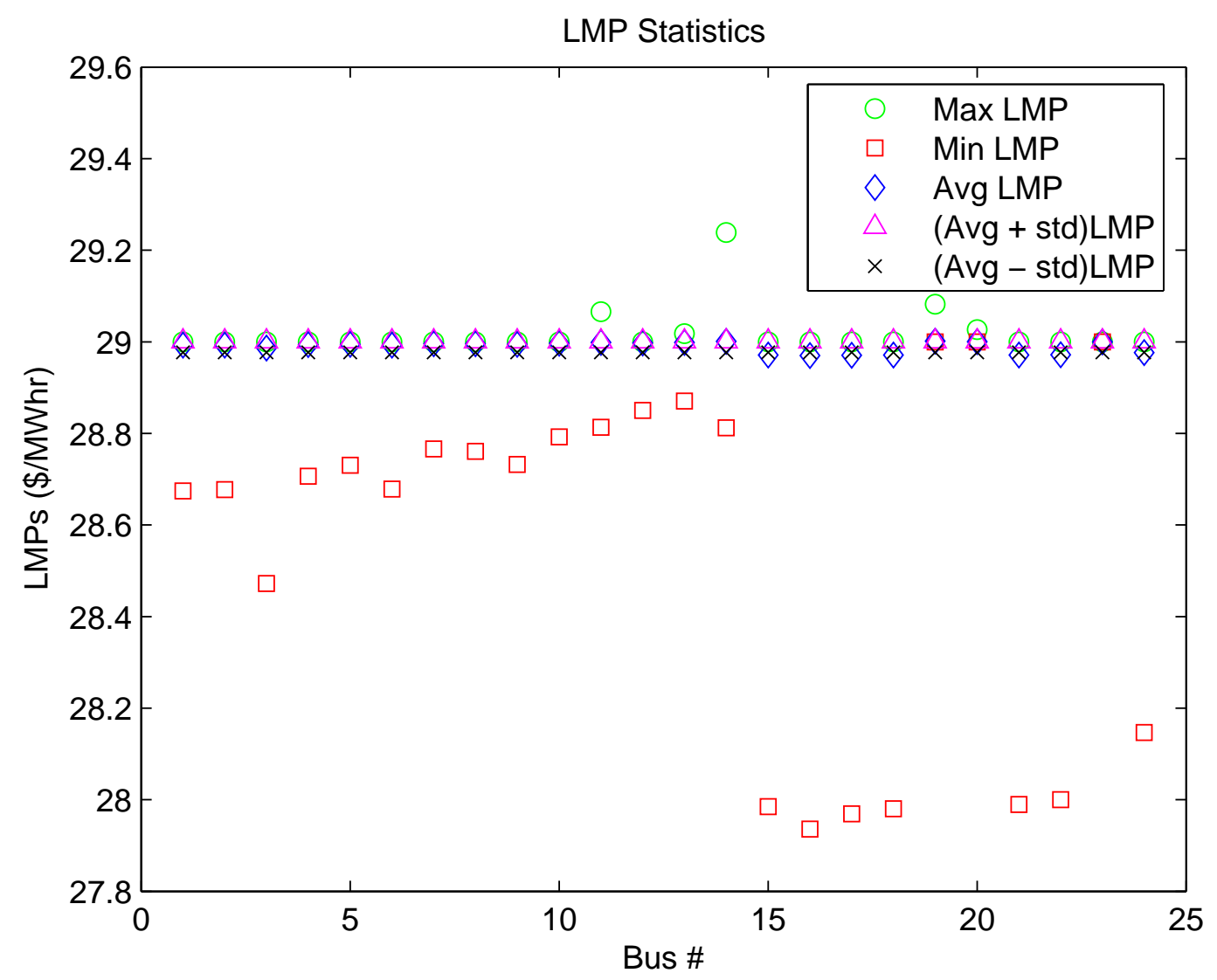

Figure 5.9: LMP Statistics of IEEE RTS for 70 ( $N-1)$ contingencies with TLR Sensitivity Method

disconnected from the system. The IEEE 24 bus RTS has already two VAR support devices provided with the system data. A capacitor with 100 MVAR capacity is connected at bus 6 and a synchronous condenser with 200 and -50 as the maximum and minimum MVAR limits is connected at bus 14. Apart from the most congested line between the buses 2 and 6 , second line that is congested most often is line from bus 7 to bus 8 . Therefore a switched shunt with 30 MVAR capacity is connected at bus 8. This additional VAR support is supplied to the system when the congestion relief with VAR support is chosen. The LMP statistics after installing the VAR Support are shown in Figure 5.11. The maximum LMPs are in the range of 29 to $29.2 \$ / M W h$. It can be observed that the average LMPs are $29 \$ / M W h$ and installing VAR support achieves (N-1) security.

Comparison of load curtailment for different VAR support 


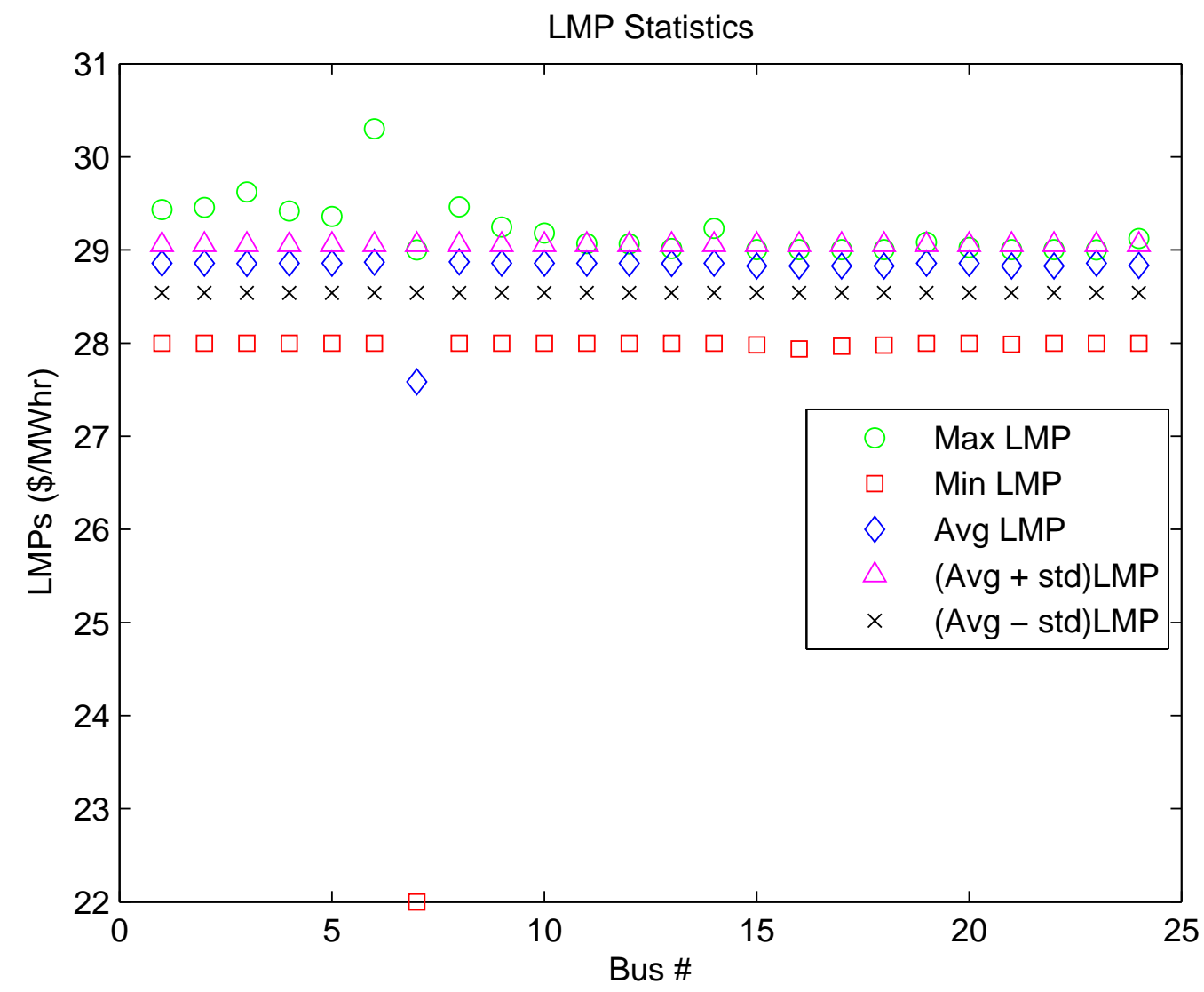

Figure 5.10: LMP Statistics of IEEE RTS for 70 (N-1) contingencies with Economic Load Management Method

The data given in Table 5.7 compares the maximum amount of load served through different MVAR capacities of VAR support to obtain (N-1) secure LMPs. A switched shunt with maximum value of 30 MVAR capacity is used as additional VAR support at bus 8 . Load curtailment is minimum for highest MVAR capacity.

Table 5.7: Max load served for 70 (N-1) contingencies - IEEE 24 Bus RTS

\begin{tabular}{|c|c|c|}
\hline MVAR Capacity & Total Load (MW) & Curtailment (MW) \\
\hline \hline 30 & 2831.98 & 18.02 \\
\hline 25 & 2826.78 & 23.22 \\
\hline 20 & 2818.04 & 31.96 \\
\hline 15 & 2810.55 & 39.45 \\
\hline 10 & 2800 & 50 \\
\hline 5 & 2785.98 & 64.02 \\
\hline 1 & 2766 & 84 \\
\hline
\end{tabular}




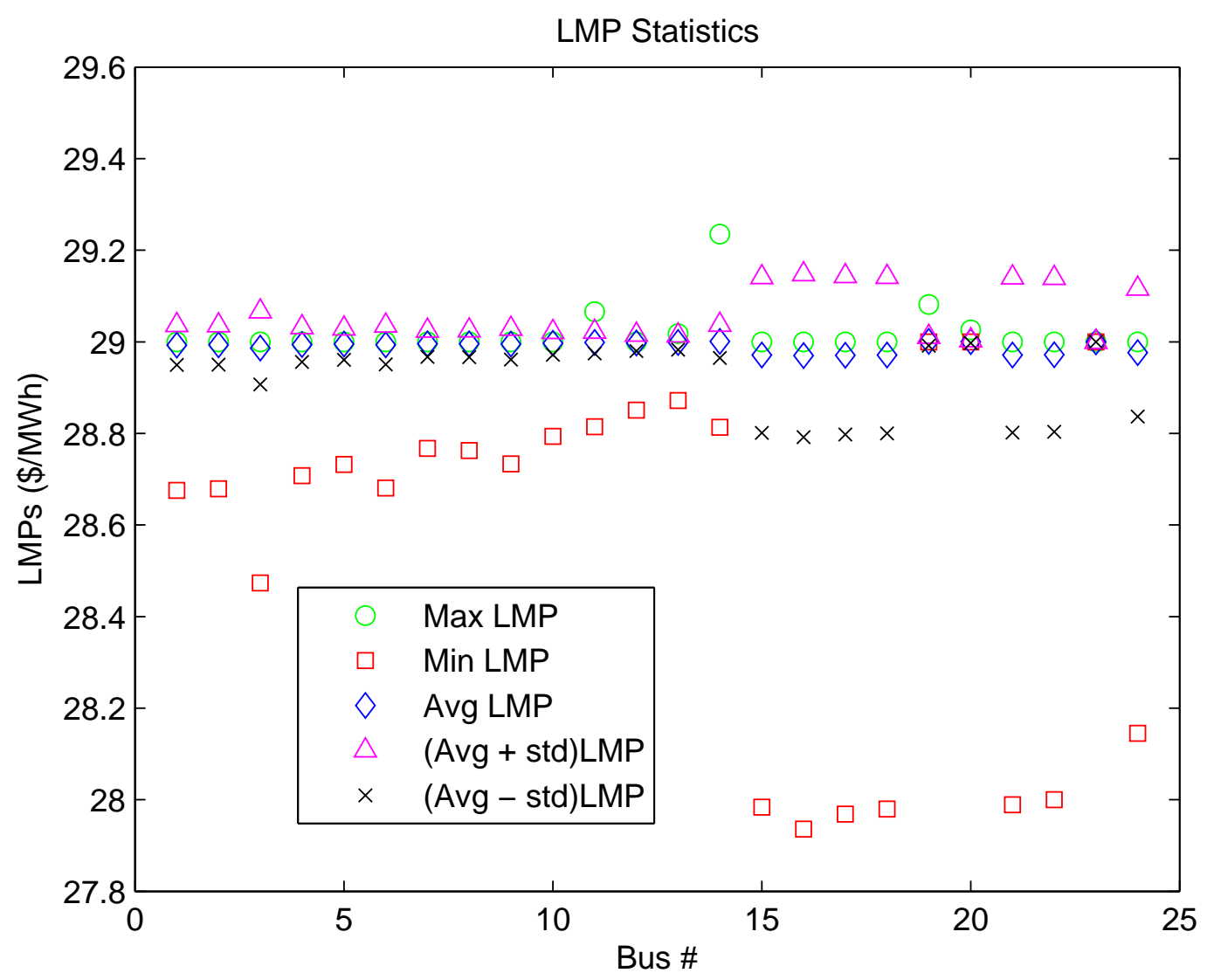

Figure 5.11: LMP Statistics of IEEE RTS for 70 (N-1) contingencies with VAR Support

\section{Comparison of the three Congestion Relieving Methods}

The load curtailment requirements to obtain (N-1) secure LMPs are different for the three congestion relieving methods.

Table 5.8: Comparison of all the Congestion Relief Methods - IEEE 24 RTS

\begin{tabular}{|c|c|c|c|c|c|c|}
\hline Congestion Relief Method & Total Load (MW) & Curtailment (MW) & Average LMP & Min LMP & Max LMP & STD \\
\hline None & 2850 & - & 200 & 29 & 2200 & 550 \\
\hline TLR Sensitivity & 2764.95 & 85.05 & 29 & 27.9 & 29.2 & 0.1 \\
\hline Economic Load Management & 2673 & 177 & 29 & 22 & 30.2 & 1.5 \\
\hline VAR Support & 2831.98 & 18.02 & 29 & 27.9 & 29.2 & 0.2 \\
\hline
\end{tabular}

From Table 5.8 it can be observed that by installing VAR support at the load buses, the requirement for load curtailment is the least. The Economic Load Management curtails the most load to obtain (N-1) secure LMPs. Of course though the VAR support serves most 
load is the most expensive method of congestion relief methods presented as it requires additional components. Sensitivity Analysis method is the simple and fair method to alleviate transmission congestion for obtaining secure LMPs for the six bus test system.

It is a user's choice to make the decision about the congestion relief method. The effect of the relieving methods may vary from one power system to another power system. PMAT helps in analyzing the power system to choose the best method for congestion relief. Figure 5.12 shows the graphical view of the maximum loads served at each load bus while obtaining 70 $(\mathrm{N}-1)$ secure LMPs for all the three congestion relief methods.

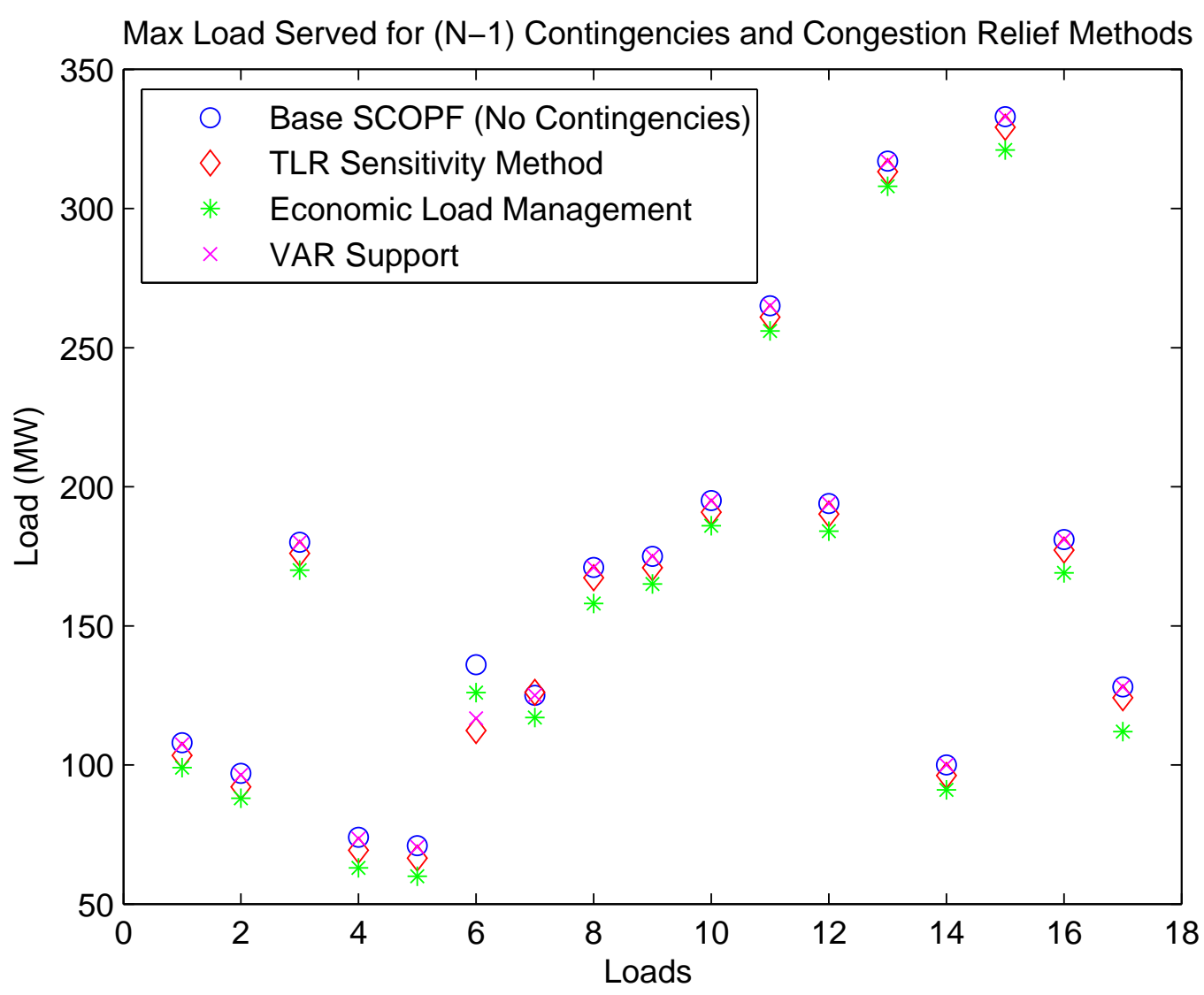

Figure 5.12: Max Loads Served at each bus for 70 (N-1) contingencies - IEEE 24 Bus Test System 


\section{Chapter}

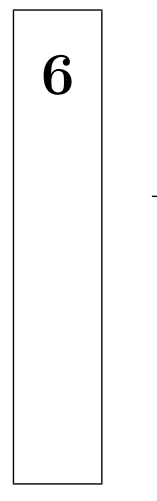

\section{Conclusions and Future Work}

\subsection{Summary}

The work in this thesis can be summarized as:

1. A power market analysis tool for congestion management (PMAT) has been designed in MATLAB.

2. An Application Programming Interface (API) has been developed in MATLAB to interact with PowerWorld for power flow computations.

3. Three methods of congestion management including TLR Sensitivity based relief, Economic Load Management, and VAR Support have been reviewed and implemented in the tool to alleviate transmission congestion.

4. PMAT is tested with standard test cases including a six bus test system and the IEEE 24 Bus Single Area Reliability Test System. LMP statistics for all the three congestion relief methods are analyzed. 
5. A graphic user interface (GUI) for the PMAT is developed to ease interaction with the tool. A help manual is provided with the PMAT GUI.

\subsection{Conclusions}

Load curtailment is a necessary option in some power systems to reduce transmission congestion. The LMPs are very high and sometimes negative in congested power systems.

The conclusions of this thesis are:

1. Among the three congestion relief methods used in this thesis, VAR support serves the maximum load but is not a cost-free method. In the cost-free relief methods, TLR sensitivity method serves more load than the Economic load management method. TLR sensitivity is simpler method than Economic load management method as it only relies on one technical index rather than including customer choices, though, markets participants may demand more influence on low load curtailment is activated.

2. On the other hand, it is first step to develop a load curtailment scheme that includes customer preferences.

\subsection{Future Work}

The thesis leads to many possible future extensions. The following additions are recommended for the enhancement of PMAT:

1. Extending the tool for real-time market applications and providing a congestion alleviation method as used by U.S electricity markets to continuously ensure (N-1) security.

2. Developing a program for the optimal installation of the reactive power support for $(\mathrm{N}-1)$ contingency analysis.

3. Considering the voltage violations in the optimization (current limitation of PowerWorld) while alleviating the transmission congestion for ( $\mathrm{N}-1)$ contingency analysis. 


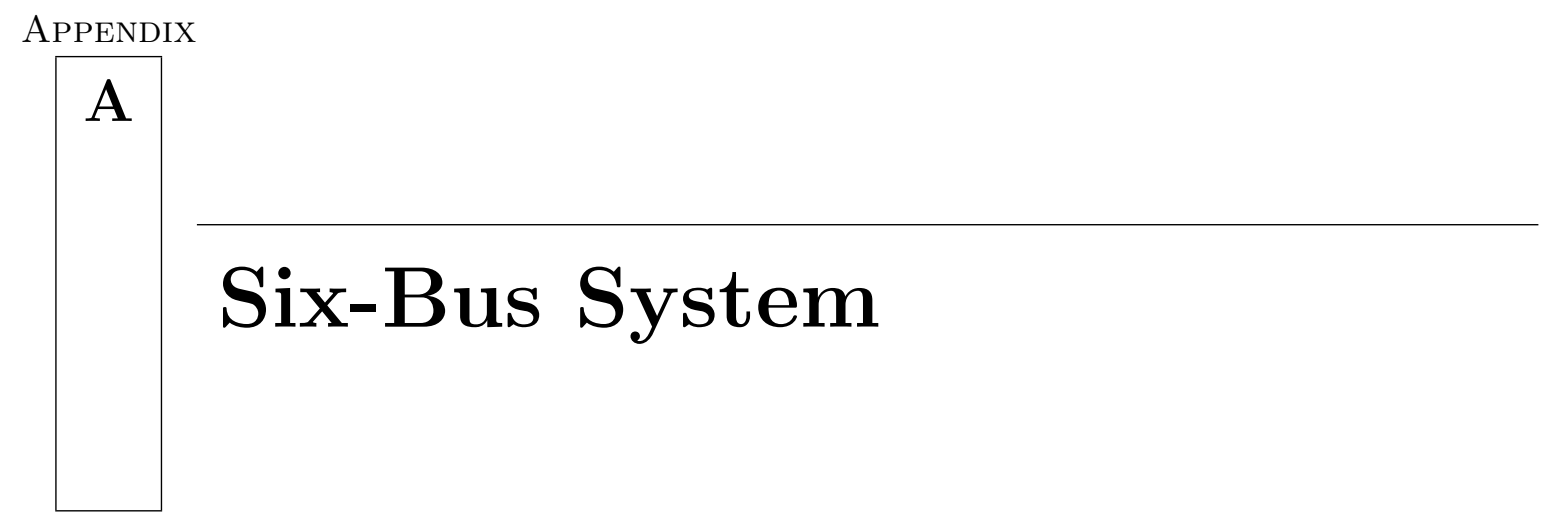

\section{A.1 Network Data}

The following tables illustrate the generator data, load data, line data and generation cost curve data respectively for the six bus test system.

Table A.1: Generator Data for Six Bus Test System

$\begin{array}{ccccccccc}\text { Bus Number } & \text { ID } & \text { Voltage(pu) } & \text { PG(MW) } & \text { QG(MVAR) } & P^{\max } & P^{\min } & Q^{\max } & Q^{\text {min }} \\ 1 & 1 & 1.05 & 0 & 0 & 200 & 50 & 100 & -100 \\ 2 & 1 & 1.05 & 50 & 0 & 150 & 37.5 & 100 & -100 \\ 3 & 1 & 1.07 & 60 & 0 & 180 & 45 & 60 & -100\end{array}$

Table A.2: Load Data for Six Bus Test System

Bus Number Base kV PLoad (MW) QLoad (MVAR)

$\begin{array}{lccc}4 & 138 & 70 & 70 \\ 5 & 138 & 70 & 70 \\ 6 & 138 & 70 & 70\end{array}$

\section{A.2 Market Data}


Table A.3: Line Data for Six Bus Test System

$\begin{array}{cccccc}\text { From Bus } & \text { To Bus } & \mathrm{R}(\mathrm{pu}) & \mathrm{X}(\mathrm{pu}) & \mathrm{B}(\mathrm{pu}) & \text { MVA Limit } \\ 1 & 2 & 0.10 & 0.20 & 0.04 & 30 \\ 1 & 4 & 0.05 & 0.20 & 0.04 & 50 \\ 1 & 5 & 0.08 & 0.30 & 0.06 & 40 \\ 2 & 3 & 0.05 & 0.25 & 0.06 & 20 \\ 2 & 4 & 0.05 & 0.10 & 0.02 & 40 \\ 2 & 5 & 0.10 & 0.30 & 0.04 & 20 \\ 2 & 6 & 0.07 & 0.20 & 0.05 & 30 \\ 3 & 5 & 0.12 & 0.26 & 0.05 & 20 \\ 3 & 6 & 0.02 & 0.10 & 0.02 & 60 \\ 4 & 5 & 0.20 & 0.40 & 0.08 & 20 \\ 5 & 6 & 0.10 & 0.30 & 0.06 & 20\end{array}$

Table A.4: Generator Cost Data for Six Bus Test System Gen Fixed Cost (a) Proportional Cost (b) Quadratic Cost (c)

$\begin{array}{lccc}\text { Gen1 } & 213.1 & 11.67 & 0.0053 \\ \text { Gen2 } & 200 & 10.33 & 0.0089\end{array}$

$\begin{array}{lll}\text { Gen3 } 240 & 10.83 & 0.0074\end{array}$

Table A.5: Load Cost Data for Six Bus System

$\begin{array}{ccc}\text { Load } & \text { MW } & \$ / M W h \\ \text { Load1 } & 70 & 14 \\ \text { Load2 } & 70 & 13 \\ \text { Load3 } & 70 & 12\end{array}$




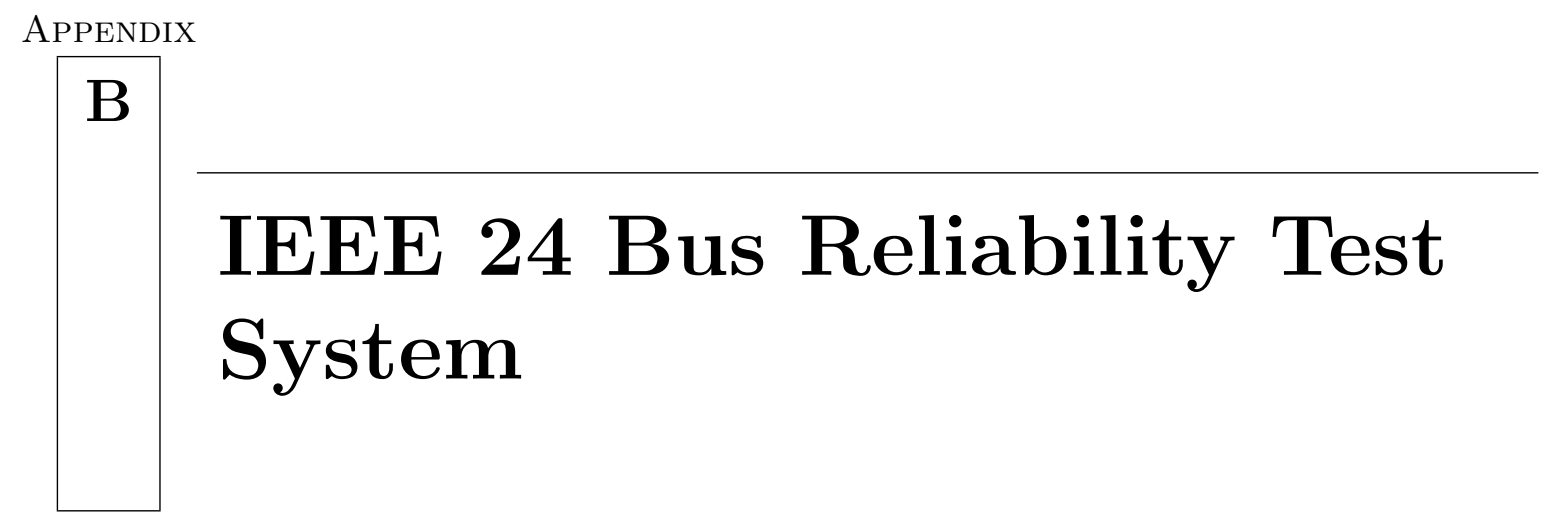

\section{B.1 Network Data}

The following tables illustrate the generator data, load data, line data, generator and load cost curve data respectively for the single area RTS. 
Table B.1: Generator Data for IEEE 24 Bus RTS

$\begin{array}{ccccccccc}\text { Bus No: } & \text { ID } & \text { Voltage(pu) } & \text { PG(MW) } & \text { QG(MVAR) } & P^{\max } & P^{\min } & Q^{\max } & Q^{\text {min }} \\ 1 & 1 & 1.035 & 10 & 0 & 20 & 0 & 10 & 0 \\ 1 & 2 & 1.035 & 10 & 0 & 20 & 0 & 10 & 0 \\ 1 & 3 & 1.035 & 76 & 14.1 & 76 & 0 & 30 & -25 \\ 1 & 4 & 1.035 & 76 & 14.1 & 76 & 0 & 30 & -25 \\ 2 & 1 & 1.035 & 10 & 0 & 20 & 0 & 10 & 0 \\ 2 & 2 & 1.035 & 10 & 0 & 20 & 0 & 10 & 0 \\ 2 & 3 & 1.035 & 76 & 7.0 & 76 & 0 & 30 & -25 \\ 2 & 4 & 1.035 & 76 & 7.0 & 76 & 0 & 30 & -25 \\ 7 & 1 & 1.025 & 80 & 17.2 & 100 & 0 & 60 & 0 \\ 7 & 2 & 1.025 & 80 & 17.2 & 100 & 0 & 60 & 0 \\ 7 & 3 & 1.025 & 80 & 17.2 & 100 & 0 & 60 & 0 \\ 13 & 1 & 1.02 & 95.1 & 40.7 & 197 & 0 & 80 & 0 \\ 13 & 2 & 1.02 & 95.1 & 40.7 & 197 & 0 & 80 & 0 \\ 13 & 3 & 1.02 & 95.1 & 40.7 & 197 & 0 & 80 & 0 \\ 14 & 1 & 0.980 & 0 & 13.7 & 0 & 0 & 200 & -50 \\ 15 & 1 & 1.014 & 12 & 0 & 12 & 0 & 6 & 0 \\ 15 & 2 & 1.014 & 12 & 0 & 12 & 0 & 6 & 0 \\ 15 & 3 & 1.014 & 12 & 0 & 12 & 0 & 6 & 0 \\ 15 & 4 & 1.014 & 12 & 0 & 12 & 0 & 6 & 0 \\ 15 & 5 & 1.014 & 12 & 0 & 12 & 0 & 6 & 0 \\ 15 & 6 & 1.014 & 155 & 0.05 & 155 & 0 & 80 & -50 \\ 16 & 1 & 1.017 & 155 & 25.22 & 155 & 0 & 80 & -50 \\ 18 & 1 & 1.05 & 400 & 137.4 & 400 & 0 & 200 & -50 \\ 21 & 1 & 1.05 & 400 & 108.2 & 400 & 0 & 200 & -50 \\ 22 & 1 & 1.05 & 50 & -4.96 & 50 & 0 & 16 & -10 \\ 22 & 2 & 1.05 & 50 & -4.96 & 50 & 0 & 16 & -10 \\ 22 & 3 & 1.05 & 50 & -4.96 & 50 & 0 & 16 & -10 \\ 22 & 4 & 1.05 & 50 & -4.96 & 50 & 0 & 16 & -10 \\ 22 & 5 & 1.05 & 50 & -4.96 & 50 & 0 & 16 & -10 \\ 22 & 6 & 1.05 & 50 & -4.96 & 50 & 0 & 16 & -10 \\ 23 & 1 & 1.05 & 155 & 31.79 & 155 & 0 & 80 & -50 \\ 23 & 2 & 1.05 & 155 & 31.79 & 155 & 0 & 80 & -50 \\ 23 & 3 & 1.05 & 350 & 71.78 & 350 & 0 & 150 & -25\end{array}$

Table B.2: Load Data for IEEE 24 Bus RTS Bus Number Base kV PLoad (MW) QLoad (MVAR)

$\begin{array}{cccc}1 & 138 & 108 & 22 \\ 2 & 138 & 97 & 20 \\ 3 & 138 & 180 & 37 \\ 4 & 138 & 74 & 15 \\ 5 & 138 & 71 & 14 \\ 6 & 138 & 136 & 28 \\ 7 & 138 & 125 & 25 \\ 8 & 138 & 171 & 35 \\ 9 & 138 & 175 & 36 \\ 10 & 138 & 195 & 40 \\ 11 & 230 & 0 & 0 \\ 12 & 230 & 0 & 0 \\ 13 & 230 & 265 & 54 \\ 14 & 230 & 194 & 39 \\ 15 & 230 & 317 & 64 \\ 16 & 230 & 100 & 20 \\ 17 & 230 & 0 & 0 \\ 18 & 230 & 333 & 68 \\ 19 & 230 & 181 & 37 \\ 20 & 230 & 128 & 26 \\ 21 & 230 & 0 & 0 \\ 22 & 230 & 0 & 0 \\ 23 & 230 & 0 & 0\end{array}$


Table B.3: Line Data for IEEE 24 Bus RTS

$\begin{array}{ccccccc}\text { From Bus } & \text { To Bus } & \mathrm{R}(\mathrm{pu}) & \mathrm{X}(\mathrm{pu}) & \mathrm{B}(\mathrm{pu}) & \text { MVA Limit } & \text { Tr. ratio } \\ 1 & 2 & 0.003 & 0.014 & 0.461 & 200 & 0 \\ 1 & 3 & 0.055 & 0.211 & 0.057 & 150 & 0 \\ 1 & 5 & 0.022 & 0.085 & 0.023 & 160 & 0 \\ 2 & 4 & 0.033 & 0.1327 & 0.034 & 150 & 0 \\ 2 & 6 & 0.05 & 0.192 & 0.052 & 150 & 0 \\ 3 & 9 & 0.031 & 0.119 & 0.032 & 220 & 0 \\ 3 & 24 & 0.002 & 0.084 & 0 & 600 & 1.015 \\ 4 & 9 & 0.027 & 0.104 & 0.028 & 220 & 0 \\ 5 & 10 & 0.023 & 0.088 & 0.024 & 220 & 0 \\ 7 & 8 & 0.016 & 0.061 & 0.017 & 180 & 0 \\ 8 & 9 & 0.043 & 0.165 & 0.045 & 220 & 0 \\ 8 & 10 & 0.043 & 0.165 & 0.045 & 220 & 0 \\ 9 & 11 & 0.002 & 0.084 & 0 & 600 & 1.03 \\ 9 & 12 & 0.002 & 0.084 & 0 & 600 & 1.03 \\ 10 & 11 & 0.002 & 0.084 & 0 & 600 & 1.015 \\ 10 & 12 & 0.002 & 0.084 & 0 & 600 & 1.015 \\ 11 & 13 & 0.006 & 0.048 & 0.1 & 625 & 0 \\ 11 & 14 & 0.005 & 0.042 & 0.088 & 625 & 0 \\ 12 & 13 & 0.006 & 0.048 & 0.1 & 625 & 0 \\ 12 & 23 & 0.012 & 0.097 & 0.203 & 625 & 0 \\ 13 & 23 & 0.011 & 0.087 & 0.182 & 625 & 0 \\ 14 & 16 & 0.005 & 0.059 & 0.082 & 350 & 0 \\ 15 & 16 & 0.002 & 0.017 & 0.036 & 625 & 0 \\ 15 & 21 & 0.006 & 0.049 & 0.103 & 625 & 0 \\ 15 & 21 & 0.006 & 0.049 & 0.103 & 625 & 0 \\ 15 & 24 & 0.007 & 0.052 & 0.109 & 625 & 0 \\ 16 & 17 & 0.003 & 0.026 & 0.055 & 625 & 0 \\ 16 & 19 & 0.006 & 0.023 & 0.049 & 450 & 0 \\ 17 & 18 & 0.002 & 0.014 & 0.03 & 625 & 0 \\ 17 & 22 & 0.014 & 0.105 & 0.221 & 625 & 0 \\ 18 & 21 & 0.003 & 0.026 & 0.055 & 625 & 0 \\ 18 & 21 & 0.003 & 0.026 & 0.055 & 625 & 0 \\ 19 & 20 & 0.005 & 0.04 & 0.083 & 400 & 0 \\ 19 & 20 & 0.005 & 0.04 & 0.083 & 625 & 0 \\ 20 & 23 & 0.003 & 0.022 & 0.046 & 625 & 0 \\ 20 & 23 & 0.003 & 0.022 & 0.046 & 625 & 0 \\ 21 & 22 & 0.009 & 0.068 & 0.142 & 625 & 0 \\ & & & & & & 0\end{array}$




\section{B.2 Market Data}

Table B.4: Generator Cost Data for IEEE 24 Bus RTS

\begin{tabular}{|c|c|c|c|}
\hline Gen & Fixed Cost (a) & Proportional Cost (b) & Quadratic Cost (c) \\
\hline Gen1 & 0 & 20 & 0 \\
\hline Gen2 & 0 & 20 & 0 \\
\hline Gen3 & 0 & 20 & 0 \\
\hline Gen4 & 0 & 20 & 0 \\
\hline Gen5 & 0 & 21 & 0 \\
\hline Gen6 & 0 & 21 & 0 \\
\hline Gen7 & 0 & 21 & 0 \\
\hline Gen8 & 0 & 21 & 0 \\
\hline Gen9 & 0 & 22 & 0 \\
\hline Gen10 & 0 & 22 & 0 \\
\hline Gen11 & 0 & 22 & 0 \\
\hline Gen12 & 0 & 23 & 0 \\
\hline Gen13 & 0 & 23 & 0 \\
\hline Gen14 & 0 & 23 & 0 \\
\hline Gen15 & 0 & 0 & 0 \\
\hline Gen16 & 0 & 24 & 0 \\
\hline Gen17 & 0 & 24 & 0 \\
\hline Gen18 & 0 & 24 & 0 \\
\hline Gen19 & 0 & 24 & 0 \\
\hline Gen20 & 0 & 24 & 0 \\
\hline Gen21 & 0 & 24 & 0 \\
\hline Gen22 & 0 & 25 & 0 \\
\hline Gen23 & 0 & 26 & 0 \\
\hline Gen24 & 0 & 27 & 0 \\
\hline Gen25 & 0 & 28 & 0 \\
\hline Gen26 & 0 & 28 & 0 \\
\hline Gen27 & 0 & 28 & 0 \\
\hline Gen28 & 0 & 28 & 0 \\
\hline Gen29 & 0 & 28 & 0 \\
\hline Gen30 & 0 & 28 & 0 \\
\hline Gen31 & 0 & 29 & 0 \\
\hline Gen32 & 0 & 29 & 0 \\
\hline Gen33 & 0 & 29 & 0 \\
\hline
\end{tabular}


Table B.5: Load Cost Data for IEEE 24 Bus RTS

$\begin{array}{ccc}\text { Load } & \text { MW } & \$ / M W h \\ \text { Load1 } & 108 & 18 \\ \text { Load2 } & 97 & 25 \\ \text { Load3 } & 180 & 19 \\ \text { Load4 } & 74 & 24 \\ \text { Load5 } & 71 & 22 \\ \text { Load6 } & 136 & 19 \\ \text { Load7 } & 125 & 22 \\ \text { Load8 } & 171 & 20 \\ \text { Load9 } & 175 & 20 \\ \text { Load10 } & 195 & 19 \\ \text { Load11 } & 265 & 19 \\ \text { Load12 } & 194 & 25 \\ \text { Load13 } & 317 & 25 \\ \text { Load14 } & 100 & 23 \\ \text { Load15 } & 333 & 18 \\ \text { Load16 } & 181 & 19 \\ \text { Load17 } & 128 & 23\end{array}$




\section{APPENDIX}

\section{Data Formats}

This section describes the data format of the generator and load bid data imported/exported into PMAT. The data format is saved as *.mat file and can be opened/viewed by MATLAB.

Table C.1: Generator and Load Data Format

\begin{tabular}{c|c}
\hline Column & Description \\
\hline \hline Bus \# & Bus number \\
Generator ID & The ID of generator \\
Load ID & The ID of load \\
Cost Model & Cubic or Piecewise Linear \\
MW & Generator output in MW \\
\$MWh & Cost of operating the generator \\
A & Fixed cost \\
B & Proportional Cost \\
C & Quadratic Cost \\
D & Cubic Cost \\
N & No: of break points \\
\hline
\end{tabular}

Table C.2: Generator Data format of Six Bus System

\begin{tabular}{|c|c|c|c|c|c|c|c|c|}
\hline Bus \# & Generator ID & Cost Model & MW & $\$ / M W h$ & $\mathrm{~A}$ & $\mathrm{~B}$ & $\mathrm{C}$ & $\mathrm{D}$ \\
\hline 1 & 1 & Cubic & 0 & 0 & 213.1 & 11.67 & 0.0053 & 0 \\
\hline 2 & 1 & Piecewise Linear & 37.5 & 11.2 & - & - & - & - \\
\hline 2 & 1 & Piecewise Linear & 60 & 11.6 & - & - & - & - \\
\hline 2 & 1 & Piecewise Linear & 82.5 & 12 & - & - & - & - \\
\hline 2 & 1 & Piecewise Linear & 105 & 12.4 & - & - & - & - \\
\hline 2 & 1 & Piecewise Linear & 127.5 & 12.8 & - & - & - & - \\
\hline 3 & 1 & Cubic & 0 & 0 & 240 & 10.83 & 0.0074 & 0 \\
\hline
\end{tabular}


Table C.3: Load Data format of Six Bus System

$\begin{array}{ccccc}\text { Bus \# } & \text { Load ID } & \text { MW } & \text { \$/MWh } & \text { N } \\ 4 & 1 & 70 & 14 & 5 \\ 5 & 1 & 70 & 13 & 5 \\ 6 & 1 & 70 & 12 & 5\end{array}$

Table C.4: Generator Data format of IEEE 24 Bus RTS

$\begin{array}{cccccccccc}\text { Bus \# } & \text { Generator ID } & \text { Cost Model } & \text { MW } & \$ / \text { MWh } & \text { A } & \text { B } & \text { C } & \text { D } & \text { N } \\ 1 & 4 & \text { Cubic } & 0 & 0 & 0 & 20 & 0 & 0 & 5 \\ 2 & 4 & \text { Cubic } & 0 & 0 & 0 & 21 & 0 & 0 & 5 \\ 7 & 3 & \text { Cubic } & 0 & 0 & 0 & 22 & 0 & 0 & 5 \\ 13 & 3 & \text { Cubic } & 0 & 0 & 0 & 23 & 0 & 0 & 5 \\ 14 & 1 & \text { Cubic } & 0 & 0 & 0 & 0 & 0 & 0 & 5 \\ 15 & 6 & \text { Cubic } & 0 & 0 & 0 & 24 & 0 & 0 & 5 \\ 16 & 1 & \text { Cubic } & 0 & 0 & 0 & 25 & 0 & 0 & 5 \\ 18 & 1 & \text { Cubic } & 0 & 0 & 0 & 26 & 0 & 0 & 5 \\ 21 & 1 & \text { Cubic } & 0 & 0 & 0 & 27 & 0 & 0 & 5 \\ 22 & 6 & \text { Cubic } & 0 & 0 & 0 & 28 & 0 & 0 & 5 \\ 23 & 3 & \text { Cubic } & 0 & 0 & 0 & 29 & 0 & 0 & 5\end{array}$

Table C.5: Load Data format of IEEE 24 Bus RTS

$\begin{array}{ccccc}\text { Bus \# } & \text { Load ID } & \text { MW } & \$ / \text { MWh } & \text { N } \\ 1 & 1 & 108 & 18 & 1 \\ 2 & 1 & 97 & 25 & 1 \\ 3 & 1 & 180 & 19 & 1 \\ 4 & 1 & 74 & 24 & 1 \\ 5 & 1 & 71 & 22 & 1 \\ 6 & 1 & 136 & 19 & 1 \\ 7 & 1 & 125 & 22 & 1 \\ 8 & 1 & 171 & 20 & 1 \\ 9 & 1 & 175 & 20 & 1 \\ 10 & 1 & 195 & 19 & 1 \\ 13 & 1 & 265 & 19 & 1 \\ 14 & 1 & 194 & 25 & 1 \\ 15 & 1 & 317 & 25 & 1 \\ 16 & 1 & 100 & 23 & 1 \\ 18 & 1 & 333 & 18 & 1 \\ 19 & 1 & 181 & 19 & 1 \\ 20 & 1 & 128 & 23 & 1\end{array}$




\section{APPENDIX}

\section{$\mathrm{D}$ \\ API Documentation}

The file system hierarchy tree diagram is shown in Figure D.1 and a brief description of the functions used in PMAT is given in Table D.1 are shown in this section.

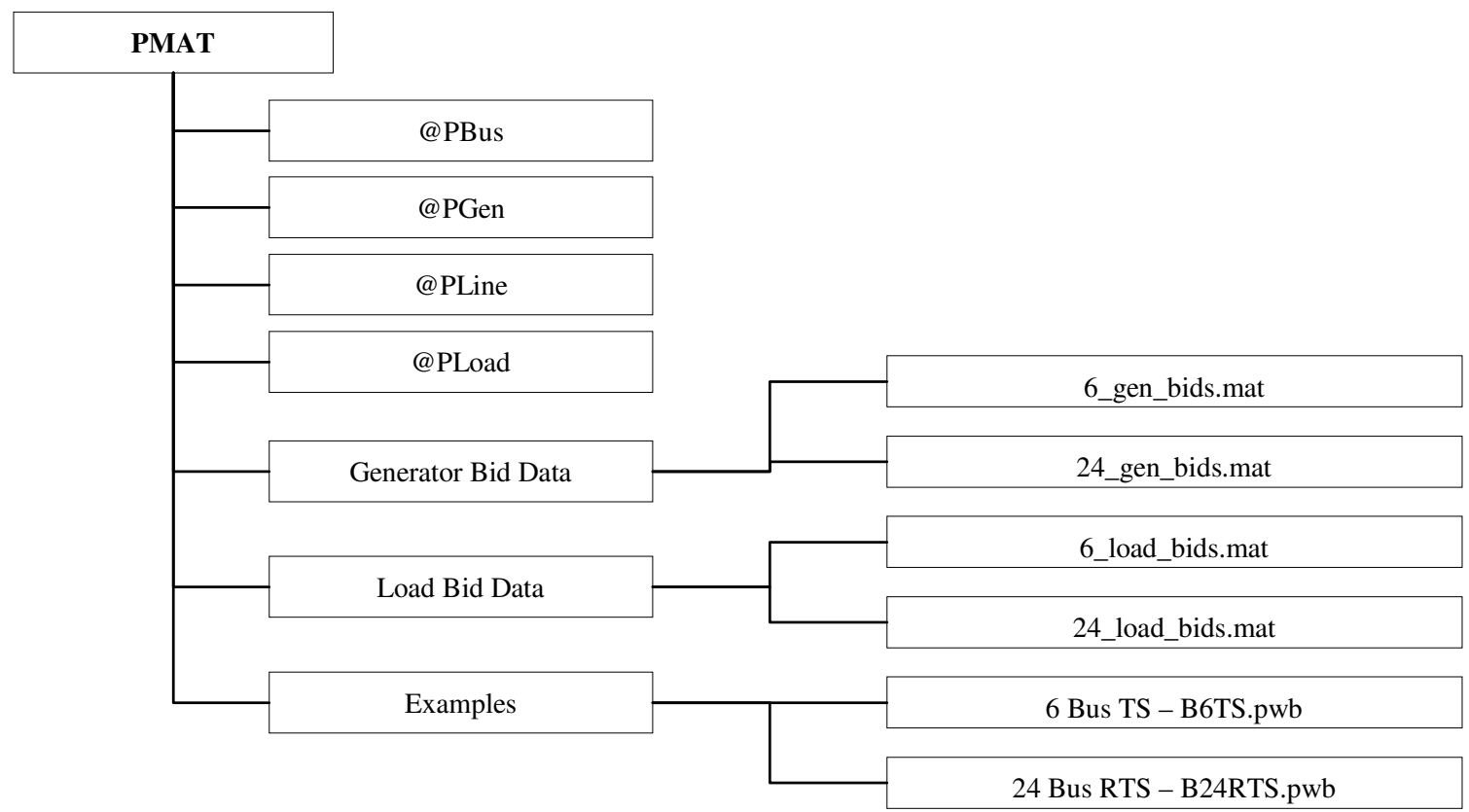

Figure D.1: PMAT file system hierarchy

In the Figure D.1, the boxes on the right are the files and the boxes in the middle and left are 
the folders.

Table D.1: Description of functions in PMAT API

\begin{tabular}{ll} 
Main Functions & Description \\
\hline Function & Starts the PMAT gui \\
pmat & Performs the (N-1) contingency analysis \\
pmat_contingencies & Plots the generator and load cost functions \\
pmat_cost_fn & Exports the generator bids as *.mat file \\
pmat_export_gen_bids & Exports the load bids as *.mat file \\
pmat_export_load_bids & Plots the LMP statistics for contingencies \\
pmat_gui_plot_avglmp & Plots the line flows and limits for contingencies \\
pmat_gui_plot_lineflow & Plots the LMPs for contingencies \\
pmat_gui_plot_lmp & Plots the voltage angles at buses \\
pmat_gui_plot_voltageangle & Plots the voltage magnitudes at buses \\
pmat_gui_plot_voltagemagnitude & Solves the base case power flow \\
pmat_gui_run_powerflow & Solves the optimal power flow \\
pmat_gui_run_opf & Solves the security constrained optimal power flow \\
pmat_gui_run_scopf & Imports the generator bids as *.mat file \\
pmat_import_gen_bids & Imports the load bids as *.mat file \\
pmat_import_load_bids & Performs Economic load management method to alleviate congestion \\
pmat_index & Saves the power flow report as a .txt file \\
pmat_report & Performs TLR sensitivity relief method to alleviate congestion \\
pmat_tlr & Performs VAR support method to alleviate congestion \\
pmat_var &
\end{tabular}

\section{Helper Functions}

\section{Function}

pmat_options

pmat_base_lmps

pmat_contingencies_close

pmat_gen_contingency

pmat_gen_cost_fn

pmat_get_base_values

pmat_getpara_opf

pmat_getpara_powerflow

pmat_gui_base_plot

pmat_index_contingency

pmat_init

pmat_line_contingency

pmat_load_cost_fn

pmat_relief

pmat_tlr_contingency

pmat_var_contingency

\section{Description}

Opens the options window for Economic Load Management and VAR support

Retrieves the LMPs without contingencies

Closes the contingencies

Adds the generator contingencies

Obtains data for generator cost function

Retrieves the LMPs and line flows without contingencies

Gets the data for opf and scopf solution

Gets the data for power flow solution

Plots the LMPs without contingencies

Performs the mathematical equations of Economic Load Management method

Initializes the objects and global variables in PMAT

Adds the line contingencies

Obtains data for load cost function

Provides the congestion relief methods

Performs the mathematical equations of TLR sensitivity method Adds the VAR support

\section{PowerWorld COM Server Functions}

\section{Function \\ pw_start \\ pw_stop}

\section{Description}

Connects to the PowerWorld server

Closes connection to PowerWorld server 


\section{References}

[1] Ambriz-Perez, H., Acha, E., Fuerte-Esquivel, C. R., "Advanced SVC models for NewtonRaphson load flow and Newton optimal power flow studies," IEEE Transactions on Power Systems, Vol. 15, No. 1, pp. 129-136, February 2000.

[2] Ambriz-Perez, H. et al., "Incorporation of a UPFC model in an optimal power flow using Newton's method," IEE Proceedings: Generation, Transmission and Distribution, Vol. 145, No. 3, pp. 336-344, May 1998.

[3] Arabi, S., Kundur, P., Adapa, R., "Innovative Techniques in Modeling UPFC for Power System Analysis," IEEE Transactions of Power Systems, Vol. 15, No. 1, pp. 336-341, February 2000.

[4] Bastian Jeffrey, Jinxiang Zhu, Venkat Banunarayanan, Rana Mukerji, "Forecasting energy prices in a competitive market," IEEE Computer Applications in Power, Vol. 12, No. 3, pp. 40-45, July 1999.

[5] Brosda, J., Handschin, E., "Congestion management methods with a special consideration of FACTS-devices," IEEE Porto Power Tech Proceedings, Vol. 1, pp. 6, September 2001.

[6] Cain, M. B., Alvarado, F. L., "Implications of cost and bid format on electricity market studies: linear versus quadratic costs," IEEE Large Engineering Systems Conference on Power Engineering, pp. 2-6, July 2004.

[7] California ISO, Online: http://www.caiso.com/docs/2003/11/10/20031110152407538.pdf

[8] Cañizares, C. A., Faur, Z. T., "Analysis of SVC and TCSC controllers in voltage collapse," IEEE Transactions on Power Systems,Vol. 14, No. 1, pp. 158-165, February 1999. 
[9] Cañizares, C. A., Kodsi, S. K. M., "Dynamic Versus Steady-State Modeling of FACTS Controllers in Transmission Congestion," IEEE Power Engineering Society General Meeting, pp. 6, June 2006.

[10] Cazzol, M. V. et al., "Unified power flow controller (UPFC) model in the framework of interior point based active and reactive OPF procedure," International Journal of Electrical Power and Energy Systems, Vol. 24, No. 6, pp. 431-437, August 2002.

[11] David, A. K., Fushuan Wen, "Strategic bidding in competitive electricity market: a literature survey," IEEE Porto Power Tech. Conference, September 2000.

[12] Doll, M., Verstege, J. F., "Congestion management in a deregulated environment using corrective measures," IEEE Power Engineering Society Winter Meeting, Vol. 2, pp. 393-398, February 2001.

[13] Douglas, R. Hale, Thomas, J. Overbye, "Optimization and visualization of the north american eastern interconnect power market," IEEE Proceedings of the 34th Hawaii International Conference on System Sciences, pp. 639-646, January 2001.

[14] Energy Dictionary, Online: http://www.energyvortex.com/energydictionary/transmission_congestion.html

[15] ERCOT, Online: http://www.ercot.com/about/index.html

[16] ERCOT Emergency Electric Curtailment Plan, Online: http://nodal.ercot.com/protocols/nprr/040/keydocs/040NPRR01_Synchronization_of_Emergency_Electric_Curtailment.doc

[17] ERCOT Mitigation, Online: http://www.ercot.com/meetings/tac/keydocs/2004/1202/TAC12022004-19.doc

[18] ERCOT Transmission Operator Readiness, Online: http://www.ercot.com/mktrules/compliance/nerc/archives/2005/ERCOT_Readiness_Audi.pdf

[19] Feng, W., Shrestha, G. B., "Allocation of TCSC devices to optimize total transmission capacity in a competitive power market," Proceedings of the IEEE Power Engineering Society Transmission and Distribution Conference, Vol. 2, pp. 587-593, 2001.

[20] FERC, Online: http://www.ferc.gov.

[21] Goncalves, M. J. D., Zita, A. Vale, "Evaluation of transmission congestion impact in market power," IEEE Bologna Power Tech Conference, Vol.4, pp. 6, June 2003.

[22] Gyugyi, L., "Power Electronics in Electrical Utilities: Static Var Compensators," Proceedings of the IEEE, Vol. 76 No. 4, pp.483-494, April. 1988.

[23] Gyugyi, L. et al., "The Unified power flow controller: a new approach to power transmission control," IEEE Transactions on Power Delivery, Vol. 10, No. 2, pp. 1085-1093, April 1995.

[24] Habur, K., Oleary, D., "A FACTS - flexible AC transmission systems for cost effective and reliable transmission of electrical energy," Online : http://www.siemenstd.com/TransSys/pdf/CostEffectiveReliabTrans.pdf

[25] Hingorani, N. G., "Power Electronics in Electrical utilities: Rule of Power Electronics in Future Power Systems," Proceedings of the IEEE, Vol. 76, No. 4, pp. 481-482, April 1988 . 
[26] Huang, G. M., Ping Yan, "The impacts of TCSC and SVC on power system load curtailments," IEEE Power Engineering Society Summer Meeting, Vol. 1, pp. 33-37, July 2001.

[27] Klein, B., Joel, "The Use of Heat Rates in Production Cost Modeling and Market Modeling," California Energy Commission, April 1998, Online: http://www.energy.ca.gov/papers/98-04-07_HEATRATE.PDF

[28] Liangzhong Yao, Phill Cartwright, Laurent Schmitt, Xiao-Ping Zhang, "Congestion Management of Transmission Systems using FACTS,", IEEE PES, Transmission and Distribution Conference and Exhibition, pp. 1-5, August 2005.

[29] Mathworks, Online: http://www.mathworks.com/

[30] Matlab Object-Oriented Programming, Online: http://www.math.carleton.ca/ help/matlab/MathWorks_R13Doc/techdoc/matlab_prog/ch14_oop.html

[31] Narayan Prasad Padhy, Yog Raj Sood, Abdel Moamen, Maruthi Kumar, H. O. Gupta, "A hybrid model for congestion management with real and reactive power transaction," IEEE Power Engineering Society Summer Meeting, Vol. 3, pp. 1366-1372, July 2002.

[32] NERC, Online:http://www.nerc.com/

[33] NERC Reliability Coordination Transmission Loading Relief, Online: ftp://www.nerc.com/pub/sys/all_updl/standards/rs/IRO-006-1.pdf

[34] New England ISO, Online: http://www.iso-ne.com/support/training/5bus/index.html

[35] NewYork ISO Emergency Operations, Online: http://www.nyiso.com/public/webdocs/documents/manuals/operations/em_op_mnl.pdf

[36] NewYork ISO Transmission and Dispatching Manual, Online: http://www.nyiso.com/public/webdocs/documents/manuals/operations/trans_disp.pdf

[37] Niimura, T., Niu, Y., "Transmission congestion relief by economic load management," IEEE Power Engineering Society Summer Meeting, Vol. 3, pp. 1645-1649, July 2002.

[38] Object-Oriented Programming, Online: http://www.startvbdotnet.com/oop/default.aspx

[39] PJM Economic Planning Process, Online:http://www.pjm.com/planning/downloads/20050331economic-planning-process.pdf

[40] PJM Locational Marginal Pricing, Online:http://www.pjm.com/services/courses/downloads/lmp101-training.pdf

[41] PJM Power Market, Online: http://www.pjm.com/index.jsp

[42] PJM Transmission and Voltage Enline: http://www.pjm.com/services/training/downloads/ops101-transemer.pdf

[43] PJM Transmission Congestion Relief, Online:http://www.pjm.com/contributions/newsreleases/2004/20040312-pjm-adv-tra.pdf

[44] PowerWorld, Online: http://www.powerworld.com

[45] PowerWorld Help, Online: http://powerworld.com/downloads/general.asp

[46] PowerWorld Negative LMPs, Online : http://powerworld.com/support/faq.asp

[47] Reliability Test System Task Force of the Application of Probability Methods Subcommittee, "The IEEE Reliability Test System - 1996," IEEE Transactions on Power Systems, Vol. 14, No.3, August 1999. 
[48] Richard, D. C, Wollenberg, B. F., Wangensteen, I., "Transmission Management in the Deregulated Environment," Proceedings of the IEEE, Vol. 88, No. 2, pp. 170-195, February 2000.

[49] Sameh, K. M., "Accounting for the effects of Power System Controllers and Stability on Power Dispatch and Electricity Market Prices," Ph.D. Thesis, University of Waterloo, 2005.

[50] Scheweppe, F. C., Caramanis, M. C., Tabors, R. D., Bohn, R. E., "Spot Pricing of Electricity," Kluwer Academic Publishers, 1988.

[51] Singh, S. N., David, A. K., "Congestion management by optimising FACTS device location," International Conference on Electric Utilities Deregulation and Restructuring and Power Technologies, pp. 23-28, April 2000.

[52] Song, Y. H., Phichaisawat, S., Taylor, G. A., "Congestion management considering voltage security constraints," International Conference on Power System Technology, Vol. 3, pp. 13-17, October 2002.

[53] Srivastava, S. C., Perveen Kumar, "Optimal power dispatch in deregulated market considering congestion management," International Conference on Electric Utility Deregulation and Restructuring and Power Technologies, pp. 53-59, April 2000.

[54] UWEE., Power System Test Case Archive, Online:http://www.ee.washington.edu/research/pstca/

[55] Wikipedia Market Definition, Online: http://en.wikipedia.org/wiki/Electricity_market

[56] Wikipedia OOP, Online: http://en.wikipedia.org/wiki/Object-oriented_programming

[57] Wood, A. J., Wollenberg, F. B., Power Generation, Operation, and Control, 2nd ed. NewYork: John Wiley \& Sons, Inc.

[58] Xiaoming Feng, Jiuping Pan, Le Tang, Henry Chao, Jian Yang, "Economic evaluation of transmission congestion relief based on power market simulations," IEEE Power Engineering Society General Meeting, Vol. 2, pp. 13-17, July 2003.

[59] Yan, H. H., "PTDF and TLR From A Power Marketer's Perspective," IEEE Power Engineering Society Summer Meeting, Vol. 1, pp. 156-161, July 1999.

[60] Yuen, Y. S., Lo, K. L., Snider, L. A., "Congestion management in deregulated electricity markets," IEEE International Conference on Electric Utility Deregulation and Restructuring and Power Technologies, pp. 47-52, April 2000.

[61] Zamani, F. V., Kazemi, A., Biglari, M. A., "Congestion management in bilateral based power market by FACTS devices and load curtailments," IEEE Power India Conference, pp. 6, April 2006. 